Aus dem Institut für Vegetative Physiologie und Pathophysiologie

(Prof. Dr. med. G. Burckhardt)

im Zentrum Physiologie und Pathopysiologie

der Medizinischen Fakultät der Universität Göttingen

\title{
Klonierung und funktionelle Charakterisierung des pOAT1 in ok-Zellen
}

\author{
INAUGURAL - DISSERTATION \\ zur Erlangung des Doktorgrades \\ der Medizinischen Fakultät der \\ Georg-August-Universität zu Göttingen
}

vorgelegt von

Mark Florian Sendler

aus Osterode

Göttingen 2015 
Dekan: Prof. Dr. rer. nat. H. K. Kroemer

I. Berichterstatter: Prof. Dr. rer. nat. Y. Hagos

II. Berichterstatter/in: Prof. Dr. rer. nat. M. Bohnsack

III. Berichterstatter/in: Prof. Dr. hum. biol. M. Schön

Tag der mündlichen Prüfung: 25.11.2015 


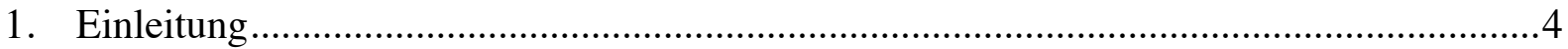

1.1 Die organischen Anionen-Transporter (SLC22) …..................................................5

1.1.1 Mechanismus der basolateralen Aufnahme von organischen Anionen ..................5

1.1.2 Mechanismus der luminalen Ausscheidung von organischen Anionen ..................7

1.1.3 Struktur, Gewebsverteilung und Substratspezifität der OAT-Familie ....................8

1.1.4 Mechanismus der renalen Sekretion von organischer Anionen .............................14

1.2 Bedeutung der organischen Anionen-Transporter in der Medizin .............................14

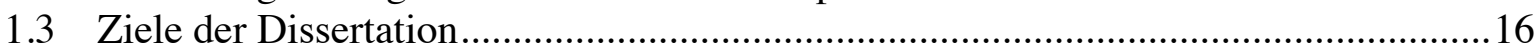

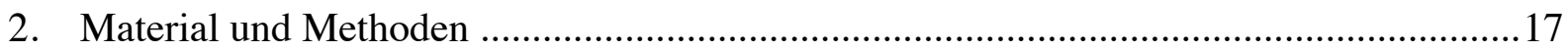

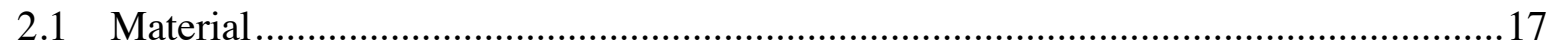

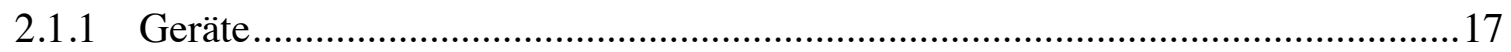

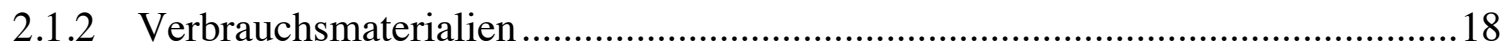

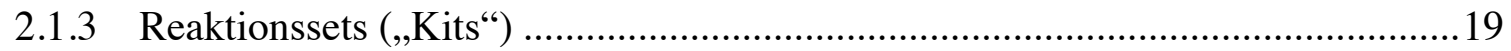

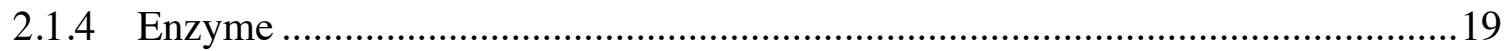

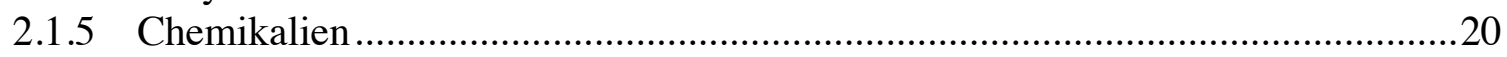

2.1.6 Zelllinien, Bakterienstämme und Phagen .......................................................2 21

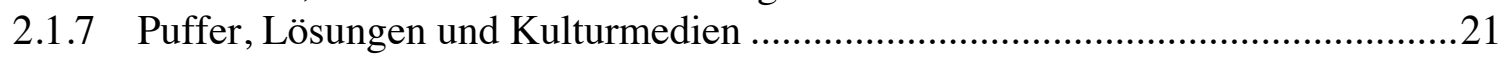

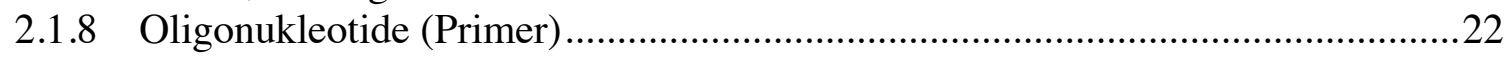

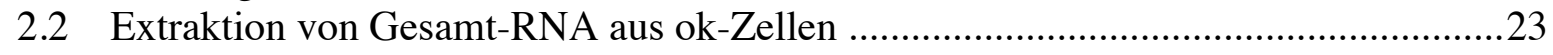

2.3 Extraktion von mRNA aus Gesamt-RNA der ok-Zellen ........................................24

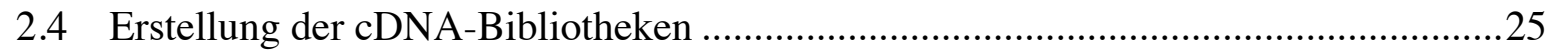

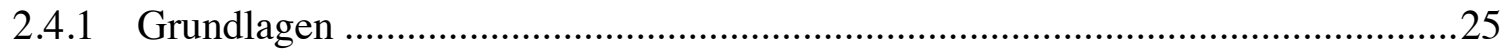

2.4.2 CDNA-Synthese und Vorbereitungen zum Vektoreinbau .................................25

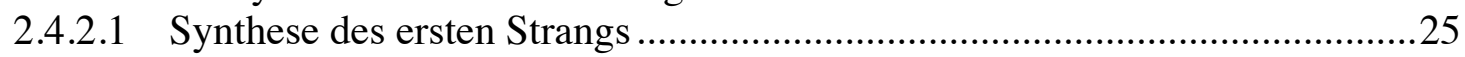

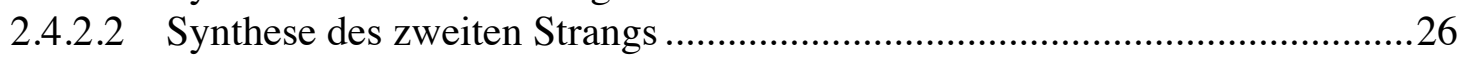

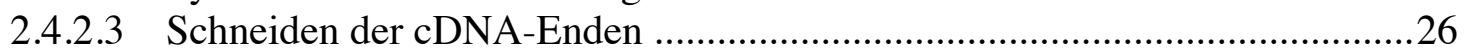

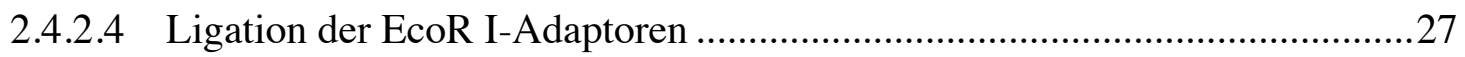

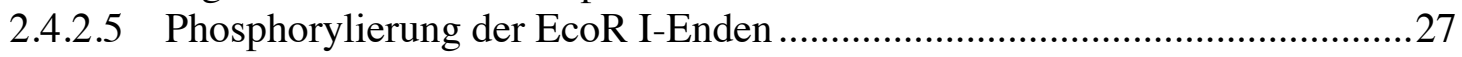

2.4.2.6 Verdau der cDNA mit Xho I ..................................................................2

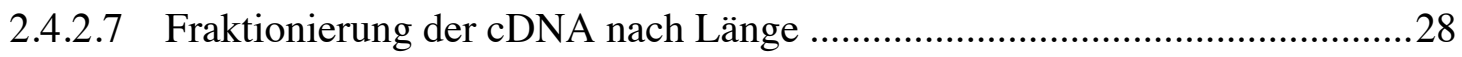

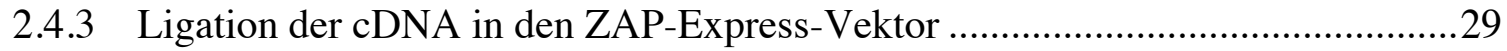

2.4.4 Verpacken des Vektors zum infektiösen Phagen ..............................................29

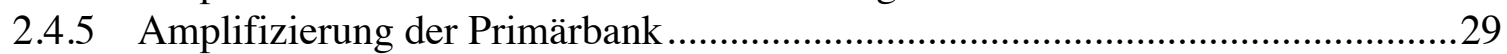

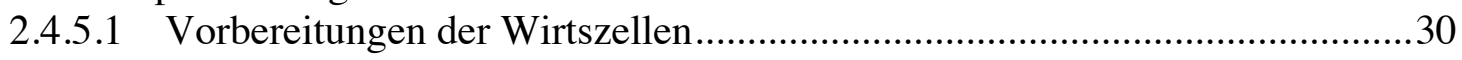

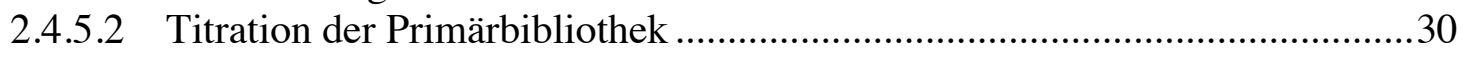

2.4.5.3 Vermehrung der Primärbibliothek ........................................................ 31

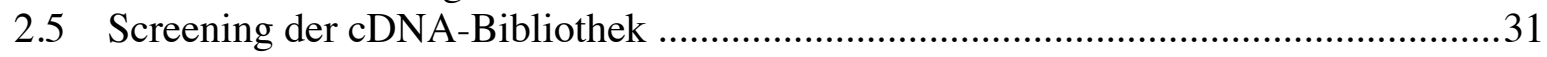

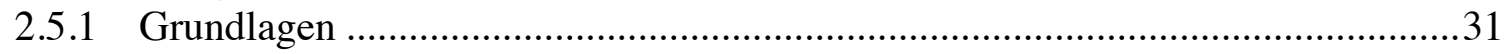

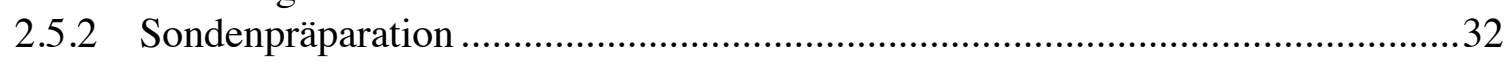

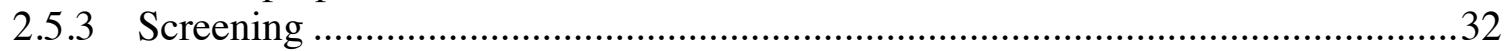

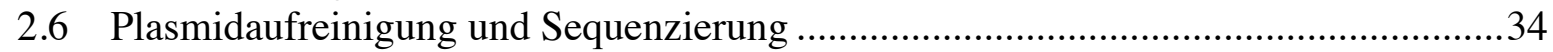

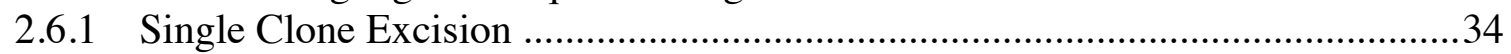

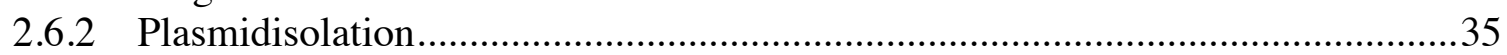

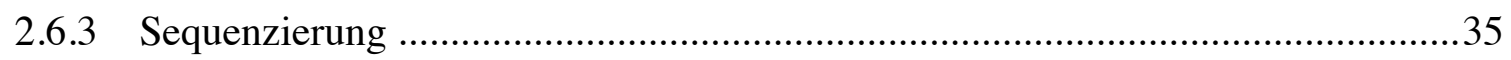

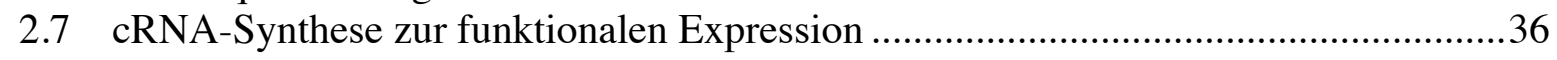

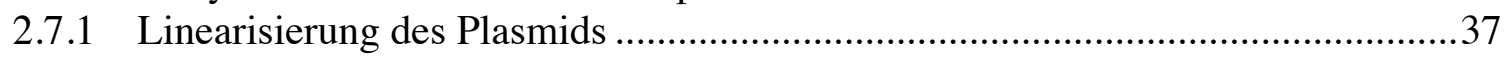

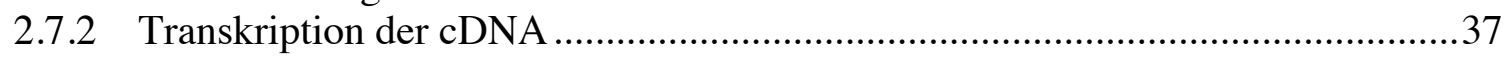

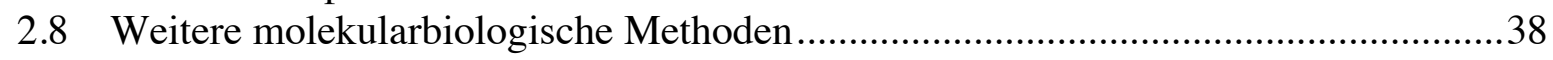

2.8.1 Photometrische Konzentrationsbestimmung von Nukleinsäuren ........................38

2.8.2 Photometrische Konzentrationbestimmung von Proteinen ................................38

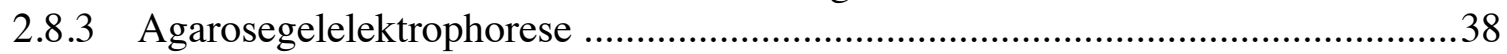




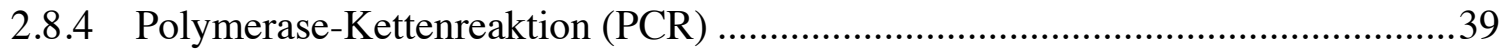

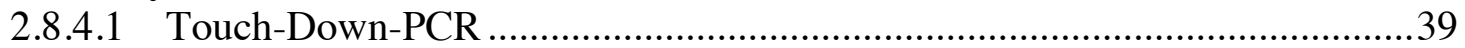

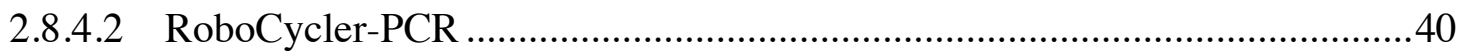

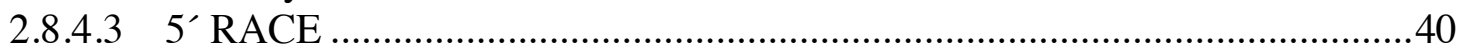

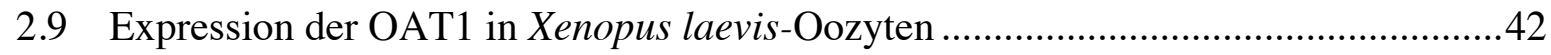

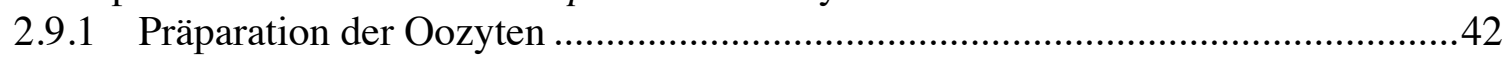

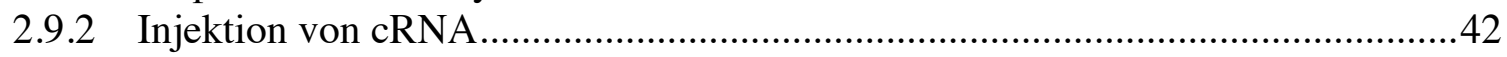

2.9.3 OAT1-vermittelte Aufnahme von organischen Anionen in Oozyten ...................43

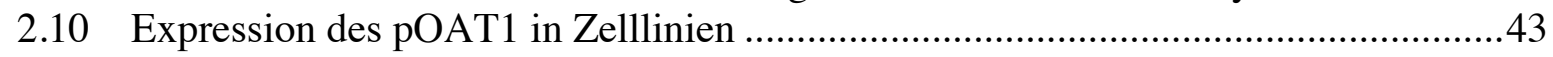

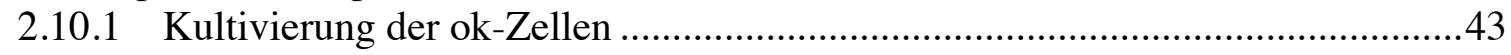

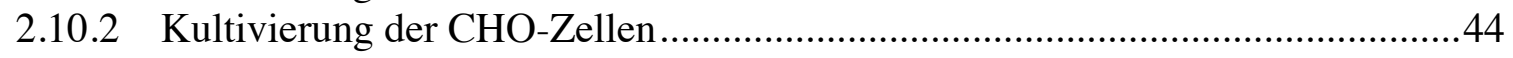

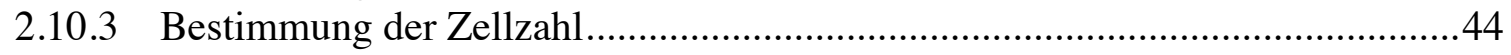

2.10.4 Aussaat und Ernte der Zellen.........................................................................4

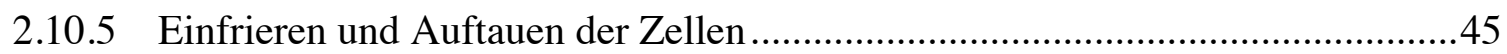

2.10.6 Transfektion des pOAT1 in Zelllinien...........................................................45

2.10.7 pOAT1-vermittelte Aufnahme von organischen Anionen in Zelllinien..............46

2.10.7.1 pOAT1-vermittelte PAH-Aufnahme in ok- und CHO-Zellen ......................46

2.10.7.2 pOAT1-vermittelte Fluorescein-Aufnahme in ok- und CHO-Zellen ...........47

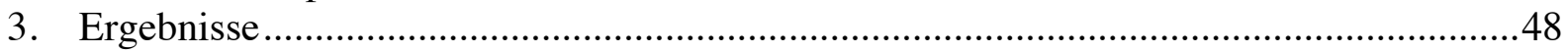

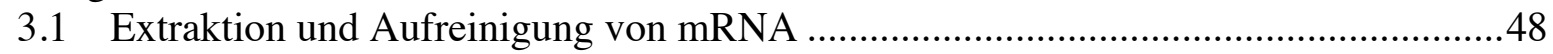

3.2 Erstellung der ok-Zelle- und Schweineniere-cDNA-Bank ......................................... 48

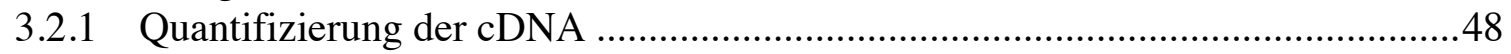

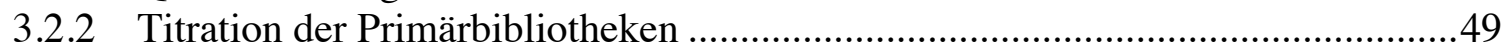

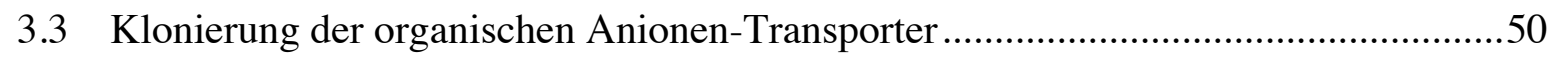

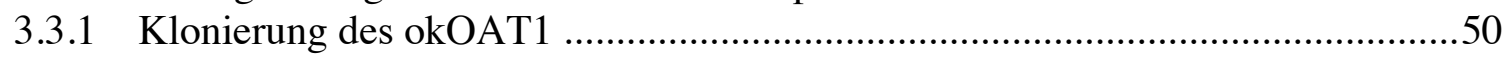

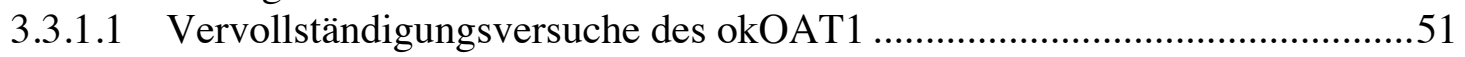

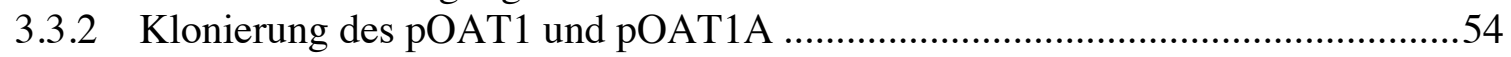

3.4 Funktionelle Charakterisierung des okOAT1, pOAT1 und pOAT1A .......................56

3.4.1 Expression der OAT1 in Xenopus laevis-Oozyten ............................................56

3.4.1.1 Bestimmung des Km-Wertes für PAH in Oozyten ....................................58

3.4.2 Testung verschiedener Expressionssysteme und Substrate für den pOAT1 ........58

3.4.3 Radioaktive Transportversuche mit pOAT1-transfizierten ok-Zellen..................61

3.4.3.1 Kinetik der PAH-Aufnahme in ok-Zellen .................................................61

3.4.3.2 Bestimmung des Km-Wertes für PAH in ok-Zellen ...................................61

3.4.3.3 cis-Inhibition der pOAT1-vermittelten PAH-Aufnahme durch organische

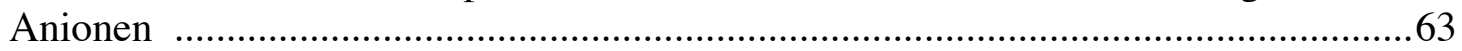

3.4.3.4 trans-Stimulation der pOAT1-vermittelten PAH-Aufnahme durch Glutarat 64

3.4.3.5 Chloridabhängigkeit der pOAT1-vermittelten PAH-Aufnahme ....................65

3.4.3.6 pOAT1-vermittelte Urat-Aufnahme .........................................................65

3.4.3.7 cis-Inhibition der pOAT1-vermittelten PAH-Aufnahme durch Steroide ......66

3.4.3.8 Konzentrationabhängige cis-Inhibition der PAH-Aufnahme durch DHEA-

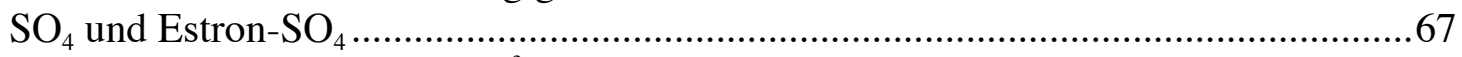

3.4.3.9 pOAT1-vermittelte $\left[{ }^{3} \mathrm{H}\right]$ Estronsulfat-Aufnahme ....................................6

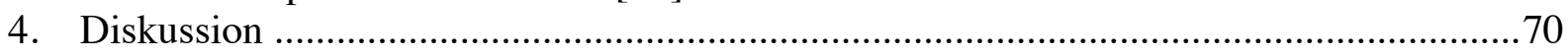

4.1 cDNA-Bank aus ok-Zellen und Schweinenierengewebe ...................................... 70

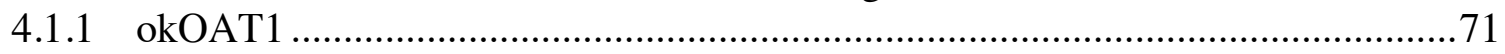

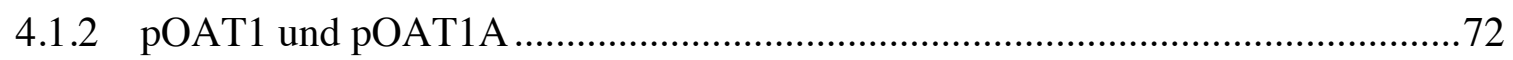

4.2 Funktionelle Grundcharakterisierung der klonierten OAT1 ....................................72

4.2.1 Testung der Funktionalität in Xenopus laevis-Oozyten aller Klone ......................72

4.2.2 Funktionelle Grundcharakterisierung des pOAT1 in unterschiedlichen

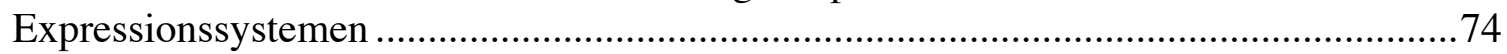


4.2.3 Konzentrationsabhängige pOAT1-vermittelte PAH-Aufnahme .75

4.2.4 trans-Stimulation der pOAT1-vermittelten PAH-Aufnahme .76

4.2.5 Hemmstoffprofil der pOAT1-vermittelten PAH-Aufnahme. .77

4.2.6 Chloridabhängigkeit der pOAT1-vermittelten PAH- und Urat-Aufnahme...........78

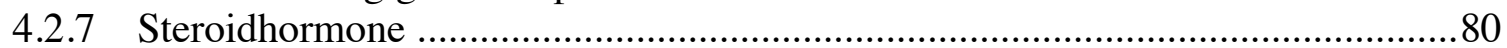

4.2.8 Übersicht der pOAT1-Eigenschaften im Vergleich mit pOAT3 und BLMV ......81

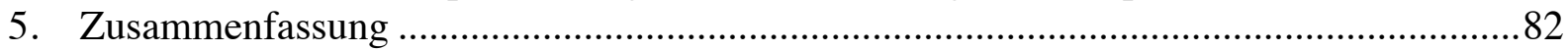

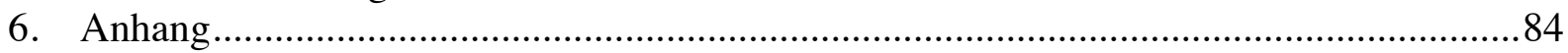

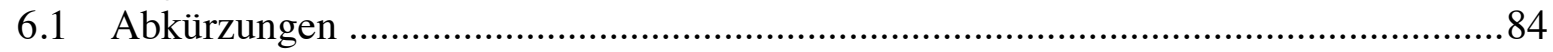

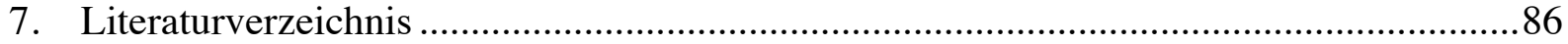




\section{Einleitung}

Der menschliche Körper ist stets einer Reihe von potenziell toxischen Substanzen ausgesetzt. Es handelt sich häufig um organische Anionen und Kationen, die dem Organismus exogen in Form von Nahrung, Medikamenten oder Umweltgiften zugeführt werden, aber auch endogen im Rahmen von Stoffwechselprozessen entstehen können. Exkretorische Organe wie Leber und Niere schützen den Körper vor diesen Substanzen durch eine Biotransformation in weniger toxische Metabolite (Leber) oder aber durch sekretorische Transportprozesse in der Niere (van Aubel et al. 2000). Mit diesen Transportprozessen beschäftigt sich diese Arbeit.

Die Ausscheidung derartiger Substanzen durch die Niere erfolgt überwiegend in ionisierter Form. Neben der glomerulären Filtration spielt die aktive Sekretion und Reabsorbtion im Tubulussystem der Niere eine entscheidende Rolle. Einer der ersten Nachweise über die Fähigkeit der Niere zur Sekretion von Anionen wurde 1928 von Marshall mit der Ausscheidung von Phenol-Rot durch Lophius piscatorius, einem aglomerulären Fisch, erbracht.

Spätere Daten aus Mikropunktionsstudien und Untersuchungen an isolierten Tubuli und Membranvesikeln des Tubulussystems führten zur Beschreibung zweier klassischer Transportsysteme: des organischen Kationen-Transportsystems (OCT) und des organischen Anionen-Transportsystems (OAT), deren Hauptvorkommen die proximalen Tubuli sind. (Lotspeich 1958; Pritchard und Miller 1993).

Vor allem durch den Einsatz von molekularbiologischen Techniken zeigt sich jedoch zum heutigen Zeitpunkt, dass diese jeweils für ihr Substrat als einheitlich beschriebene Wege in und aus der Tubuluszelle die Summe von parallel arbeitenden Transportern darstellen. So sind, neben den klassischen Systemen der OCT und OAT, die zusammen mit weiteren Transporten wie dem OCTN (Organische Zwitterion/Kationen-Transporter), dem URAT1 (UratTransporter) und dem CT2 (Carnitin-Transporter) aufgrund struktureller Ähnlichkeiten zur SLC22-Familie zusammengefasst werden, auch Mitglieder der ABC-Transporter wie der $\mathrm{MDR}($ multi drug resistance)- und MRP(multidrug resistance associated protein)-Transporter und die zur SLC21- bzw. SLCO21-Familie gehörigen OATP(organic anion transporting polypeptide)-Transporter beteiligt sind (Wright und Dantzler 2004; Koepsell und Endou 2004).

Aber auch innerhalb der OAT und der OCT konnten verschiedene Subtypen kloniert und funktionell charakterisiert werden. So unterscheidet man z. B. bei den organischen KationenTransportern gegenwärtig drei Subtypen: OCT1, OCT2 und OCT3. 
Unter den Transportern des organischen Anionen-Systems konnten bislang zehn Subtypen (OAT1-OAT10) mit unterschiedlichen Transportmerkmalen und Gewebsverteilungen kloniert werden. Bislang konnten jedoch nicht alle Subtypen in allen Spezies nachgewiesen werden und zum Teil steht deren funktionelle Charakterisierung noch aus. Eine Übersicht zu einigen bekannten SLC22-Transportern und deren funktionellen Eigenschaften bzw. Gewebsverteilungen zeigt Tabelle 1.1 und wird in Abschnitt 1.1.3 detailliert beschrieben.

Im folgenden Abschnitt soll spezieller auf die organischen Anionen-Transporter eingegangen werden, die in dieser Arbeit im Mittelpunkt stehen.

\subsection{Die organischen Anionen-Transporter (SLC22)}

An der Sekretion von endogenen und exogenen organischen Anionen sind in der Niere eine Vielzahl von Transportproteinen beteiligt. Der Hauptweg der Anionen ist durch die organischen Anionen-Transporter der SLC22-Familie vermittelt und setzt sich aus zwei Schritten zusammen: Zunächst werden die organischen Anionen vom Blut über die basolaterale Zellmembran in die Tubuluszelle aufgenommen und transzellulär über die luminale Membran in den Primärharn ausgeschieden. Die evolutionäre Wichtigkeit dieses Prozesses zeigt sich in der Beobachtung, dass die Fähigkeit zur Anionensekretion bei fast allen Wirbeltieren und auch einigen Nichtwirbeltieren gefunden wurde (Dantzler 1989; Pritchard und Miller 1991).

Als Modellsubstrat zur Testung dieses Systems wurde früher p-Aminohippurat (PAH) genutzt. PAH, ein Monocarboxylat, besitzt eine sehr hohe Ausscheidungsrate über die Niere. Über $90 \%$ des sich im Plasma befindlichen PAH, bei einer Konzentration $<1 \mathrm{mM}$, werden beim einmaligen Fluss durch die Niere ausgeschieden. Dies erfolgt durch glomeruläre Filtration $(20 \%)$ und tubuläre Sekretion (70 \%). Aufgrund dieser hohen Clearance wurde PAH in der Medizin auch zur diagnostischen Bestimmung des renalen Plasmaflusses eingesetzt (Chasis et al. 1945).

\subsubsection{Mechanismus der basolateralen Aufnahme von organischen Anionen}

Aus frühen Studien ging hervor, dass sich organische Anionen trotz ihrer hohen Sekretionsrate in den Tubuluszellen anreicherten. Daraus schlossen Foulkes und Miller bereits 1959, dass sich die Wege der Anionen in und aus der Zelle voneinander unterscheiden mussten. Des Weiteren stellten sie fest, dass es sich bei der Aufnahme in die Zelle um einen aktiven Trans- 
portprozess handeln muss, da die Anionen sowohl gegen einen Konzentrationsgradienten als auch gegen das negativ geladene innere Zellpotenzial transportiert werden müssen. Auch wenn gezeigt werden konnte, dass eine Hemmung des Energiestoffwechsels zu einer Verminderung der PAH-Aufnahme führte, konnte keine direkte Koppelung an die Hydrolyse von ATP nachgewiesen werden. Weiterhin war bekannt, dass die PAH-Aufnahme von einem bestehenden einwärts gerichteten Natriumgradienten abhängig ist. Diese Entdeckung führte zunächst zu der Hypothese, dass der PAH-Transport analog zu den Zucker- und AminosäureTransportern aus intestinalen Epithelien ein $\mathrm{Na}^{+} / \mathrm{PAH}-$ Kotransporter sein könnte. Dieser $\mathrm{Zu}-$ sammenhang konnte aber nie nachgewiesen werden. Auf der Suche nach dem Mechanismus, der die Natriumabhängigkeit und die Frage nach der Kopplung mit der Energieproduktion erklären sollte, waren vor allem zwei Beobachtungen von Bedeutung.

Einerseits zeigte sich, dass eine Reihe von anionischen Stoffwechselprodukten die PAHAufnahme in renalem Gewebe stimulierte (Kippen und Klinenberg 1978; Sheikh und Moller 1983). Andererseits konnten Kasher et al. (1983) nachweisen, dass die Aufnahme von radioaktiv markiertem PAH durch einen auswärts gerichteten Gradienten von unmarkiertem PAH und einen einwärts gerichteten Natriumgradienten erhöht wird. Daraus entstand die Hypothese, dass die PAH-Aufnahme mithilfe eines Austauschs durch ein anderes Anion erfolgen könnte. Diese Hypothese beinhaltete aber noch nicht den energieliefernden Schritt. Erst 1987 stellten Shimada et al. ein bis heute gültiges Modell der basolateralen Aufnahme von Anionen in der proximalen Nierentubuluszelle auf (siehe Abbildung 1.1).

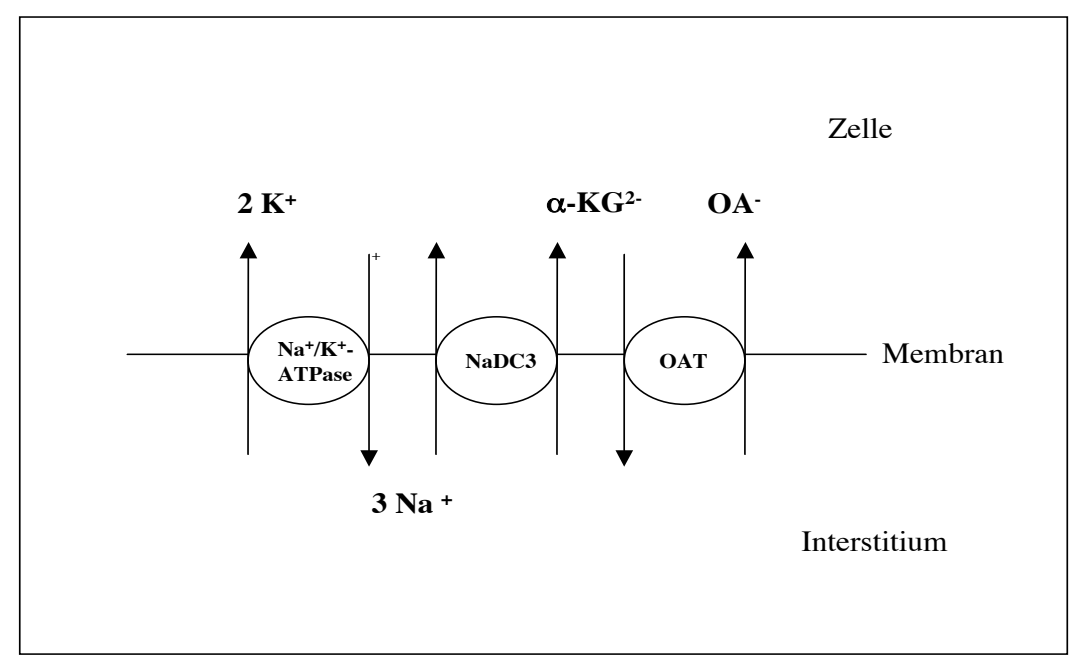

Abbildung 1.1: Mechanismus der basolateralen Aufnahme von organischen Anionen als tertiär aktiver Prozess 
Hier zeigt sich, dass das Anion mithilfe eines sogenannten Antiportes über die basolaterale Zellmembran aus dem Interstitium aufgenommen wird. Dies geschieht im Austausch gegen ein intrazelluläres Dicarboxylat, das in funktionellen Studien (Shimada et al. 1987) als alphaKetoglutarat identifiziert wurde. Dieses Dicarboxylat liegt in vivo intrazellulär in einer deutlich höheren Konzentration gegenüber dem Blut vor und dient als treibende Kraft für den Austausch. Für den Konzentrationgradienten ist sowohl die endogene Produktion im Rahmen des mitochondrialem Zitronensäurezyklus als auch die Anreicherung über die direkte Koppelung der Aufnahme von drei Natriumionen verantwortlich. Die Abbildung zeigt, dass dies über den Natrium-Dicarboxylat-Kotransporter (NaDC3) erfolgt, dessen Existenz erstmals 1984 durch Burckhardt in basolateralen Membranvesikeln nachgewiesen werden konnte und der 1999 durch Kekuda et al. kloniert wurde. Die Triebkraft hierfür liefert wiederum der einwärtsgerichtete Natriumgradient, der unter Hydrolyse eines ATP durch die $\mathrm{Na}^{+} / \mathrm{K}^{+}$-ATPase aufgebaut wird.

In der Nettobilanz handelt es sich bei der Aufnahme eines organischen Anions also um einen tertiär-aktiven, indirekt natriumabhängigen Vorgang, der ein ATP verbraucht (Burckhardt et al. 2001).

\subsubsection{Mechanismus der luminalen Ausscheidung von organischen Anionen}

Den zweiten Schritt der Sekretion von organischen Anionen stellt deren Ausscheidung aus der Tubuluszelle über die apikale Zellmembran in das Tubuluslumen und somit in den Primärharn dar. Dieses ist im Gegensatz zur Aufnahme ein dem Konzentrationgefälle folgender Transport. Trotzdem wurde auch hier ein durch spezifische Transporter vermittelter Vorgang postuliert. Zu Beginn der Untersuchung des luminalen Efflux-Systems dienten Vesikelstudien der apikalen Membran (BBMV) von Hunden und Ratten. Hier konnte ein elektroneutraler Probenecid-hemmbarer Austausch von Anionen wie PAH, Urat, Laktat, Chlorid- und Hyrdroxidionen nachgewiesen werden (Sekine et al. 2000). Des Weiteren fand sich ein spannungsabhängiger Mechanismus bei Schweinen und Kaninchen (Sekine et al. 2000; Blomstedt und Aronson 1980; Martinez et al. 1990; Werner et al. 1990), der zunächst lange die Theorie einer erleichterten Diffusion entlang eines elektrochemischen Gradienten aus der Zelle stützte.

Erst mit der Klonierung und Charakterisierung weiterer OAT sowie anderer Transporter wie des MRP2 und des MRP4 der ABC-Familie, die unter hohem ATP-Verbrauch organische Anionen über die apikale Membran sezernieren, entstand ein genaueres Bild des Efflux (siehe Abbildung 1.3). 
Ähnlich der basolateralen Aufnahme handelt es sich um ein komplexes System aus mehreren parallel arbeitenden Tranportproteinen. Erwähnt seien im Speziellen der OAT4 und der Urat1 aus der SLC22-Familie. Ihre detaillierte Beschreibung folgt in Abschnitt 1.1.3.

\subsubsection{Struktur, Gewebsverteilung und Substratspezifität der OAT-Familie}

Nach dem Beginn der funktionellen Charakterisierung der OAT in perfundierten Tubuli oder Membranvesikeln erfolgte auch die Klärung der molekularen Struktur. Im Jahre 1997 konnten zwei voneinander unabhängige Forschergruppen (Sweet et al. 1997; Sekine et al. 1997) mithilfe der Expressionsklonierung einen OAT aus Rattennieren isolieren, der als OAT1 bezeichnet wurde. Bei bestehenden strukturellen Ähnlichkeiten wurden die im Weiteren klonierten Transporter zur bereits erwähnten SLC22-Familie zusammengefasst.

Gemeinsam ist ihnen eine Aminosäuresequenz von 535-568 AS Länge, die in der Sekundärstruktur zu einem Protein mit 12 alpha-helikalen Transmembrandomänen (TMD) führt. Diese weisen eine große extrazelluläre Schleife zwischen der ersten und zweiten TMD und eine große intrazelluläre Schleife zwischen der sechsten und siebten TMD auf. Sowohl das Nterminale Ende als auch das C-terminale Ende liegen intrazellulär (Sekine et al. 2000; Burckhardt und Wolff 2000).

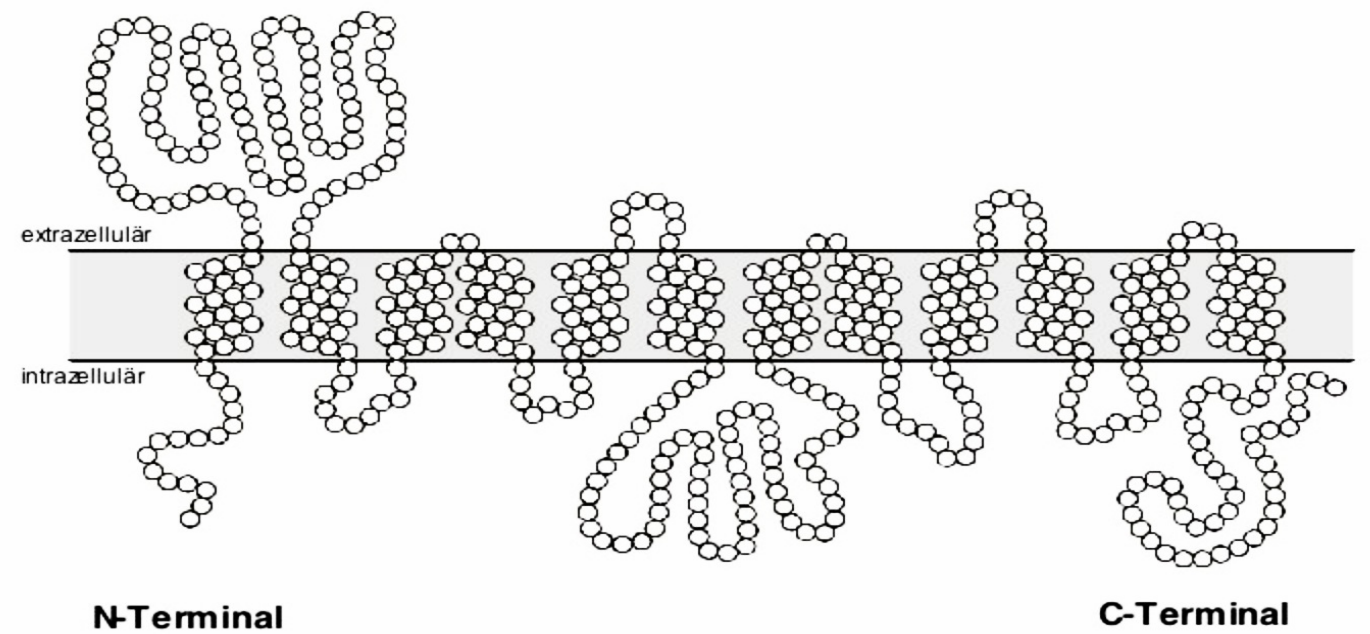

Abbildung 1.2: Sekundäres Strukturmodell des organischen Anionen-Transporters 1 der Ratte (rOAT1). Das Modell basiert auf Strukturanalysen mit TopPred2. 
Im Laufe der Entdeckung weiterer Klone auch aus anderen Spezies wie z. B. des Menschen durch Reid et al. im Jahre 1998 entwickelte sich eine Nomenklatur zur genaueren Beschreibung der Transporter durch Anhängen von Zusätzen, welche die Spezies benennen (z. B. r für rat, $\mathrm{m}$ für mouse, h für human, $\mathrm{p}$ für pig etc.). Des Weiteren fand sich, dass diese Klone sich sowohl in ihren funktionellen Eigenschaften als auch in ihrer Gewebsverteilung unterschieden, weshalb die einzelnen OAT zusätzlich nummeriert werden. Eine Auswahl der bekannten OAT und weitere Mitglieder der SLC22-Familie sind in Tabelle 1.1 dargestellt.

\begin{tabular}{|c|c|c|c|}
\hline & Vorkommen & Zelllokalisation & Substrat \\
\hline OAT1 & Niere $>>$ Gehirn & basolateral & $\begin{array}{l}\text { PAH, Dicarboxylate, } \mathrm{PGE}_{2} \text {, Acetyl- } \\
\text { salicylat, Aciclovir, MTX, Captopril }\end{array}$ \\
\hline OAT2 & Leber $>$ Niere & $\begin{array}{l}\text { basolateral (hOAT2), } \\
\text { apikal (rOAT2) }\end{array}$ & $\begin{array}{l}\text { PAH, Dicarboxylate, } \\
\mathrm{PGE}_{2} \text {, Salicylate }\end{array}$ \\
\hline OAT3 & $\begin{array}{c}\text { Niere }>\text { Skelettmuskel, } \\
\text { Gehirn (hOAT3); } \\
\text { Leber }>\text { Niere; } \\
\text { Gehirn > Auge (rOAT3) }\end{array}$ & basolateral & PAH, Östronsulfat, Cimetidin, Urat \\
\hline OAT4 & Niere, Plazenta & Apikal & $\begin{array}{c}\text { Östronsulfat, DHEA-Sulfat, } \\
\text { OchratoxinA }\end{array}$ \\
\hline OAT5 & Niere & Apikal & Ochratoxin $\mathrm{A}$ \\
\hline OAT10 & $\begin{array}{c}\text { Niere }>>\text { Gehirn, Herz, } \\
\text { Dickdarm }\end{array}$ & Apikal & Nikotinat, Laktat, Urat, PAH \\
\hline OCT1 & Leber $>>$ Niere & basolateral & $\begin{array}{l}\text { TEA, MPP, Desipramin, Aciclovir, } \\
\text { Metformin, Serotonin, } \mathrm{PGE}_{2}\end{array}$ \\
\hline OCT2 & $\begin{array}{c}\text { Niere }>>\text { Plazenta (hOCT2); } \\
\text { Thymus (rOCT2) }\end{array}$ & basolateral & $\begin{array}{c}\text { TEA, MPP, Dopamin, Cholin, } \\
\text { Histamin, Serotonin, } \\
\text { Amantadin, Cimetidin }\end{array}$ \\
\hline OCT3 & Niere & basolateral & MPP \\
\hline OCTN1 & $\begin{array}{l}\text { Niere, Skelettmuskel, } \\
\text { Plazenta, Herz }\end{array}$ & Apikal & $\begin{array}{c}\text { TEA, Quinidin, Pyralamin, } \\
\text { Verapamil }\end{array}$ \\
\hline OCTN2 & $\begin{array}{l}\text { Skelettmuskel, Niere, } \\
\text { Herz, Gehirn }\end{array}$ & Apikal & $\begin{array}{c}\text { TEA, Verapamil, Quinidin, } \\
\text { Cephaloridin, L-Lysin; }\end{array}$ \\
\hline URAT1 & Niere & Apikal & Urat, Chlorid, Lakatat, Nikonitat \\
\hline CT2 & Testis & Apikal & Carnitin \\
\hline
\end{tabular}

Tabelle 1.1: Überblick von Vorkommen, Lokalisation und Substratspezifität einiger SLC22-Transporter

Zusammengefasst aus Bahn et al. (2008); Sekine et al. 2000; Burckhardt und Burckhardt 2003; Koepsell und Endou 2004; Koepsell et al. 2007. 
OAT1: In Untersuchungen wurde der OAT1 in der basolateralen Membran des proximalen Nierentubulus lokalisiert und zusammen mit dem OAT3 als Haupttransporter für die oben beschriebene Aufnahme von organischen Anionen in die Tubuluszelle identifiziert. Es handelt sich um einen Antiporter, der tertiär aktiv angetrieben wird. Zudem konnte der Transporter u. a. im humanen Plexus choroideus (Aleboyeh et al. 2003) und in Neuronen des Cortex und des Hippocampus der Maus (Bahn et al. 2005) nachgewiesen werden. Mittlerweile sind Isoformen von Mensch, Maus, Ratte, Flunder und Hase kloniert. Bei der funktionellen Charakterisierung des Transporters spielte PAH eine große Rolle, da es eine hohe Affinität zu diesem besitzt und als Modellsubstrat dient. Aufgrund dessen wurde der OAT1 auch häufig als PAHTransporter bezeichnet.

$\mathrm{Zu}$ seinen Substraten zählen eine Reihe von endogenen Substanzen (Sekine und Endou 2000), wie z. B. PGE 2 , cAMP, cGMP, Urat, Neurotransmittermetabolite und Folat, bei denen ein aktiver Transport nach intrazellulär nachgewiesen werden konnte. Hinzu kommen noch Substrate, die in Versuchen eine cis-Hemmung der PAH-Aufnahme zeigten und so potenziell auch transportiert werden könnten, z. B. $\mathrm{PGD}_{2}$ und Dopamin. Als exogene Transportmetabolite wurden u. a. eine Reihe von Medikamenten wie Penicillin G, Acetylsalicylsäure, Captopril oder Methotrexat identifiziert (Sekine et al. 2000; Rizwan und Burckhardt 2007). Insgesamt konnte die Interaktion mit über einhundert Substanzen nachgewiesen werden, weshalb der OAT1 als ein multispezifischer Transporter gilt.

OAT2: Die Klonierung dieses Subtyps erfolgte bereits 1994 durch Simonson et al. und somit bereits vor dem OAT1. Damals wurde der Transporter jedoch im Lebergewebe nachgewiesen und als NLT (novel liver-specific transporter) bezeichnet. Erst später erkannte man die Homologie zum OAT1 bzw. die Mitgliedschaft zur SLC22-Familie und benannte ihn um.

Im Gegensatz zum OAT1 sind die Kenntnisse über den OAT2 noch relativ gering und teilweise widersprüchlich. Im Speziesvergleich zeigt der OAT2 unterschiedliche Lokalisationen in der Tubuluszelle. So lokalisieren Enomoto et al. (2002b) den humanen Transporter in der basolateralen Membran des proximalen Tubulus, während er von Kojima et al. (2002) in Ratten- und Mäusenieren in der apikalen Membran des proximalen Tubulus oder den Sammelrohren gefunden wurde. Insgesamt scheint aber die Leber Hauptexpressionsorgan des Transporters zu sein.

Uneinigkeit besteht auch bei der Substratspezifität. Es wurde ein Transport von alphaKetoglutarat beschrieben, jedoch konnte die cis-Hemmung einer PAH-Aufnahme durch die- 
ses Dicarboxylat nicht gezeigt werden. Ähnliches gilt für den Transport von DHEAS (Sun et al. 2001).

Eine weitere Eigenschaft des OAT2 beschreiben Cropp et al. 2008 mit dem Nachweis eines von Splice-Varianten abhängigen Transports von cGMP. Hierbei unterscheiden sich die Splice-Varianten um lediglich 2 Aminosäuren, zeigen aber grundsätzlich unterschiedliche Eigenschaften für den cGMP-Transport. Das um 2 Aminosäuren längere Protein verlor komplett die Fähigkeit zum cGMP-Transport und konnte nicht mehr in der Zellmembran nachgewiesen werden, sondern lag intrazellulär vor. Die Triebkräfte und der genaue Transportmechanismus des OAT2 sind immer noch unklar.

OAT3: Ähnlich wie der OAT1 ist der OAT3 in der basolateralen Membran des proximalen Tubulus lokalisiert und transportiert organische Anionen ebenfalls als Antiporter im Austausch mit alpha-Ketogluterat. Auch in der Gewebsverteilung zeigen sich Parallelen. So konnte der OAT3 ebenfalls im Plexus choroideus beim Menschen (Aleboyeh et al. 2003), der Leber und in Kapillaren des Gehirns im Bereich der Blut-Hirn-Schranke von Ratten (Kusuhara et al. 1999; Kikuchi et al. 2003) nachgewiesen werden. Des Weiteren befindet sich der Transporter in der Skelettmuskulatur, in den Knochen und auch in der humanen Nebenniere (Asif et al. 2005).

In Bezug auf die Substratspezifität gibt es weitere Gemeinsamkeiten. So werden einige endogene Metabolite wie z. B. cAMP, Prostaglandine oder Kortikosteroide als Substrat akzeptiert (Cha et al. 2001). In der Zusammenschau der Daten, insbesondere auch in Hinblick auf seine Verteilung, scheint die Sekretion von Kortikosteroidhormonen und Neurotransmittermetaboliten die Hauptaufgabe des OAT3 zu sein (Aleboyeh et al. 2003).

OAT4: Der OAT4 wurde aus humanem Plazentagewebe kloniert, konnte aber auch in der Niere nachgewiesen werden (Cha et al. 2000). Im Gegensatz zu den zuvor beschriebenen OAT ist der OAT4 jedoch per Immunhistologie in der apikalen und nicht in der basolateralen Membran des proximalen Tubulus lokalisiert worden (Babu et al. 2002). Durch diese Lage sind zwei mögliche Funktionen denkbar: zum einen die Sekretion von organischen Anionen, die zuvor über den OAT1 und OAT3 in die Zelle aufgenommen wurden, zum anderen die Reabsorption von organischen Anionen aus dem Tubuluslumen aus dem Ultrafiltrat der Glomeruli. Als Mechanismus postulierten Hagos et al. (2007) einen asymmetrischen Austauscher im Sinne einer Anionen-Sekretion gegen Chloridionen und eine Absorption von Urat im Austausch gegen Hydroxidionen. Ekaratanawong et al. (2004) beschrieben den hOAT4 als einen bidirektional arbeitenden Anionen/Dicarboxylat-Austauscher in der apikalen Membran des 
proximalen Tubulus, der eine entscheidende Rolle in der Reabsorption von organischen Anionen aus dem Primärharn darstellt.

Die Anzahl der bislang getesteten Substrate für den OAT4 ist im Verhältnis zum OAT1 oder OAT3 noch gering. Als Beispiele für Substrate seien Estronsulfat und Urat, die von der luminalen Zellseite transportiert werden, und alpha-Ketoglutarat, Glutarat und PAH, die von intrazellulär transportiert werden, genannt (Hagos et al. 2007).

OAT5: Dieser OAT wurde ebenfalls in der apikalen Zellmembran der Niere nachgewiesen und arbeitet ähnlich wie OAT4 als ein Antiporter im Austausch mit Dicaboxylaten (Youngblood et al. 2004; Anzai et al. 2005). Als Besonderheit konnten Anzai et al. (2005) zeigen, dass dieser Transporter im Gegensatz zu den Isoformen des OAT1 und OAT3 auch mit Succinat interagiert. Hierbei handelt es sich um ein C4-Dicarboxylat im Unterschied zu alphaKetoglutarat, das einem C5-Dicarboxylat entspricht. Des Weiteren konnte eine Hemmung des OAT5 mit Succinat nachgewiesen werden, was auf eine funktionelle Trennung der apikalen Transporter von den basolateralen hinweisen könnte.

OAT6: Monte et al. (2004) konnten den OAT6 in der olfaktorischen Schleimhaut der Maus nachweisen. Als weitere Lokalisation wird Hodengewebe angegeben. Seine funktionelle Charakterisierung steht jedoch noch aus.

OAT7: Der OAT7 wird ausschließlich in der Leber exprimiert und ist auf der sinusoidalen Seite der Hepatozyten angesiedelt. Er weist eine hohe Affinität zu Steroidhormonen wie DHEA und Estronsulfat auf (Shin et al. 2005).

OAT8: Ähnlich dem OAT7 konnten Yokoyama et al. (2008) nach Expression des Proteins in Xenopus-Oozyten auch ein Transport von Steroidhormonen zeigen. In vivo ist bislang nur die Niere der Ratte als Expressionsort des Transporters nachgewiesen.

OAT9: Tsuchida et al. (2010) entdeckten beim Screening einer Maus-cDNA-Bank der Leber diesen weiteren Transporter. Als Vorkommen wird neben der sinusoidalen Seite der Hepatozyten auch die apikale Membran der proximalen Tubuluszellen angegeben. Als Substrat werden L-Carnitin, Salizylsäure und Cimetidin angegeben.

OAT10: Bahn et al. (2008) konnten im Rahmen der funktionellen Charakterisierung nachweisen, dass der hORCTL3 (human organic cation transporter like) überraschenderweise als Anionentransporter arbeitet. Daraufhin wurde er von dieser Arbeitsgruppe zum hOAT10 umbenannt. Die Arbeitsweise des Transporters wird als hochaffiner Nikotinat-Antiporter beschrieben. Hierbei wird extrazelluläres Nikotinat im Austausch mit intrazellulärem Laktat 
oder Succinat in die Zelle aufgenommen. Ebenfalls wird eine wenn auch geringere affine Aufnahme von Urat und PAH gezeigt. Als Hauptlokalisation des hOAT10 geben Bahn et al. (2008) die apikale Membran der Niere an.

URAT1: Beim Durchsuchen der humanen Genom-Datenbank nach OAT-ähnlichen Genen entdeckten Enomoto et al. (2002a) einen weiteren Anionentransporte, der nach dessen funktionellen Eigenschaften als URAT1 bezeichnet wurde. Mithilfe von Antikörpern wurde als Sitz des Transporters die apikale Membran der Nierentubuluszelle identifiziert.

Wie bereits der Name impliziert, gilt Urat, das als Endprodukt des Purinstoffwechsels anfallende Salz der Harnsäure, als Hauptsubstrat des Transporters. Funktionell arbeitet URAT1 als Antiporter mit Laktat und Nikotinat, die zum einen endogen in der Zelle anfallen und einem Konzentrationsgradienten folgend die Zelle verlassen, zum anderen wird Laktat mithilfe des SMCT (sodium monocarboxylate cotransporter) über die apikale Membran in die Zelle aufgenommen. Damit ergibt sich eine Reabsorption von einem Harnsäuremolekül gegen die Sekretion eines Anions in Form von Laktat oder Nikotinat durch den URAT1.

Unter anderem konnte gezeigt werden, dass Probenecid zu einer starken Hemmung des Transporters führt, was sich mit der klinischen Wirkung als Urikosurikum deckt und die vorliegenden Daten zur Arbeitsweise bestätigt (Enmoto et al. 2002a). 


\subsubsection{Mechanismus der renalen Sekretion von organischer Anionen}

Im Zuge der bereits erwähnten Entdeckung weiterer Transporter und Subtypen der SLC22Familie liegt ein komplexes Modell des organischen Anionen-Transports in der proximalen Tubuluszelle vor (siehe Abbildung 1.3).

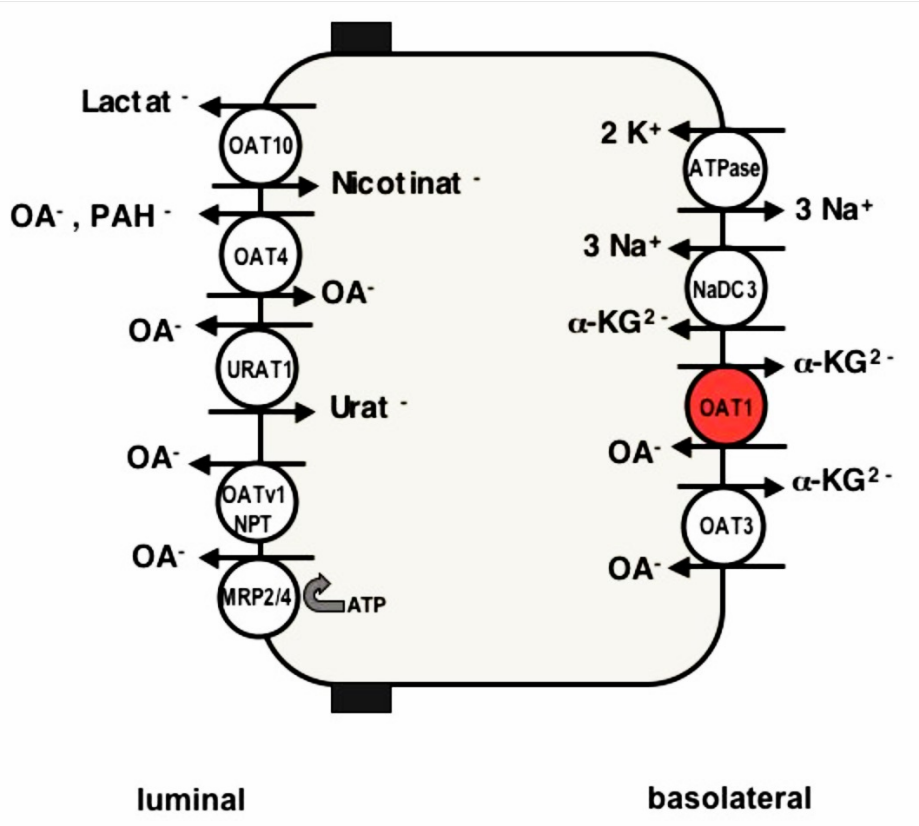

Abbildung 1.3: Mechanismus der organischen Anionen-Transporter in der proximalen Tubuluszelle

Aus der Vielzahl der beteiligten Transporter mit ihrem multipezifischen Substratverhalten ergeben sich ebenso vielfältige pharmakologische Interaktionen, die mit dem aktuellen Wissen erklärbar werden.

Zudem deutet der zunehmende Nachweis der Transporter auch in anderen Organen und Geweben auf die Wichtigkeit dieser Transportsysteme in der Physiologie des gesamten Organismus hin. Außerdem erschließen sich weitere Forschungsfelder außerhalb der direkten Nierenphysiologie. Einige Beispiele zur Bedeutung der OAT in der Medizin sind in Abschnitt 1.2 aufgeführt.

\subsection{Bedeutung der organischen Anionen-Transporter in der Medizin}

Eine große Rolle spielen die OAT in der Pharmakologie, insbesondere für die Erklärung von Wechselwirkungen zwischen verschiedenen Medikamenten. Als ein Beispiel sei die Hem- 
mung der Sekretion von $\beta$-Lactam-Antibiotika über die Niere, durch das bereits erwähnte Urikosurikum Probenecid genannt, das zur Gichttherapie eingesetzt wird. Diese Wirkung wurde bereits 1997 von Roch-Ramel et al. anhand von Vesikelstudien beschrieben, ohne jedoch den genauen Mechanismus zu kennen. Durch die Charakterisierung der einzelnen beteiligten Transporter, insbesondere des OAT1 und OAT3, ist dieser Mechanismus auf der Ebene einzelner Transporter erklärbar. Für beide OAT konnte gezeigt werden, dass diese das Penicillin als Substrat transportieren und durch Probenecid hemmbar sind (Deguchi et al. 2004; Van Wert et al. 2010). Neben den B-Lactam-Antibiotika gibt es eine Reihe weiterer Medikamentengruppen, bei denen eine Interaktion mit den OAT beschrieben wird. Hierzu gehören u. a. antivirale Medikamente wie Aciclovir und Ganciclovir, aber auch ACE-Inhibitoren (z. B. Captopril, Quinapril), Angiotensin-II-Rezeptorblocker (z. B. Lorsartan, Valsartan), HMGCoA-Reduktasehemmer (z. B. Simvastatin, Pravastatin) und Zytostatika (z. B. Methotrexat, 5Fluoruracil) (Burckhardt 2012).

Im Bereich der Zytostatika ergeben sich mit der detaillierten Charakterisierung der OAT und OCT ebenfalls neue Aspekte für die Therapie von Tumorerkrankungen. Es konnte nachgewiesen werden, dass eine Vielzahl von Tumoren Transporter der SLC22-Familie exprimieren und diese Transporter die Aufnahme von Zytostatika in die Tumorzelle vermitteln (Gupta et al. 2011). Beispielsweise interagiert der OAT1 mit Methotrexat oder der OAT2 mit 5Fluoruracil. White et al. (2010) vermuten eine Korrelation des Nachweises von OCT1 in Zellen der chronisch myeloischen Leukämie (CML) mit dem Langzeit-Outcome der Patienen unter Therapie mit Imatinib, das ein Substrat dieser Transporter ist (Thomas et al. 2004).

Das Verständnis derartiger Zusammenhänge in Kombination mit einem prätherapeutischen Screening nach bestimmten Transportern im Tumormaterial des einzelnen Patienten könnte ein Schritt in Richtung individualisierte Tumortherapie des Patienten bedeuten.

Die idiopathischen Hypourikämie ist eine seltene Erkrankung, bei der es durch starke körperliche Anstrengung zum akuten Nierenversagen kommt (Kikuchi et al. 2000). Durch mangelnde Reabsorption von Harnsäure im Tubulus kristallisiert diese bei hohem Harnsäureaufkommen in der Niere und schädigt diese. Ursächlich hierfür ist eine genetische Mutation im Gen des hURAT1, die Enomoto et al. (2002a) im Rahmen seiner Klonierung identifizierte. Durch eine Transition von Guanin zu Adenin resultiert ein Wechsel von Tryptophan zu einem StopCodon, sodass ein unvollständiges und nicht transportierendes Protein entsteht. 


\subsection{Ziele der Dissertation}

Ziel der Arbeit ist es, den Mechanismus und das Zusammenspiel der organischen Anionentransporter besser zu verstehen, um geeignete in vitro-Modelle z. B. zur Untersuchung von Medikamentenwirkung und Wechselwirkungen zu entwickeln oder zu bestätigen. Hierzu sollte der OAT1 kloniert und funktionell charakterisiert werden, um diesen mit Daten aus Vesikel- und Tubulusstudien, die die Summe vieler Transporter widerspiegeln, vergleichen zu können.

Als Ausgangsbasis, auch zur Klonierung weiterer Subtypen, sollten cDNA-Banken aus okZellen und Schweinenierengewebe angelegt werden. Sowohl für die ok-Zellen, einer immortalisierten Zelllinie, die bereits 1978 von Koyama et al. aus amerikanischen Opossum-Nieren (Didelphys virginiana) etabliert wurde, als auch für Schweinegewebe gilt, dass beide Systeme leicht verfügbar sind und dementsprechend viele Daten aus Vesikel- und Tubulusstudien vorliegen. Ebenfalls aus Gründen der leichten Verfügbarkeit sind beide Systeme für die Nutzung als in vitro-Modell geeignet. 


\section{Material und Methoden}

\subsection{Material}

\subsubsection{Geräte}

\begin{tabular}{|c|c|c|}
\hline Gerät & Тур & Hersteller \\
\hline Begasungsbrutschrank & BB-16 & Heraeus (Hanau, Deutschland) \\
\hline Brutschrank & B-6200 & Heraeus (Hanau, Deutschland) \\
\hline Filmkassette & Medium & Kodak (Rochester, NY, USA) \\
\hline Geldokumentation & Gel Print $2000 \mathrm{I}$ & Biophotonics (Ann Arbor, MI, USA) \\
\hline Gelkammer & Mini, Medi & $\begin{array}{l}\text { Amersham Biosciences (Freiburg, } \\
\text { Deutschland) }\end{array}$ \\
\hline Kühlzentrifuge & $400 \mathrm{R}$ & Heraeus (Hanau, Deutschland) \\
\hline Magnetrührer & RCT B & IKA (Staufen, Deutschland) \\
\hline Mikroskop & Stemi 1000 & Zeiss (Jena, Deutschland) \\
\hline Nanoliter Injektor & Nanoliter 2000 & $\begin{array}{l}\text { World Precision Instrument (Sara- } \\
\text { sota, FL, USA) }\end{array}$ \\
\hline pH-Meter & PH-Meter 611 & $\begin{array}{l}\text { Orion Research Inc. (Beverly, MA, } \\
\text { USA) }\end{array}$ \\
\hline Pipetten & Research, Reference & Eppendorf (Hamburg, Deutschland) \\
\hline Schüttelinkubator & 3031,3032 & GFL (Burgwedel, Deutschland) \\
\hline Schüttelwasserbad & 1083 & GFL (Burgwedel, Deutschland) \\
\hline Sequenzieranlage & ABI 373A & $\begin{array}{l}\text { Applied Biosystems (Foster City, } \\
\text { CA, USA) }\end{array}$ \\
\hline Sicherheitswerkbank & Microflow 51424/1 & Nunc (Wiesbaden, Deutschland) \\
\hline Spannungsgerät & Elpho P24 & Biometra (Göttingen, Deutschland) \\
\hline Spektralfluorimeter & F2000 & Hitachi (Tokyo, Japan) \\
\hline Spektralphotometer & GeneQuant II / Novaspec II, & Pharmacia, (Uppsala, Schweden) \\
\hline ß-Szintillationszähler & Liquid Tri Carb 2100 TR & Packard (Dreieich, Deutschland) \\
\hline Thermocycler & GeneAmp PCR system 2400 & Perkin Elmer (Waltham, MA, USA) \\
\hline & Robocycler Gradient 96 & Stratagene (La Jolla, CA, USA) \\
\hline
\end{tabular}




\begin{tabular}{lll}
\hline Gerät & Typ & Hersteller \\
\hline & & \\
UV-Transilluminator & TM40 & UVP Inc (Upland, CA, USA) \\
Vakuumzentrifuge & SpeedVac Concentrator 100H & Savant, (Holbrook, NY, USA) \\
Vortexer & MS1-minishaker & IKA (Staufen, Deutschland) \\
Waage & 2662, T3159M, LC6215 & Sartorius (Göttingen, Deutschland) \\
Zentrifugen & Biofuge fresco & Heraeus (Hanau, Deutschland) \\
& 5417R & Eppendorf (Hamburg, Deutschland)
\end{tabular}

\subsubsection{Verbrauchsmaterialien}

Material

Glaskapillaren

Kryoröhrchen

Mehrzweckgefäße mit Schnappdeckel

Mikroreaktionsgefäße

Nitrozellulosefolien

Petrischalen, Gewebekulturplatten, Kulturflaschen

Röntgenfilm (Bio Max Film)

Szintillationsröhrchen (Mini Vials)

Whatman-3MM-Papier

Zentrifugenröhrchen
Hersteller

World Precision Instruments (Sarasota, FL, USA)

Greiner Bio-One (Frickenhausen, Deutschland)

Greiner Bio-One (Frickenhausen, Deutschland)

Eppendorf (Hamburg, Deutschland)

Stratagene (La Jolla, CA, USA)

Deutschland)

Kodak (Rochester, NY, USA)

Sarstedt (Sarstedt, Deutschland)

Schleicher \& Schuell (Dassel, Deutschland)

Falcon BD (Franklin Lakes, NJ, USA) 


\subsubsection{Reaktionssets (,Kits")}

Reaktionsset

Hersteller

NucleoTrap Extraction Kit for Nucleic Acids

Machery-Nagel (Düren, Deutschland)

Lipofectamine

Invitrogen (Karlsruhe, Deutschland)

PCR-purification Kit

Qiagen (Hilden, Deutschland)

QIAprep Spin Miniprep Kit

Qiagen (Hilden, Deutschland)

rediprime II labelling system

Amersham Pharmacia Biotech (Freiburg,

Deutschland)

RNeasy Midi Präparations Kit

Qiagen (Hilden, Deutschland)

T7 mMESSAGE mMACHINE Kit

Ambion (Austin, TX, USA)

ZAP Express cDNA Gigapack III

Stratagene (La Jolla, CA, USA)

Gold Cloning Kit

ZAP Express cDNA Synthesis Kit

Stratagene (La Jolla, CA, USA)

\subsubsection{Enzyme}

\begin{tabular}{ll}
\hline Enzyme & Hersteller \\
\hline DNA-Polymerase I & Stratagene (La Jolla, CA, USA) \\
MMLV Reverse Transcriptase & Stratagene (La Jolla, CA, USA) \\
Pfu DNA-Polymerase I & Stratagene (La Jolla, CA, USA) \\
Restriktionsenzym NotI & Gibco BRL (Invitrogen, Karlsruhe, Deutschland) \\
Restriktionsenzym Xho I & Stratagene (La Jolla, CA, USA) \\
RNase Block Ribonuclease Inhibitor & Stratagene (La Jolla, CA, USA) \\
RNase H & Stratagene (La Jolla, CA, USA) \\
T4 DNA-Ligase & Stratagene (La Jolla, CA, USA) \\
Taq-Polymerase & Powerscrpit (Boehringer Mannheim, Deutschland) \\
& Hotstaq (Qiagen, Hilden, Deutschland) \\
Terminale Transferase & Gibco BRL (Invitrogen, Karlsruhe, Deutschland) \\
\hline
\end{tabular}




\subsubsection{Chemikalien}

Alle verwendeten Chemikalien wurden, wenn nicht anders angegeben, von den Firmen Amersham (Freiburg, Deutschland), BioRad (München, Deutschland), Boehringer (Mannheim, Deutschland), Merck (Haar, Deutschland), Serva (Heidelberg, Deutschland) Sigma (Deisenhofen, Deutschland) und Roth (Karlsruhe, Deutschland) bezogen.

\begin{tabular}{ll}
\hline Material & Hersteller \\
\hline 1 kB DNA-Leiter & Gibco BRL (Karlsruhe, Deutschland) \\
GBX developer and replenisher & Kodak (Rochester, NY, USA) \\
GBX fixer and replenisher & Kodak (Rochester, NY, USA) \\
Heringsperma-DANN & Boehringer (Mannheim, Deutschland) \\
Oligo(dT)-Zellulose & BioRad (München, Deutschland) \\
Sepharose CL-2B Gel & Stratagene (La Jolla, CA, USA) \\
Szintillationslösung & Packard Goldstandard (Packard Dreieich, Deutschland) \\
& Lumasafe (Lumac LSC, Groningen, Niederlande) \\
& \\
Radiochemikalien & Hersteller \\
\hline [glycyl-2- ${ }^{3}$ H]PAH \\
spez. Aktivität: $3,97 \mathrm{Ci} / \mathrm{mmol}$ \\
{$\left[6,7-{ }^{3} \mathrm{H}\right]$ Estronsulfat } \\
spez. Aktivität: 43,5 Ci/mmol \\
[8- ${ }^{14}$ C]Urat & NEN Life Science (Boston, MA, USA) \\
spez. Aktivität: 50-60 mCi/mmol & \\
\hline
\end{tabular}




\subsubsection{Zelllinien, Bakterienstämme und Phagen}

Stamm

Hersteller

Chinese hamster ovary cells, CHO-K1-Zellen

ATCC (Manessas, VA, USA)

(ATCC No. CCL-61)

Opossum kidney cells, ok-Zellen

ATCC (Manessas, VA, USA)

(ATCC No. CRL-1840)

E.coli XL1-Blue MRF'

Stratagene (La Jolla, CA, USA)

E.coli XLOLR

Stratagene (La Jolla, CA, USA)

ExAssist Helper Phage

Stratagene, (La Jolla, CA, USA)

$\lambda$ ZAP-Phage

Stratagene (La Jolla, CA, USA)

\subsubsection{Puffer, Lösungen und Kulturmedien}

Neben den Puffern, Lösungen und Kulturmedien der entsprechenden Reaktionssets (siehe Herstellerangaben) wurden folgende andere verwendet. Gegebenenfalls erfolgte Änderungen der Zusammensetzung sind im jeweiligen Methodenteil beschrieben.

Puffer, Lösung, Medium

0,5x TBE-Puffer

1x Waschpuffer

20x SCC-Puffer

5x Probenpuffer

Agarosegel (0,8 oder $1 \%)$

Barth-Lösung

\section{Zusammensetzung}

45 mM Tris, 45 mM Borsäure, 1 mM EDTA; pH 8

$20 \mathrm{mM}$ Tris/HCl, $1 \mathrm{mM}$ EDTA/NaOH,

$0,5 \mathrm{M} \mathrm{NaCl}, 0,1 \%$ SDS

$3 \mathrm{M} \mathrm{NaCl}, 0,3 \mathrm{M}$ Natriumcitrat

$30 \%$ Ficoll, $1 \%$ SDS, $10 \mathrm{mM}$ Tris $/ \mathrm{HCl}, 0,05 \%$

Xynenxyanol, 0,05 \% Bromphenolblau; $\mathrm{pH}$ 7,5

0,5 x TBE Puffer mit entsprechender Menge

Agarose

$88 \mathrm{mM} \mathrm{NaCl}, 1 \mathrm{mM} \mathrm{KCl}, 0.3 \mathrm{mM} \mathrm{Ca}\left(\mathrm{NO}_{3}\right)_{2}$,

$0.41 \mathrm{mM} \mathrm{CaCl}_{2}, 0.82 \mathrm{mM} \mathrm{MgSO}_{4}, 15 \mathrm{mM}$ HEPES,

$10 \mathrm{mg} / 1$ Steptomycin or Gentamicin;

pH 7,6 mit $1 \mathrm{M} \mathrm{NaOH}$ 
Puffer, Lösung, Medium

Denaturierungspuffer

DEPC-Wasser

DMEM-Medium

Dulbecco's PBS-Lösung

Ham's F12-Medium

High-stringency wash buffer II

Hybridization solution II

Low-stringency wash buffer II

Neutralisierungspuffer

Oozyten Ringer-Lösung (ORI)
Zusammensetzung

$0,5 \mathrm{~m} \mathrm{NaOH}, 1,5 \mathrm{M} \mathrm{NaCl}$

$0,1 \%(\mathrm{v} / \mathrm{v})$ Diethyldicarbonat in aqua dest.

26,75 g DMEM powder, 7,39 $\mathrm{g} \mathrm{NaHCO}_{3}$,

5 mM Glukose, 4 mM L-Glutamin, ad. 21 aqua dest.

4 PBS Tabs, 34 mg Phenolrot ad. 21 aqua dest.

21,5 g Ham's F12 powder, $19.04 \mathrm{~g}$ Hepes,

ad. 21 aqua dest.; pH 7,4 mit $1 \mathrm{M} \mathrm{NaOH}$

1 mM NaEDTA, 40 mM NaHPO4, $1 \%$ SDS;

$\mathrm{pH} \mathrm{7,2}$

$1 \%$ kristallines BSA, 1 mM EDTA,

$0,5 \mathrm{M} \mathrm{NaHPO}_{4}, 7 \%$ SDS; $\mathrm{pH} \mathrm{7,2}$

0,5\% BSA, 1 mM Na 2 EDTA, $40 \mathrm{mM}$ NaHPO, 4,5

$\%$ SDS; pH 7,2

0,5 M Tris 1,5 M NaCl; $\mathrm{pH} 7,4$

$90 \mathrm{mM} \mathrm{NaCl}, 3 \mathrm{mM} \mathrm{KCl}, 2 \mathrm{mM} \mathrm{CaCl} 2,1 \mathrm{mM}$

$\mathrm{MgCl}_{2}, 5 \mathrm{mM}$ HEPES; $\mathrm{pH}$ 7,6 mit $1 \mathrm{mM}$ Tris

\subsubsection{Oligonukleotide (Primer)}

Die Primer wurden mit den Computerprogramm „Gene runner“ (Hastings Software Inc., Hastings, NY, USA) und dem Onlineservice „Primer3“ des Whitehead Institute for Biomedical Research des Massachusetts Institute of Technology htttp//www.genome.wi.mit.edu/cgibin/primer/primer3.cgi) entworfen. Für die Primer wurden folgende Parameter vorgegeben: eine Länge von 20-24 Nukleotiden, einen Guanosin- und Cytosin-Anteil von 50-60 \% und eine Schmelztemperaturdifferenz des Forward- und Reverseprimers kleiner als $1^{\circ} \mathrm{C}$. Synthetisiert wurden die Primer von der Firma NAPS (Göttingen, Deutschland) und auf eine Konzentration von $100 \mathrm{pmol} / \mu 1$ eingestellt. 


\begin{tabular}{|c|c|c|}
\hline Bezeichnung & Sequenz $5^{\prime}-3^{\prime}$ & Verwendung \\
\hline rbOAT1-101F22 & ACAACACCCTGCAGAACTTCAC & Sondenpräparation \\
\hline rbOAT1-1071R23 & GACCAACCCGTAGTAGGCAAAGC & Sondenpräparation \\
\hline rOAT1-271F20 & GAATCTTGCCTCCGCTTTAC & Nachweis von okOAT1 in cDNA \\
\hline rOAT1-1938R22 & CCGCCACCTCCAGGACCTTGCA & Nachweis von okOAT1 in cDNA \\
\hline rbOAT1-101F22 & ACAACACCCTGCAGAACTTCAC & Nachweis von okOAT1 in cDNA \\
\hline rbOAT1-1117R24 & ATTTTTGGCGCCGTGGACCTGCCT & Nachweis von okOAT1 in cDNA \\
\hline okOAT1-267F22 & TTCTCGGAGCCATGATATTCGG & Vervollständigung \\
\hline okOAT1-1448R22 & TCTGTTTCTGCTGCTCCTGCTG & Vervollständigung \\
\hline hgOAT1 5UTR-2393F22 & GGAGAAATTCCACTGACACAAG & Vervollständigung aus genomischer DNA \\
\hline hgOAT1 5UTR-2438F22 & CTGACACCAAGTCACACTTTAC & Vervollständigung aus genomischer DNA \\
\hline okOAT1-447R22 & TCCACATTCAGTGTCATGCAGC & Vervollständigung aus genomischer DNA \\
\hline okOAT1-624R21 & CCGATTCGATGAAGAACCAGG & Vervollständigung aus genomischer DNA \\
\hline \multirow[t]{2}{*}{ QoQiT(17) } & CGCAGATGTACGTCCTACCATCGCCTC- & 5'RACE \\
\hline & 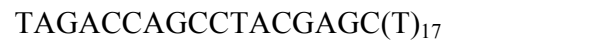 & \\
\hline Qo & CGCAGATGTACGTCCTACCATCGCC & 5'RACE \\
\hline Qi & ATCGCCTCTAGACCAGCCTACGAGC & 5'RACE \\
\hline $\mathrm{T} 7$ & GTAATACGACTCACTATAGGGC & Sequenzierung \\
\hline $\mathrm{T} 3$ & AATTAACCCTCACTAAAGGG & Sequenzierung \\
\hline
\end{tabular}

\subsection{Extraktion von Gesamt-RNA aus ok-Zellen}

Zur Extraktion der Gesamt-RNA wurden 5 Platten $(120 \mathrm{~mm})$ mit Opossum Kidney-Zellen (ok-Zellen) geerntet, was einer Anzahl von 4,3 x $10^{7}$ Zellen entspricht. Diese Zellen wurden in 3,8 ml Lysepuffer des „RNeasy Midi Präparations Kit“ (Qiagen, Hilden, Deutschland) aufgenommen. Die Extraktion der Gesamt-RNA orientierte sich an Angaben des Herstellers und wurde in $0,5 \mathrm{ml}$ RNAse-freiem Wasser aufgenommen. Die Konzentrationsbestimmung erfolgte photometrisch (siehe Abschnitt 2.8.1). 


\subsection{Extraktion von mRNA aus Gesamt-RNA der ok-Zellen}

Die Isolierung der mRNA erfolgte mithilfe der Oligo(dT)-Säulenchromatographie. Prinzip dieser Methode ist die Hybridisierung der Poly-A-Regionen der mRNA mit Oligo(dT)Nukleotiden, die an einem Zellulosegel anheften. Anschließend kann die gebundene mRNA eluiert werden.

Säulenvorbereitung: 0,165 g Oligo(dT)-Zellulose (BioRad, München, Deutschland) wurden in $0,5 \mathrm{ml} \mathrm{H}_{2} \mathrm{O}$ suspendiert und in eine Säule gefüllt. Die Säule wurde nacheinander mit 2,5 ml Puffer $(0,1 \mathrm{mM} \mathrm{NaOH}, 5 \mathrm{mM}$ EDTA) und DEPC-Wasser gewaschen. Das Waschen mit DEPC-Wasser wurde so oft wiederholt, bis der Durchlauf bei einem $\mathrm{pH}$ von 6-7 lag. Die vorbereitete Säule wurde mit $5 \mathrm{ml}$ des $1 \mathrm{x}$ Waschpuffers equilibriert.

Probenvorbereitung: Die Gesamt-RNA wurde in $1 \mathrm{ml}$ Rnase-freiem Wasser aufgenommen und 5 min bei $65{ }^{\circ} \mathrm{C}$ inkubiert. Danach wurde das gleiche Volumen des 2x Waschpuffers hinzugegeben und die Probe sofort auf Eis gestellt.

Die vorbereitete Probe wurde auf die Säule aufgetragen und der Durchlauf gesammelt. Nach einer erneuten Inkubation des Durchlaufs für $5 \mathrm{~min}$ bei $65^{\circ} \mathrm{C}$ wurde dieser nochmals auf die Säule aufgetragen. Danach wurde die Säule mit $5 \mathrm{ml} \mathrm{1x}$ Waschpuffer gespült. Die mRNA wurde mit $2 \mathrm{ml}$ DEPC-Wasser eluiert, in $200 \mu 1$ Fraktionen gesammelt und auf Eis gestellt. Pro Fraktion wurden $5 \mu 1$ mit $145 \mu 1$ DEPC-Wasser verdünnt und deren RNA Konzentrationen photometrisch bestimmt. Nach der Konzentrationsbestimmung wurden die RNApositiven Fraktionen 1-5 vereinigt und nochmals wie oben beschrieben vorbereitet.

Die Säule wurde abermals mit $5 \mathrm{ml}$ 1x Waschpuffer gespült und hinterher mit der Probe beladen. Die mRNA wurde mit $2 \mathrm{ml}$ DEPC-Wasser eluiert und in $200 \mu 1$ Fraktionen gesammelt. Anschließend erfolgte wiederum die photometrische Konzentrationsbestimmung und Vereinigung der positiven Fraktionen (Endvolumen: 0,75 ml). Zur Aufreinigung der mRNA durch Präzipation wurde das 0,1-fache Probenvolumen an 3 M NaAcetat und das 2,2-fache Probenvolumen mit absolutem Ethanol hinzugefügt und über Nacht bei $-20^{\circ} \mathrm{C}$ inkubiert. AbschlieBend erfolgte eine Zentrifugation bei 12000 g über 30 min. Das Pellet wurde mit $70 \%$ Ethanol gewaschen und in $50 \mu 1$ DEPC-Wasser resuspendiert. 


\subsection{Erstellung der cDNA-Bibliotheken}

\subsubsection{Grundlagen}

Da RNA-Moleküle in ihrer natürlichen Form sehr labil und schwer zu vermehren sind, ist es günstig, mRNA in stabile Doppelstrang-DNA zu überführen und eine sogenannte cDNABibliothek anzulegen. cDNA-Bibliotheken enthalten DNA-Sequenzen, die komplementär zu mRNA sind. Diese cDNA kann dann anschließend in einen Vektor integriert werden, was den Umgang mit den genetischen Informationen der mRNA eines Organismus erheblich vereinfacht. Die cDNA-Bibliotheken wurden mithilfe eines Lambda-Phagen-Derivats ( $\lambda$ ZAPPhage), dem „ZAP Express cDNA Synthesis Kit“ und „ZAP Express cDNA Gigapack III Gold Cloning Kit“ (Stratagene, La Jolla, CA, USA) nach Herstellerangaben erstellt.

Die Bibliotheken aus ok-Zellen und Schweinenierengewebe wurden zwar nacheinander erstellt, werden aber aufgrund der gleichen Arbeitsschritte im Folgenden zusammenhängend dargestellt. Die mRNA zur Erstellung der cDNA-Bank wurden aus 8 g Nierenrindengewebe vom Schwein isoliert und von Prof. Dr. Y. Hagos zur Verfügung gestellt.

\subsubsection{CDNA-Synthese und Vorbereitungen zum Vektoreinbau}

\subsubsection{Synthese des ersten Strangs}

Die Synthese der cDNA erfolgte in mehreren Schritten: Zur Synthese des sogenannten ersten Strangs wurden 7,17 $\mu \mathrm{g}$ mRNA aus ok-Zellen bzw. 7,5 $\mu \mathrm{g}$ mRNA aus Schweinenieren eingesetzt. Die mRNA wurde jeweils zusammen mit $5 \mu 1$ 10x first-strand buffer, $3 \mu 1$ first-strand methyl nukleotide mixture, $2 \mu$ linker-primer, $1 \mu$ RNase Block Ribonuclease Inhibitor (40

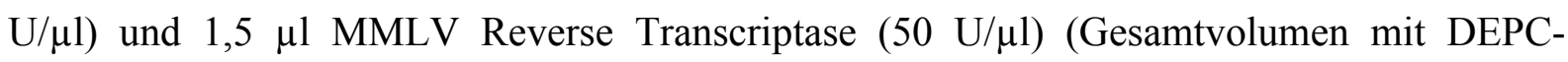
Wasser auf $50 \mu \mathrm{l}$ aufgefüllt) für $1 \mathrm{Std}$. im Wasserbad bei $37^{\circ} \mathrm{C}$ inkubiert. Anschließend wurde der Reaktionsansatz auf Eis gestellt. Bei dem Linker-Primer handelt es sich um ein Oligonukleotid mit einer GAGA-Sequenz, einer XhoI-Schnittstelle und einem Oligo(dT)-Ende.

\section{5'-GAGAGAGAGAGAGAGAACTAGTCTCGAGTTTTTTTTTTTTTTT-3' \\ $\begin{array}{lll}\text { GAGA-Sequenz } & \text { XhoI } & \text { Oligo(dT) }\end{array}$}

Die GAGA-Sequenz dient zum Schutz der XhoI-Schnittstelle und des Oligo(dT)-Endes. Die XhoI-Schnittstelle wird für den späteren gerichteten Einbau der fertigen cDNA in den Vektor 
benötigt. Mit dem Oligo(dT)-Ende lagert sich der Primer komplementär an die 3'Poly-ARegion der mRNA an und dient der Reverse-Transcriptase als Startpunkt für die Synthese des ersten Strangs.

Das Nukleotidgemisch enthält neben normalen dATP, dGTP und dTTP auch 5-methyl dCTP. Der erste Strang besitzt an jedem Cytosin eine Methyl-Gruppe, die den ersten Strang der cDNA bei weiteren enzymatischen Syntheseschritten schützt.

\subsubsection{Synthese des zweiten Strangs}

Zur Synthese des zweiten Strangs wurden $20 \mu 110$ x second strand buffer, $6 \mu 1$ second-strand dNTP mixture, $116 \mu \mathrm{l}$ steriles Aqua dest., $2 \mu \mathrm{l}$ RNase $\mathrm{H}(1,5 \mathrm{U} / \mu \mathrm{l})$ und $11 \mu \mathrm{l}$ DNAPolymerase I (9 U/ $\mu$ l) hinzugefügt. Der Ansatz wurde für $2,5 \mathrm{Std}$. bei $16^{\circ} \mathrm{C}$ inkubiert und anschließend sofort auf Eis gestellt.

Die RNase verdaut die am ersten cDNA-Strang gebundene RNA zu multiplen Fragmenten, sodass der zweite Strang synthetisiert werden kann. Gleichzeitig dienen die Fragmente der DNA-Polymerase I als Primer.

\subsubsection{Schneiden der cDNA-Enden}

Im nächsten Schritt wurden die stufigen Enden der doppelsträngigen cDNA aufgefüllt oder abgeschnitten, um die Ligation von Adaptoren zu ermöglichen.

Dazu wurden dem Reaktionsansatz $23 \mu \mathrm{l}$ blunting dNTP mix und $2 \mu 1$ Pfu DNA-Polymerase I $(2,5 \mathrm{U} / \mu)$ beigegeben und dieser bei $72{ }^{\circ} \mathrm{C}$ für 30 min inkubiert. Anschließend wurden $200 \mu 1$ Phenol-Chloroform (1:1 [v/v]) hinzugefügt. Der Ansatz wurde mit $12000 \mathrm{~g}$ für 2 min bei RT zentrifugiert. Die obere wässrige Schicht, die die DNA enthielt, wurde in ein neues Mikroreaktionsgefäß überführt. Es wurden $20 \mu 13 \mathrm{M}$ Acetate und $400 \mu 1$ absolutes Ethanol hinzugegeben, um die DNA zu präzipitieren. Der Ansatz wurde über Nacht bei $-20{ }^{\circ} \mathrm{C}$ inkubiert und bei $12000 \mathrm{~g}$ für $1 \mathrm{Std}$. bei $4{ }^{\circ} \mathrm{C}$ zentrifugiert und mit $500 \mu 170 \%$ Ethanol gewaschen. Der Alkohol wurde aspiriert und das DNA-Pellet durch Lyophilisation getrocknet. 


\subsubsection{Ligation der EcoR I-Adaptoren}

Die Adaptoren bestehen aus zwei 10- bzw. 14-Basen langen Oligonukleotiden, die komplementär zueinander sind und eine EcoR-I-Schnittstelle beinhalten. Die Adaptoren besitzen folgende Sequenz:

5'-OH-AATTCGGCACGAGG - 3'

3'-GCCGTGCTCCp - 5'

Das 10er-Oligonukleotid ist am 5'Ende phosphoriliert, was eine Ligation des Adaptors an die Enden der cDNA ermöglicht. Das 14er-Oligonukleotid hingegen trägt am 5'Ende keine Phosphorgruppe, um dessen Ligation an andere Fragmente oder eine Ringbildung zu verhindern. Erst wenn die Adaptoren ligiert sind und die Ligase inaktiviert wurde, werden auch diese Enden phosphoriliert (siehe Abschnitt 2.4.2.5), um den Einbau der cDNA in den Vektor zu ermöglichen.

Zur vollständigen Resuspension des cDNA-Pellets wurden $9 \mu 1$ der EcoR-I-Adaptoren hinzugefügt und der Ansatz für 45 min bei $4{ }^{\circ} \mathrm{C}$ inkubiert. Die geschnittene cDNA und die EcoR-IAdaptoren wurden mit $1 \mu 1$ 10x Ligase Puffer, $1 \mu 110$ mM rATP und $1 \mu 1$ T4 DNA-Ligase $(4 \mathrm{U} / \mu \mathrm{l})$ gemischt und bei $4{ }^{\circ} \mathrm{C}$ über Nacht inkubiert. Nach der Inkubation wurde die Ligase durch Erwärmen im Wasserbad auf $70^{\circ} \mathrm{C}$ für 30 min inaktiviert.

\subsubsection{Phosphorylierung der EcoR I-Enden}

Der Reaktionsansatz wurde auf RT abgekühlt, mit folgenden Reagenzien gemischt und bei $37^{\circ} \mathrm{C}$ inkubiert: $1 \mu \mathrm{l}$ 10x Ligase Puffer, $2 \mu 110 \mathrm{mM}$ rATP, $6 \mu 1 \mathrm{H}_{2} \mathrm{O}$ und $6 \mu \mathrm{l} 4$ Polynukleotid-Kinase $(5 \mathrm{U} / \mu \mathrm{l})$. Die Kinase wurde durch $30 \mathrm{~min}$ Erhitzen auf $70^{\circ} \mathrm{C}$ inaktiviert.

\subsubsection{Verdau der cDNA mit Xho I}

Im Bereich des Linker-Primers (siehe Abschnitt 2.4.2.1) wurde die bis hier behandelte cDNA mit einem Restriktionsenzym (XhoI) geschnitten, um den gerichteten Einbau der cDNA in den Vektor zu ermöglichen.

Hierzu wurden der Reaktionsansatz mit $28 \mu 1$ XhoI-Puffer und $3 \mu 1$ Xho I (40 U $\mu 1$ ) für 1,5 Std. bei $37^{\circ} \mathrm{C}$ im Wasserbad inkubiert. Anschließend wurden $5 \mu 110$ x STE-Puffer und 125 $\mu l$ absolutes Ethanol hinzugefügt und der Ansatz über Nacht bei $-20^{\circ} \mathrm{C}$ präzipitiert. Nach der 
Inkubationszeit wurde die cDNA mit $12000 \mathrm{~g}$ für $1 \mathrm{Std}$. bei $4{ }^{\circ} \mathrm{C}$ abzentrifugiert und der Überstand verworfen. Das vollständig getrocknete Pellet wurde in $14 \mu 11$ x STE-Puffer resuspendiert.

\subsubsection{Fraktionierung der cDNA nach Länge}

Vor dem Einbau der cDNA in den Vektor wurde diese der Länge nach fraktioniert, um kurze Fragmente $(<400 \mathrm{bp})$ auszusortieren und deren Einbau in die cDNA-Bibliothek zu vermeiden.

Die cDNA wurde mithilfe von Sepharose CL-2B Gel (Stratagene, La Jolla, CA, USA) nach dem Prinzip der Chromatographie fraktioniert. Als Säule diente eine 1-ml-Pipette, die mithilfe eines PVC-Schlauchs mit einer 10-ml-Spritze verbunden wurde. In die Pipettenspitze wurde ein kleines Stück Watte eingeführt, um diese leicht zu verschließen (siehe Abbildung 2.1). Anschließend wurde die Sepharose CL-2B Gel-Suspension langsam in die Pipette eingefüllt und gewartet, bis das Gel auspolymerisiert war. Im Folgenden wurde die 10-ml-Spritze, die als Reservoir diente, mit insgesamt ca. $12 \mathrm{ml}$ 1x STE-Puffer befüllt, um die Säule zu spülen.

Die cDNA wurde mit 3,5 $\mu$ l Ladefarbstoff gemischt, um die Flüssigkeit besser sichtbar zu machen. Die so vorbereitete Probe wurde kurz vor dem vollständigen Durchlaufen des 1 x STEPuffers (noch ca. $50 \mu$ Restvolumen in der Spritze) vorsichtig direkt auf die Säule aufgetragen. Nachdem sich die Probe auf der Säule abgesetzt hatte, wurden $3 \mathrm{ml} 1$ x STE-Puffer in das Reservoir eingefüllt, möglichst ohne die Probe wieder aufzuwirbeln. Der Durchlauf wurde in ca. $100 \mu$ l-Fraktionen (entspricht etwa drei Tropfen) in je einem Mikroreaktionsgefäß gesammelt. Mit dem Auffangen des Durchlaufs wurde begonnen, wenn der führende Anteil des Farbstoffs die -0,4-ml-Marke der Pipette erreich-

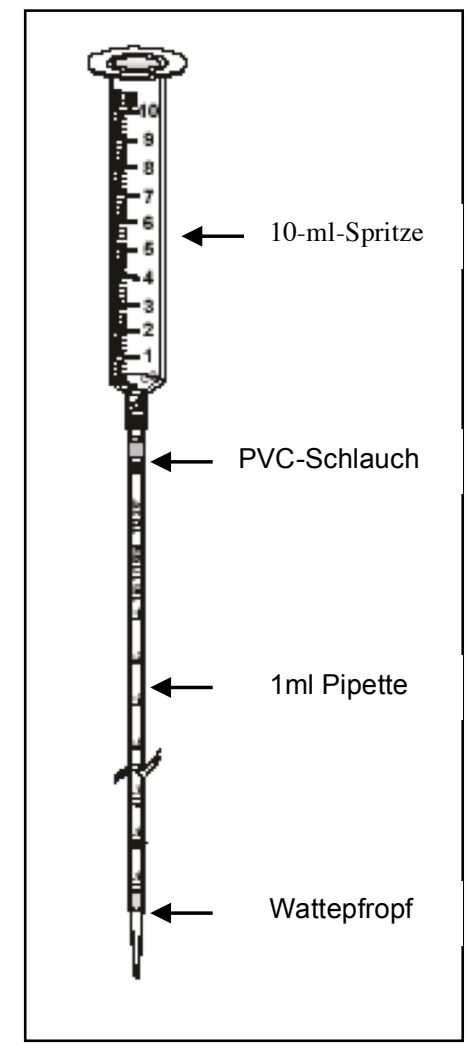

Abb. 2.1: Sepharose Gel Säule te; beendet wurde das Auffangen mit dem Erreichen der 0,3-ml-Marke des hinteren Anteils des Farbstoffs. Jeweils $5 \mu 1$ der einzelnen Fraktionen wurden auf ein 1-\%-Agarosegel aufgetragen und elektrophoretisch aufgetrennt. 
Die positiven Fraktionen wurden mit Fragmenten entsprechender Größe vereinigt. AnschlieBend wurde die cDNA-Konzentration relativ zu einem Heringsperma-DNA-Standard bestimmt. Dazu wurde eine Konzentrationsreihe $(25 \mathrm{ng} / \mu \mathrm{l}, 50 \mathrm{ng} / \mu 1,75 \mathrm{ng} / \mu 1,100 \mathrm{ng} / \mu \mathrm{l}, 200$ $\mathrm{ng} / \mu 1,300 \mathrm{ng} / \mu 1,500 \mathrm{ng} / \mu 1,750 \mathrm{ng} / \mu 1,1000 \mathrm{ng} / \mu \mathrm{l})$ des Standards im Vergleich mit der Probe auf ein 0,8-\%-Agarosegel aufgetragen und unter UV-Licht vergleichend abgelesen.

\subsubsection{Ligation der cDNA in den ZAP-Express-Vektor}

Zur Ligation in den ZAP-Express-Vektor (Stratagene, La Jolla, CA, USA) wurden jeweils ca. 200 ng der ok- bzw. p-cDNA eingesetzt und diese jeweils mit 0,5 $\mu 1$ des 10x-Ligase-Puffers, $0,5 \mu 110 \mathrm{mM}$ rATP, $1 \mu \mathrm{l}$ des ZAP-Express-Vektors $(1 \mu \mathrm{g} / \mu \mathrm{l})$ und 0,5 $\mu 1$ T4 DNA-Ligase

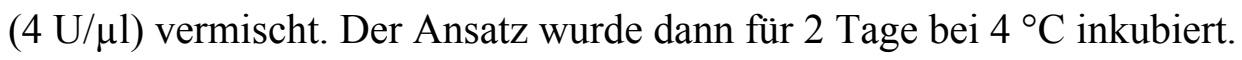

\subsubsection{Verpacken des Vektors zum infektiösen Phagen}

Der ZAP-Express-Vektor mit integrierter cDNA wurde mittels „Gigapack III Gold Packaging Extract“" (Stratagene, La Jolla, CA, USA) zu infektiösen Phagen vervollständigt. Dieser primäre Phagenbestand wird auch als Primärbank bezeichnet. Zum Verpacken des ZAP-ExpressVektors wurden $4 \mu 1$ des Ligationsansatzes verwendet, der mit $25 \mu 1$ des packing extract gut gemischt und für $2 \mathrm{Std}$. bei $22^{\circ} \mathrm{C}$ inkubiert wurde. Nach der Inkubation wurden $500 \mu \mathrm{l}$ SMPuffer und $20 \mu$ l Chloroform hinzugegeben und der Ansatz wurde kurz zentrifugiert. Der Überstand enthält den kompletten infektiösen Phagen und kann bei $4{ }^{\circ} \mathrm{C}$ gelagert werden.

\subsubsection{Amplifizierung der Primärbank}

Um die Anzahl der einzelnen Klone aus der Primärbank zu erhöhen und genügend Ausgangsmaterial für spätere Versuche zu bekommen, wurde die sogenannte Primärbibliothek amplifiziert. Hierfür wurde der E.coli-Stamm XL1-Blue MRF' benutzt, der speziell auf die Erfordernisse des ZAP-Express-Vektors abgestimmt ist. Nach Infektion der Wirtszellen ist es dem Bakteriophagen möglich, sich über einen lytischen Zyklus zu vermehren und damit auch die eingebaute Information zu vervielfachen.

Eine optimale Amplifikation wird u. a. durch ein bestimmtes Ausgangsverhältnis von Phagen

zu Bakterien bestimmt. Laut Herstellerangaben liegt dies bei ca. $5 \times 10^{4}$ Phagen zu 2,4 x $10^{8}$ Bakterien. Während die photometrische Bestimmung der Bakterienzahl relativ einfach mög- 
lich ist (siehe Abschnitt 2.4.5.1), musste die Phagenanzahl in der Primärbibliothek über deren Ausplattierung und eine direkte Auszählung bestimmt werden (siehe Abschnitt 2.4.5.2).

\subsubsection{Vorbereitungen der Wirtszellen}

Zunächst wurden die E.coli ausgehend von einem Glycerolstock auf einer LB-TetracyclinAgarplatte ausgestrichen und über Nacht bei $37^{\circ} \mathrm{C}$ inkubiert. Am nächsten Tag wurde von einer Einzelkolonie eine Schüttelkultur angelegt. Dazu wurden $8 \mathrm{ml}$ LB-Medium, dem zuvor $10 \mathrm{mM} \mathrm{MgSO}_{4}$ und 0,2\% Maltose zugesetzt wurden, mit einer Einzelkolonie von der Agarplatte beimpft und über Nacht bei $30^{\circ} \mathrm{C}$ auf einem Schüttler inkubiert.

Anschließend wurde die Schüttelkultur mit 500 g für 10 min abzentrifugiert und der Über-

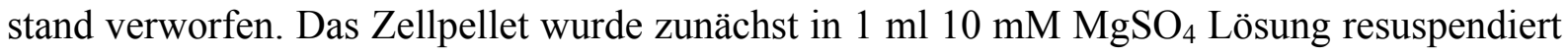
und mithilfe eines Photometers bei $600 \mathrm{~nm}$ auf eine optische Dichte $\left(\mathrm{OD}_{600}\right)$ von 0,5 (entspricht ca. 4 × $10^{8}$ Zellen/ml) mit $10 \mathrm{mM} \mathrm{MgSO}_{4}$ eingestellt.

\subsubsection{Titration der Primärbibliothek}

Zur Titration der Primärbibliothek wurden $1 \mu 1$ der Phagen mit $200 \mu 1$ der vorbereiteten Bakteriensuspension (siehe Abschnitt 2.4.5.1) in einem $15 \mathrm{ml}$ Zentrifugenröhrchen für $15 \mathrm{~min}$ bei $37{ }^{\circ} \mathrm{C}$ inkubiert, was eine Infektion der Bakterien durch die Phagen erlaubt. Im nächsten Schritt wurden ca. $4 \mathrm{ml}$ des zuvor geschmolzenen und auf $48^{\circ} \mathrm{C}$ abgekühlten NZY-Top-Agar hinzugegeben, gemischt und schnell auf eine $150 \mathrm{~mm}$ NZY-Agarplatte gegossen. Durch rasches, vorsichtiges Schwenken der Agarplatte wurde der Top-Agar gleichmäßig verteilt. Dabei ist darauf zu achten, dass der NZY-Top-Agar primär komplett geschmolzen ist, um ein Ausflocken beim Plattieren zu verhindern und eine glatte Oberfläche zu erreichen. Auf der anderen Seite ist darauf zu achten, dass der Agar vor Zugabe der Bakteriensuspension genügend abgekühlt ist, da sonst die Bakterien abgetötet werden können.

Die Platten wurden für einige Minuten bei RT stehen gelassen, bis der NZY-Top-Agar fest war. Die Platten wurden dann mit der Agarseite nach oben bei $37^{\circ} \mathrm{C}$ im Brutschrank inkubiert. Die ersten Plaques wurden nach ca. 6-8 Std. sichtbar. Es war darauf zu achten, dass die Plaques nicht konfluent wachsen und die Platten entsprechend rechtzeitig bei $4{ }^{\circ} \mathrm{C}$ gelagert wurden, um den Wachstumsprozess zu verlangsamen. Dies war nach ca. 10 Std. Inkubations- 
zeit der Fall. Anschließend konnten die einzelnen Plaques ausgezählt und damit die Konzentration der Primärbibliothek bestimmt werden.

\subsubsection{Vermehrung der Primärbibliothek}

Zur Vermehrung der Primärbibliothek wurden zunächst wieder (vgl. Abschnitt 2.4.5.1), Wirtszellen vorbereitet. Die Transfektion und Ausplattierung (vgl. Abschnitt 2.4.5.2), wurden mit veränderten Volumina wiederholt: Es wurden $50 \mu \mathrm{l}$ Phagensuspension (entspricht ca. $5 \times 10^{4} \mathrm{pfu}$ ) mit $600 \mu \mathrm{l}$ Wirtszellen bei einer $\mathrm{OD}_{600}$ von 0,5 vermengt. Insgesamt wurden 20 dieser Ansätze auf je eine 150-mm-NZY-Agarplatte gegeben und für 6-8 Std. bei $37{ }^{\circ} \mathrm{C}$ inkubiert, bis die Plaques eine Größe von 1-2 mm Durchmesser erreicht hatten.

Nach der Inkubationszeit wurden die Platten mit jeweils $8 \mathrm{ml}$ SM-Puffer überschichtet und bei $4{ }^{\circ} \mathrm{C}$ auf einem Schüttler über Nacht inkubiert. Dieser Vorgang erlaubt es den Phagen, sich im SM-Puffer zu lösen, der dann in ein steriles 15-ml-Zentrifugenröhrchen überführt wurde. Die Platten wurden dann nochmals mit $2 \mathrm{ml}$ SM-Puffer gespült, der den entsprechenden Röhrchen zugegeben wurde. Jedem Röhrchen wurde eine entsprechende Menge Chloroform beigegeben, sodass sich eine Endkonzentration von $5 \%(\mathrm{v} / \mathrm{v})$ ergab. Anschließend wurde der Zelldetritus bei $500 \mathrm{~g}$ abzentrifugiert und der Überstand in ein neues 15-mlZentrifugenröhrchen überführt. Jedem Röhrchen wurde wiederum entsprechend Chloroform zugegeben, um eine Endkonzentration von 0,3 \% (v/v) zu erreichen. Die amplifizierte Bibliothek ist so bei $4{ }^{\circ} \mathrm{C}$ über längere Zeit lagerbar.

\subsection{Screening der cDNA-Bibliothek}

\subsubsection{Grundlagen}

Da die Sequenzen der OAT1 über die Spezies hinweg stark konserviert sind, wurde davon ausgegangen, dass die von uns gesuchten Sequenzen des okOAT1 bzw. des pOAT1 ebenfalls in weiten Teilen homolog zu den bereits bekannten Sequenzen sind. Zur Isolierung der Klone aus den $\lambda$ ZAP-cDNA-Phagen-Banken wurde eine radioaktiv markierte DNA-Sonde verwendet, die mithilfe der PCR aus vorliegenden rbOAT1-Plasmiden (Bahn et al. 2002) generiert wurde. Dabei handelte es sich um ein 970 bp langes Fragment einer über die Spezies hinweg hochkonservierten Region. Zum eigentlichen Screening nach Strauss (2001) wurden die amplifizierten cDNA-Bibliotheken ausplattiert. Die Agarplatten wurden anschließend mit 
einem Blatt Nitrozellulose bedeckt und deren Position auf der Platte mit drei Nadeldurchstichen markiert. Hierdurch kommt es zu einer Bindung der Phagen-DNA an die Nitrozellulose und in folgenden Arbeitsschritten konnten durch die Nadelstichmarkierungen die entsprechenden Plaques wieder eindeutig aufgesucht werden. Der Nachweis unserer gesuchten Sequenz wurde durch Hybridizierung des Abdrucks mit der oben beschriebenen und radioaktiv markierten DNA-Sonde durchgeführt. Zur Detektion der markierten Sonde wurden Röntgenfilme verwendet, die auf die Nitrozellulosefolien gelegt wurden. Zur späteren Lokalisierung auf der Agarplatte wurden die Nadelstichmarkierungen auch auf den Röntgenfilm übertragen. Von den Röntgenfilmen ausgehend konnten dann die positiven Klone als Plaques auf den Agarplatten lokalisiert und isoliert werden. Die beschriebenen Arbeitsschritte wurden, ausgehend von den isolierten Einzelklonen, zu deren Amplifikation und Selektion bis zu viermal wiederholt, bevor sie für die Sequenzierung aufbereitet wurden.

\subsubsection{Sondenpräparation}

Als Ausgangsmaterial zur Generierung der DNA-Sonde dienten Plasmide des rbOAT1 (Bahn et al. 2002), aus dem mithilfe der Touch-Down-PCR (siehe Abschnitt 2.8.4.1) ein 970 bp langes Fragment isoliert und amplifiziert wurde (Primer siehe Abschnitt 2.1.8).

Für die weitere Verwendung war es erforderlich, die eigentlichen PCR-Fragmente von Nebenprodukten zu trennen, um eine möglichst hohe Spezifität der Sonde zu erreichen. Dazu wurde das PCR-Produkt auf ein 1-\%-Agarosegel aufgetragen und elektrophoretisch aufgetrennt. Später wurde die Bande entsprechender Länge mit einem Skalpell aus dem Gel herausgeschnitten und die DNA mit dem „NucleoTrap Extraction Kit for Nucleic Acids“ (Machery-Nagel, Düren, Deutschland) nach Herstellerangaben extrahiert.

\subsubsection{Screening}

Von jeder der hochamplifizierten Bibliotheken wurden 10 Agarplatten ausplattiert (vgl. Abschnitt 2.4.5). Dabei wurden pro Platte $2 \mu 1$ Phagenlysat eingesetzt. Es ist insbesondere auf eine ebenmäßige Oberfläche des Agars zu achten, um anschließend die Abdrücke erstellen zu können. Zum Übertragen der Phagen-DNA auf Nitrozellulosefolien (Stratagene, La Jolla, CA, USA) wurden folgende Schritte durchgeführt: 
Die Nitrozellulosefolien wurden mit einem Bleistift beschriftet und mit der beschrifteten Seite nach oben auf die gekühlten Platten gelegt. Dabei ist darauf zu achten, dass die Nitrozellulosefolien glatt und ohne Luftblasen aufgelegt werden. Die Folien wurden für 10 min zur Übertragung der Phagen auf den Platten belassen. Unterdessen wurden die Folien mit einer sterilen Kanüle asymmetrisch an drei Stellen durchstochen, um die Position der Filter auf den Platten zu markieren. Anschließend wurden sie mit einer Pinzette von den Platten entfernt und mit der Phagenseite nach oben für 10 min bei RT getrocknet. Die Agarplatten wurden bei $4{ }^{\circ} \mathrm{C}$ bis zur weiteren Verwendung gelagert.

Nach Übertragung der Phagen-DNA auf die Folien wurde die DNA denaturiert und so für die Hybridization vorbereitet. Dazu wurden die Folien für 5 min mit der Phagenseite nach oben auf Whatman 3 MM Papier (Schleicher \& Schuell, Dassel, Deutschland) gelegt, das zuvor mit einem Denaturierungspuffer getränkt wurde. Das Papier musste so feucht sein, dass die Folien den Puffer aufsaugen konnten, aber nicht vom Puffer überspült wurden (Gefahr der PhagenVermischung). Anschließend wurden die Folien nacheinander auf gleiche Weise je 5 min auf mit Neutralisierungspuffer bzw. mit 2 x SCC Puffer getränktem Whatman 3MM Papier gelegt. Anschließend wurden die Folien bei $42{ }^{\circ} \mathrm{C}$ über Nacht getrocknet.

Vor der eigentlichen Hybridization wurden $25 \mathrm{ng}$ der DNA-Sonde mit ${ }^{32} \mathrm{P}-\mathrm{dCTP}$ radioaktiv markiert. Dies geschah mit dem „,rediprime II labelling system“ (Amersham Pharmacia Biotech Europe, Freiburg, Deutschland) nach Herstellerangaben.

Zur eigentlichen Hybridization wurden 10 Nitrozellulosefolien in einer Schale mit 40ml Hybridisierungslösung II angefeuchtet. Dazu wurden die Folien mit der Phagenseite nach oben der Lösung aufgelegt und gewartet, bis diese mit der Lösung durchtränkt waren. Dabei war zu beachten, dass die Lösung zunächst nur von unten in die Folie eindringt, um Lufteinschlüsse innerhalb der Folie zu vermeiden. Die so angefeuchteten Folien wurden zusammen mit dem Rest der Hybridisierungslösung II in einen Plastikbeutel gegeben. Anschließend wurde die Plastiktüte mit einem haushaltsüblichen Folienschweißgerät mit möglichst wenigen Lufteinschlüssen verschlossen. Insgesamt wurden nicht mehr als 10 Folien in einen Plastikbeutel gegeben.

Die Folien wurden dann bei $65^{\circ} \mathrm{C}$ für eine Stunde im Wasserbad inkubiert. Während dieser Zeit wurden der markierten Sonde $2 \mathrm{mg}$ Heringsperma-DNA zugegeben und alles für $10 \mathrm{~min}$ bei $100{ }^{\circ} \mathrm{C}$ inkubiert und dann sofort auf Eis gestellt, um die DNA-Doppelstränge zu denaturieren. Die Sonde wurde mit $2 \mathrm{ml}$ Hybridisierungslösung II gemischt und mithilfe einer sterilen Spritze und Kanüle in den Plastikbeutel gespritzt und gut vermischt. Danach wurde der 
Beutel wieder verschweißt und über Nacht bei $65^{\circ} \mathrm{C}$ unter leichtem Schütteln im Wasserbad inkubiert. Nach der Inkubationszeit wurden die Folien aus dem Plastikbeutel genommen und zweimal mit low stringency wash buffer II bei RT gewaschen. Dazu wurden die Filter jeweils in eine Schale mit $500 \mathrm{ml}$ Puffer gegeben und für 10 min leicht geschwenkt. Dabei wurden die aneinander haftenden Folien mit einer Pinzette voneinander getrennt.

Abschließend wurden die Folien einmal in $500 \mathrm{ml}$ high stringency wash buffer II bei $65^{\circ} \mathrm{C}$ für 10 min unter leichtem Schwenken gespült. Die auf diese Weise behandelten Folien wurden in einer Filmkassette (Kodak, Rochester, NY, USA) fixiert und zusammen mit einem Röntgenfilm (Bio Max Film, Kodak, Rochester, NY, USA), deren Lage zueinander markiert wurde, bei $-80{ }^{\circ} \mathrm{C}$ für 2 Tage inkubiert. Die Filme wurden in einer Dunkelkammer entwickelt und fixiert (GBX developer and replenisher, GBX fixer and replenisher, Kodak, Rochester, NY, USA).

Ausgehend von den Röntgenfilmen, auf denen sich die vermeintlich positiven Klone der cDNA-Bibliothek als schwarze Punkte abzeichneten, wurden die entsprechenden Plaques auf den Agarplatten lokalisiert. Diese Plaques wurden zusammen mit dem Agar mithilfe der großen Öffnung einer Pipettenspitze ausgestochen und in ein 15-ml-Zentrifugenröhrchen mit 4-ml-SM-Puffer gegeben und bei $4{ }^{\circ} \mathrm{C}$ gelagert.

\subsection{Plasmidaufreinigung und Sequenzierung}

\subsubsection{Single Clone Excision}

Für weitere Arbeitsschritte wurden die Klone im ZAP-Express-Vektor mithilfe einer in vivo-Excision des pBK-CMV-Phagamid in ein Plasmidsystem überführt und aufgereinigt. Dazu wurden der ExAssist Helper Phage (Stratagene, La Jolla, CA, USA) und zu den XL1Blue-MRF'-Bakterien zusätzlich E.coli XLOLR-Wirtszellen verwendet. Durch spezielle Eigenschaften der XLORL-Bakterien und des pBK-CMV-Vektors ist es nur diesen Phagen möglich, die XLORL-Zellen zu infizieren und sich darin zu vermehren. Auf diese Weise werden Verunreinigungen durch Helferphagen und ZAP-Express-Phagen im Plasmidsystem vermieden.

Zunächst wurden die Wirtszellen vorbereitet (Abschnitt 2.4.5.1). Allerdings wurde dem Medium für die XLOLR- Zellen keine Maltose und kein Magnesium zugesetzt. Zum Ausschneiden des Plasmids wurden $200 \mu \mathrm{l}$ XL1-Blue-MRF'(OD ${ }_{600}$ 1,0)-Zellsuspension, $250 \mu 1$ Phagensuspension $\left(>1 \times 10^{5}\right.$ Phagen) und $1 \mu$ ExAssist-Helfer-Phage $\left(>1 \times 10^{6} \mathrm{pfu} / \mu \mathrm{l}\right)$ gemischt 
und bei $37{ }^{\circ} \mathrm{C}$ für 15 min inkubiert. Anschließend wurden $3 \mathrm{ml}$ NZY-Medium hinzugegeben und für weitere $3 \mathrm{Std}$. inkubiert. Nach der Inkubation wurde der Ansatz für 20 min auf $70{ }^{\circ} \mathrm{C}$ erhitzt und für 15 min bei $1000 \mathrm{~g}$ zentrifugiert. Der Überstand, in dem sich die ausgeschnittenen pBK-CMV-Phagamide, Helferphagen und ZAP-Express-Phagen befanden, wurde in ein Zentrifugenröhrchen überführt.

Zur Aufreinigung des pBK-CMV-Phagamids wurden $100 \mu \mathrm{l}$ des Phagenüberstands und 200 $\mu 1$ der XLOLR-Zellsuspension $\left(\mathrm{OD}_{600} 1,0\right)$ bei $37^{\circ} \mathrm{C}$ für 15 min inkubiert und nach Zugabe von $300 \mu \mathrm{l}$ NZY-Medium für weitere 45 min bei $37^{\circ} \mathrm{C}$ belassen. Anschließend wurden $20 \mu 1$ bzw. $200 \mu 1$ des Ansatzes jeweils auf einer LB-Kanamycin-Agarplatte ausgestrichen und bei $37^{\circ} \mathrm{C}$ über Nacht inkubiert.

Am nächsten Tag wurden jeweils $5 \mathrm{ml}$ LB-Kanamycin broth mit einer Einzelkolonie beimpft und eine Schüttelkultur angelegt. Ausgehend von den Schüttelkulturen wurden zum einen die Plasmide isoliert und zum anderen ein Glycerolstock (500 $\mu$ Z Zellsuspension, $500 \mu 1$ LBGlycerol [30\% v/v]) angelegt.

\subsubsection{Plasmidisolation}

Plasmid-DNA wurde mit dem „QIAprep Spin Miniprep Kit“ (Qiagen, Hilden, Deutschland) nach Herstellerangaben isoliert. Ausgangsmaterial dazu waren die Schüttelkulturen aus Abschnitt 2.6.1 oder entsprechende Schüttelkulturen aus den angefertigten Glycerolstöcken. Nach der Isolation der Plasmide wurde deren Konzentration photometrisch bestimmt (siehe Abschnitt 2.8.2).

\subsubsection{Sequenzierung}

Die Sequenzierung (Sanger et al. 1977) von DNA wurde mit einem automatischen Sequenziergerät (ABI 373A, Applied Biosystems Inc., Foster City, CA, USA) durchgeführt. Dabei wird in einer, der PCR analogen Methode, dem cycle sequencing, ein Gegenstrang zu der zu sequenzierenden DNA synthetisiert. Durch den Einbau von Terminatoren, sogenannten DyeTerminatoren, kommt es während der Synthese des Gegenstrangs zu basenspezifischen Einzelstrangabbrüchen, die statistisch bei jeder Fragmentgröße stattfinden. So erhält man Fragmente, die jeweils um ein Basenpaar verlängert sind und in einem Polyacrilamid-Gel aufgetrennt werden können. Durch eine basenspezifische Koppelung der Dye-Terminatoren mit 
unterschiedlichen Fluoreszenzfarbstoffen kann die zu analysierende Sequenz der DNA fluorimetisch am Gel abgelesen werden.

Der Ansatz zum cycle sequencing wurde nach der Vorschrift von Applied Biosystems wie folgt vorbereitet: $5 \mu 1$ Premix, $1 \mu 1$ Primer (10 pmol), ca. 400 ng PCR-Produkt oder Plasmid mit $\mathrm{H}_{2} \mathrm{O}$ auf $20 \mu \mathrm{l}$ aufgefüllt. Im Thermocycler (GeneAmp PCR system 2400 Perkin Elmer, Waltham, MA, USA) wurde dann mit folgendem Programm das cycle sequencing durchgeführt: $\left(96^{\circ} \mathrm{C} 30 \mathrm{sec}, 55-60{ }^{\circ} \mathrm{C} 15 \mathrm{sec}, 68^{\circ} \mathrm{C} 4 \mathrm{~min}\right)$ x 25 Zyklen; $4{ }^{\circ} \mathrm{C} \infty$.

Nach Ablauf der Reaktionen wurden die Proben mithilfe von Isopropanol gefällt. Dazu wurden dem Ansatz $80 \mu \mathrm{H} \mathrm{H}_{2} \mathrm{O}$ zugegeben und dieser in ein neues 1,5-ml-Reaktionsgefäß überführt, wo des Weiteren $10 \mu 13 \mathrm{M}$ Na-Acetat und $250 \mu \mathrm{l}$ Ethanol (absolut) zugegeben wurden. Anschließend wurde der Ansatz bei 14000 U/min bei RT für 5 min zentrifugiert, der Überstand vorsichtig entfernt und das Pellet mit $250 \mathrm{ml}$ Ethanol (70 \%) gewaschen.

Nach erneuter Zentrifugation bei $14000 \mathrm{U} / \mathrm{min}$ für 5 min wurde das Pellet in einer Vakuumzentrifuge (SpeedVac concentrator SVC 100H, Savat, Holbrook, NY, USA) getrocknet und in $3 \mu 1$,Sequence Loading Buffer“ (Formamid, 25 mM EDTA pH 8,0 im Verhältnis 5:1) aufgenommen. $3 \mu 1$ der Sequenzierungsproben wurden auf ein denaturierendes 7-\%-PolyacrylamidGel aufgetragen. Mithilfe der Software „GeneScan 672“ und „SeqEd 675“ (Applied Biosystems Inc., Foster City, CA, USA) lieferte das Sequenzierungsgerät die einzelnen DNASequenzen, die anschließend online (http://www.ncbi.nlm.nih.gov/BLAST/) mit der GenBank-Datenbank (http://www.ncbi.nlm.nih.gov/Genbank/index.htm) verglichen wurden.

\section{7 cRNA-Synthese zur funktionalen Expression}

Zur funktionellen Untersuchug der identifizierten Klone wurde die heterologe Expression der Proteine in Xenopus laevis-Oozyten durchgeführt. Zu diesem Zweck wurde aus den Phagenplasmiden die DNA-Information in cRNA umgeschrieben. Diese Form der RNA ist analog der natürlichen mRNA, wie sie in den meisten eukaryotischen Zellen vorkommt, und wurde zur Mikroinjektion von Oozyten verwendet (siehe Abschnitt 2.9.2).

Die cRNA-Synthese wurde mit dem „T7 mMESSAGE mMACHINE“ Kit (Ambion, Austin, TX, USA) durchgeführt. Dieses Kit ermöglichte die in vitro-Synthese von 5'capped cRNA aus linearer cDNA durch das Anfügen von 7-Methyl-Guanosin-Gruppen am 5'Ende. Die RNA Polymerase des Kits setzt an der T7-Promotorregion des Plasmids an und erzeugt so eine gerichtete cRNA. 


\subsubsection{Linearisierung des Plasmids}

Vor der Transkription eines Plasmids in cRNA musste dieses linearisiert werden. Dazu wurde das Plasmid mit dem Restriktionsenzym NotI (Gibco BRL, Invitrogen, Karlsruhe, Deutschland) geschnitten.

Es wurden $5 \mu \mathrm{g}$ des zu verdauenden Plasmids mit $3 \mu$ React III Puffer (Gibco BRL, Invitrogen, Karlsruhe, Deutschland), $2 \mu$ NotI Enzym (15 U/ $\mu$ l) gemischt und mit hochreinem $\mathrm{H}_{2} \mathrm{O}$ auf $30 \mu \mathrm{l}$ aufgefüllt. Der Ansatz wurde nach kurzer Zentrifugation für $3 \mathrm{Std}$. bei $37^{\circ} \mathrm{C}$ inkubiert.

Anschließend wurde das linearisierte Plasmid bzw. die cDNA mithilfe des „PCR-purification kit" (Qiagen, Hilden, Deutschland) aufgereinigt und in $10 \mu \mathrm{l}$ hochreinem Wasser aufgenommen. Die Konzentration wurde photometrisch bestimmt und zur Größenbestimmung der Fragmente eine Gelelektrophorese durchgeführt.

\subsubsection{Transkription der cDNA}

Zur cRNA-Synthese wurde streng nach Herstellerangaben des „T7 mMESSAGE mMACHINE“ Kit (Ambion, Austin, USA) vorgegangen. Dazu wurden $1 \mu \mathrm{g}$ linearisierte cDNA, $10 \mu 12$ x Ribonukleotid-Mix, $2 \mu 110$ x Reaktionspuffer, $2 \mu 1$ Enzym-Mix gemischt und mit RNase-freiem Wasser auf ein Gesamtvolumen von $20 \mu 1$ gebracht. Nach einer Inkubation von 2 Std. bei $37^{\circ} \mathrm{C}$ wurde die Template-DNA durch Zugabe von $1 \mu 1$ DNase I (2 U/ $\left.\mu 1\right)$ und weiterer Inkubation für 15 min aus dem Ansatz entfernt.

Zum Beenden der Reaktion wurden dem Ansatz $115 \mu$ nukleasefreies Wasser und $15 \mu 1$ Ammoniumacetat-Stopp-Lösung (5 M Ammoniumacetat, 100 mM EDTA) zugegeben.

Die cRNA wurde dann mithilfe einer Phenol-Chloroform-Isoamylalkohol-Extraktion aufgereinigt. Die Probe wurde dazu mit $150 \mu 1$ Phenol-Chloroform-Isoamylalkohol gut vermischt und anschließend für 5 min bei $4{ }^{\circ} \mathrm{C}$ und $10000 \mathrm{~g}$ abzentrifugiert. Dieser Schritt wurde nach Überführen des wässrigen Überstandes in ein neues Mikroreaktionsgefäß wiederholt. Abschließend wurde die cRNA über Nacht durch Zugabe von $150 \mu 1$ Isopropanol bei $-20{ }^{\circ} \mathrm{C}$ gefällt und nach 45 min Zentrifugation $\left(4^{\circ} \mathrm{C}, 10000 \mathrm{~g}\right)$ mit $500 \mu$ l Ethanol (70 \%) gewaschen und erneut für 5 min zentrifugiert. Das getrocknete cRNA-Pellet wurde dann in $10 \mu 1$ nucleasefreiem Wasser resuspendiert und nach einer photometrischen Konzentrationsbestimmung auf eine Endkonzentration von $1 \mu \mathrm{g} / \mu 1$ eingestellt. 


\subsection{Weitere molekularbiologische Methoden}

\subsubsection{Photometrische Konzentrationsbestimmung von Nukleinsäuren}

Die Konzentrationsbestimmungen der Nukleinsäuren (DNA, RNA) erfolgte mit einem Spektralphotometer (GeneQuant II, Novaspec II, Pharmacia, Uppsala, Schweden) bei einer Wellenlänge von $260 \mathrm{~nm}$ bzw. $280 \mathrm{~nm}$. Vor den Messungen wurden die Proben entsprechend verdünnt. Als Berechnungsgrundlage für die Bestimmung der Nukleinsäurekonzentration gilt eine optische Dichte von 1,0. Dies entspricht einer Konzentration von $50 \mu \mathrm{g} / \mathrm{ml}$ für DNA bzw. von $40 \mu \mathrm{g} / \mathrm{ml}$ für RNA. Der Quotient der optischen Dichten bei $260 \mathrm{~nm} \mathrm{zu} 280 \mathrm{~nm}$ ist ein Maß für die Reinheit der Nukleinsäuren und sollte zwischen 1,8 bis 2,0 liegen (Sambrock et al. 1989).

\subsubsection{Photometrische Konzentrationbestimmung von Proteinen}

Die Bestimmung der Proteinkonzentration wurde nach der Methode von Bradford durchgeführt (Bradford 1976). Durch Bindung des Farbstoffes Coomassie-Brilliant-Blau G250 an Proteine verschiebt sich dessen Absorptionsmaximum von $465 \mathrm{~nm}$ auf $595 \mathrm{~nm}$. Da davon ausgegangen werden kann, dass die Proteinzusammensetzung in den für die Versuche eingesetzten Zellen konstant ist, wurde die Proteinkonzentration als Maß für die Zellmenge verwendet.

In einem 1,5-ml-Mikroreaktionsgefäß wurden je $20 \mu 1$ Zellsuspension, $20 \mu 1$ Ameisensäure und $1 \mathrm{ml}$ Coomassie-Blau-Lösung (0,007 \% Coomasie Brilliant Blau G250, 5 \% Ethanol, 8,5 \% Phosphorsäure) gut gemischt und 10 min bei RT inkubiert. Anschließend wurde bei 595nm die Extinktion in einer Doppelbestimmung gemessen. Über eine mit Rinderserumalbumin erstellte Eichkurve wurde dann die Proteinkonzentration berechnet.

\subsubsection{Agarosegelelektrophorese}

Mithilfe der Agarosegelelektrophorese wurden Nukleinsäureproben (DNA, RNA) nach ihrer Fragmentgröße aufgetrennt. Je nach Verwendungszweck wurde die Agarosekonzentration der Gele mit 0,5 x TBE-Puffer auf verschiedene Endkonzentrationen eingestellt: 0,8 \% für präparative Zwecke und $1 \%$ für analytische Zwecke. Vor dem Auftragen der Proben (ca. $5 \mu 1$ ) wurden diese mit $2 \mu 15 x$ Probenpuffer und $2 \mu 1$ Ethidiumbromid $(1 \mathrm{mg} / \mathrm{ml})$ vermischt. Aufge- 
trennt wurden die Proben in 0,5x TBE-Laufpuffer bei 70-100 V bei einer Laufzeit von ca. 45 $\min$.

Als Molekulargewichtsstandard wurde eine 1 kB DNA-Leiter (Gibco BRL, Karlsruhe, Deutschland) mitgeführt. Zur Visualisierung der Nukleinsäuren wurden das Agarosegel auf einen UV-Transilluminator (TM40, UVP Inc., Upland, CA, USA) (254 nm) gelegt. Die Dokumentation fand mit einem Videosystem statt.

\subsubsection{Polymerase-Kettenreaktion (PCR)}

Die Polymerase-Kettenreaktion wurde zur in vitro-Amplifikation spezifischer DNAAbschnitte mithilfe von hybridisierenden Oligonukleotiden (Primern) verwendet (Mullis und Faloona 1987; Saiki et al. 1988). Katalysiert wurde die Reaktion durch eine rekombinante Taq-Polymerase (Powerscrpit, Boehringer, Mannheim Deutschland; Hotstaq, Qiagen, Hilden Deutschland).

Zur Amplifikation wurden in einem Reaktionsansatz von $50 \mu 1$ ca. 10-50 ng DNA entsprechende Primer (je 10-20 pmol/Ansatz), 1,25 mM dNTP und Puffer (10 mM TRIS, pH 8,3; $50 \mathrm{mM} \mathrm{KCl} ; 2 \mathrm{mM} \mathrm{MgCl}_{2}$ ) in einem PCR-Reaktionsgefäß gemischt. Nach Zugabe von 2U-Taq-Polymerase wurde die Reaktion in einem Thermocycler (2400 Perkin Elmer, Norwalk, USA bzw. Robocycler Gradient96, Stratagene, La Jolla, CA, USA) mit unterschiedlichen Temperaturprogrammen durchgeführt.

Folgendes Standardprogramm wurde für die Polymerase-Kettenreaktion verwendet:

$94{ }^{\circ} \mathrm{C}$ für $5 \mathrm{~min}$; $\left(94{ }^{\circ} \mathrm{C}\right.$ für $30 \mathrm{sec}, 60^{\circ} \mathrm{C}$ für $45 \mathrm{sec}, 71^{\circ} \mathrm{C}$ für $\left.60 \mathrm{sec}\right)$ x 15 Zyklen; $\left(94{ }^{\circ} \mathrm{C}\right.$ für $30 \mathrm{sec}, 55{ }^{\circ} \mathrm{C}$ für $45 \mathrm{sec}, 72{ }^{\circ} \mathrm{C}$ für $60 \mathrm{sec}$ ) x 15 Zyklen; $72{ }^{\circ} \mathrm{C}$ für $5 \mathrm{~min} ; 4^{\circ} \mathrm{C}$ für $\infty$.

\subsubsection{Touch-Down-PCR}

Die sogenannte Touch-Down-PCR wurde durchgeführt, um die Spezifität der PCR zu erhöhen. Dazu wurde die Anlagerungstemperatur (annealing-Temperatur, Ta) während der ersten Amplifikationzyklen schrittweise von $61{ }^{\circ} \mathrm{C}$ auf $55^{\circ} \mathrm{C}$ reduziert (Don et al. 1991). Die Veränderung der Schmelztemperatur erfolgte über 15 Zyklen um jeweils 0,3-0,5 ${ }^{\circ} \mathrm{C}$ pro Zyklus. Somit wurde die Anfangsschmelztemperatur (Tm) $3{ }^{\circ} \mathrm{C}$ über den errechneten Tm-Wert gesetzt und schrittweise bis zu $3{ }^{\circ} \mathrm{C}$ unter den Tm-Wert abgesenkt.

Folgendes Standardprogramm wurde für die Touch-Down-PCR verwendet: 
$94{ }^{\circ} \mathrm{C}$ für $5 \mathrm{~min}$; $\left(94^{\circ} \mathrm{C}\right.$ für $30 \mathrm{sec}, 61-55^{\circ} \mathrm{C}$ für $45 \mathrm{sec}, 71^{\circ} \mathrm{C}$ für $\left.60 \mathrm{sec}\right)$ x 15 Zyklen; $\left(94^{\circ} \mathrm{C}\right.$ für $30 \mathrm{sec}, 54{ }^{\circ} \mathrm{C}$ für $45 \mathrm{sec}, 72^{\circ} \mathrm{C}$ für $60 \mathrm{sec}$ ) x 15 Zyklen; $72{ }^{\circ} \mathrm{C}$ für $5 \mathrm{~min} ; 4^{\circ} \mathrm{C}$ für $\infty$.

\subsubsection{RoboCycler-PCR}

Zur Optimierung der PCR wurde die annealing-Temperatur (Ta) bei jedem Ansatz variiert. Dazu wurde mithilfe eines Gradienten-Thermocyclers (RoboCycler Gradient 96, Stratagene, La Jolla, CA, USA) die annealing-Temperatur von $63^{\circ} \mathrm{C}$ bis $52{ }^{\circ} \mathrm{C}$ in $1{ }^{\circ} \mathrm{C}$-Intervallen pro Ansatz reduziert. Außerdem wurde die annealing-Zeit zur Standard-PCR von $45 \mathrm{sec}$ auf 60 sec erhöht.

Folgendes Standardprogramm wurde für die RoboCyler-PCR verwendet: $94{ }^{\circ} \mathrm{C}$ für 5 min; $\left(94{ }^{\circ} \mathrm{C} 30 \mathrm{sec}\right.$, Gradient von $63-52{ }^{\circ} \mathrm{C}$ für $60 \mathrm{sec}, 72{ }^{\circ} \mathrm{C}$ für $60 \mathrm{sec}$ ) x 30 Zyklen; $72{ }^{\circ} \mathrm{C}$ für 60 sec.

\subsubsection{5' RACE}

Mit der Methode des RACE (rapid amplification of $c D N A$ ends) ist es möglich, unvollständige DNA-Fagmente eines Klons, ausgehend von der ursprünglichen RNA bzw. cDNA, an deren 5'und 3'Enden zu ergänzen (Frohman et al. 1988) (siehe Abbildung 2.2). Ausgehend von der klonierten Sequenz wurden Primer entworfen, die in Richtung des fehlenden Endes orientiert waren. 


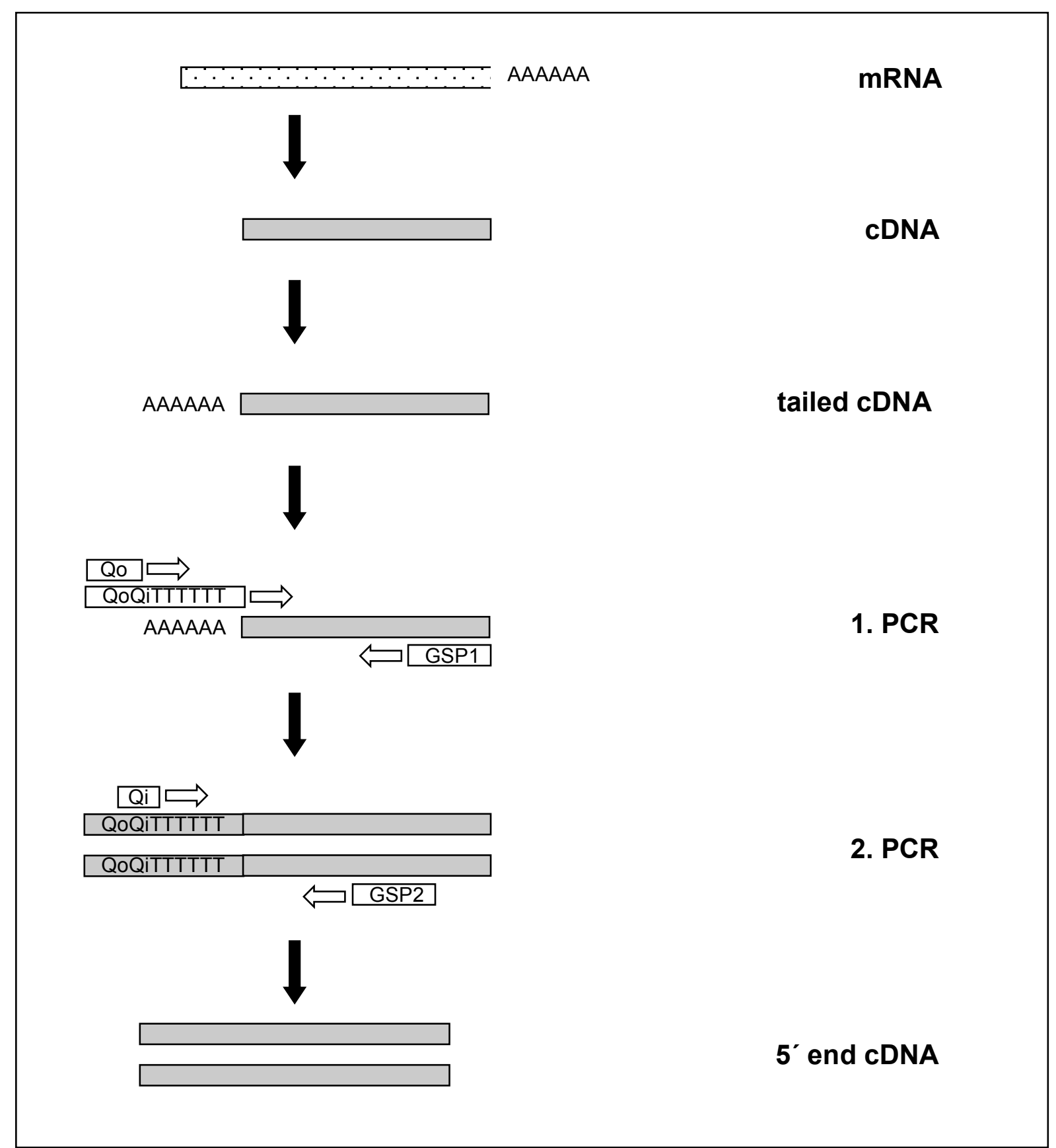

Abbildung 2.2: Syntheseschritte des 5'RACE; Qo, Qi,, QoQiT(17) bezeichnet adapterspezische Primer; GSP1 und GSP2 bezeichnet die genspezifischen Primer 1 und 2

Zunächst wurde der cDNA am 5'Ende ein Oligo(dA) angefügt. Dazu wurden ca. 100 ng cDNA, $25 \mathrm{mM}$ dATP, 30 Units Terminale-Transferase und Reaktionspuffer zu einem Gesamtvolumen von $40 \mu \mathrm{l}$ vermischt. Der Ansatz wurde für $1 \mathrm{Std}$. bei $37^{\circ} \mathrm{C}$ inkubiert. Zum Inaktivieren der Transferase wurde der Ansatz für 15 min auf $65^{\circ} \mathrm{C}$ erhitzt.

Die erste PCR wurde in zwei Ansätzen mit unterschiedlichen spezifischen Primern (okOAT447R22; okOAT1-624R21; siehe Abschnitt 2.9.4.1) durchgeführt. Je Ansatz wurden $4 \mu 1$ der cDNA, 20 pmol QoQiT(17) Primer, 20 pmol Qo Primer, 20 pmol spezifischer Primer, 1,25 
$\mathrm{mM}$ dNTP und Puffer (10 mM TRIS, pH 8,3; $50 \mathrm{mM} \mathrm{KCl;} 2 \mathrm{mM} \mathrm{MgCl}_{2}$ ) in einem PCRReaktionsgefäß gemischt (Gesamtvolumen $50 \mu 1$ ). Nach Zugabe von 2UTaq-Polymerase wurde die Reaktion im Thermocycler mit folgendem Programm gestartet: $94{ }^{\circ} \mathrm{C}$ für $5 \mathrm{~min} ; 30$ Zyklen mit $94^{\circ} \mathrm{C}$ für $30 \mathrm{sec}, 55^{\circ} \mathrm{C}$ für $45 \mathrm{sec}, 72^{\circ} \mathrm{C}$ für $60 \mathrm{sec}$.

Bei der zweiten PCR wurden je $2 \mu 1$ der Initial PCR, 20 pmol Qi Primer und 20 pmol okOAT1-447R22, 1,25 mM dNTP und Puffer (10 mM TRIS, pH 8,3; $50 \mathrm{mM} \mathrm{KCl;} 2 \mathrm{mM} \mathrm{MgCl}$ ) verwendet. Programm : $94{ }^{\circ} \mathrm{C}$ für $5 \mathrm{~min} ; 30$ Zyklen mit $94{ }^{\circ} \mathrm{C}$ für $30 \mathrm{sec}, 55^{\circ} \mathrm{C}$ für $45 \mathrm{sec}$, $72{ }^{\circ} \mathrm{C}$ für $60 \mathrm{sec}$. Anschließend wurden die PCR-Produkte gelelektrophoretisch analysiert.

\subsection{Expression der OAT1 in Xenopus laevis-Oozyten}

Für einen Teil der Transportversuche wurden Xenopus laevis-Oozyten als heterogenes Expressionssystem verwendet (Gurdon et al. 1971). Dazu wurde cRNA in den vegetativen Pol der Oozyten injiziert. Nach der Translation in ein Polypeptid und dessen Einbau in die Oozyten-Membran (Sumikawa et al. 1981) konnten mit radioaktiv-markierten PAH Substrataufnahmeversuche durchgeführt werden.

\subsubsection{Präparation der Oozyten}

Zur Gewinnung der Oozyten wurde weiblichen Krallenfröschen (Xenopus laevis) ein Teil der Ovarien chirurgisch entnommen. Mithilfe von Pinzette und Schere wurde möglichst viel Ovarialgewebe entfernt, ohne die Oozyten dabei zu beschädigen. Anschließend wurden die Oozyten in einer 20 -ml-Barth-Lösung mit $5 \mathrm{mg} / \mathrm{ml}$ Kollagenase über 12 bis 15 Stunden bei $18{ }^{\circ} \mathrm{C}$ inkubiert, um überschüssiges Bindegewebe zu verdauen. Nach der Inkubation wurden die Oozyten mehrmals mit Barth-Lösung gewaschen und für 10 min bei $22{ }^{\circ} \mathrm{C}$ in $\mathrm{Ca}^{2+}$-freiem ORI inkubiert. Danach wurden die Oozyten bis zur Injektion bei $18{ }^{\circ} \mathrm{C}$ in Barth-Lösung gelagert. Für die Injektion wurden unbeschädigte Oozyten der Stadien V und VI nach Dumont 1972 verwendet.

\subsubsection{Injektion von cRNA}

Zur cRNA-Injektion wurden die Oozyten in eine spezielle Injektionskammer überführt. Unter dem Mikroskop wurden je $23 \mathrm{nl}$ cRNA (1 ng/nl) oder Wasser als Kontrolle mithilfe einer Glaskapillare (World Precision Instruments, Sarasota, FL, USA) und eines Nanoliter-Injektors 
(Nanoliter 2000, World Precision Instruments, Sarasota, FL, USA) in den vegetativen Pol der Oozyten injiziert. Je Oozyte wurden $23 \mathrm{nl}$ cRNA (1 ng/nl) oder $23 \mathrm{nl}$ Wasser als Kontrolle in den vegetativen Pol injiziert.

Nach erfolgter Injektion wurden die Oozyten für 2 Tage bei $18{ }^{\circ} \mathrm{C}$ in einer Barth-Lösung in 24-Well-Platten inkubiert. Dazu wurden pro Well 5 Oozyten in $2 \mathrm{ml}$ Barth überführt und täglich das Medium gewechselt.

\subsubsection{OAT1-vermittelte Aufnahme von organischen Anionen in Oozyten}

Vor den Transportversuchen wurden die defekten Oozyten aussortiert und die restlichen in Gruppen von 8 bis 14 Oozyten aufgeteilt. Anschließend wurden die Gruppe jeweils in $2 \mathrm{ml}$ ORI pro Well einer 24-Well-Platte vorinkubiert.

Nach der Inkubation wurden die Oozytengruppen in 10-ml-Mehrzweckgefäße mit Schnappdeckel (Greiner Bio-One, Frickenhausen, Deutschland) gegeben, die je nach Versuchsbedingung ORI, radioaktiv markiertes PAH $\left(\left[{ }^{3} \mathrm{H}\right] \mathrm{PAH}\right)$, unmarkiertes PAH und zu testende Substanzen in unterschiedlichen Mengen und Konzentrationen enthielten. Die StandardInkubationszeit der Uptake-Versuche betrug $30 \mathrm{~min}$ bei RT. Zum Stoppen der PAHAufnahme wurden die Oozyten zweimal mit eiskalten ORI gewaschen und einzeln in Szintillationsröhrchen (Mini Vials, Sarstedt, Sarstedt, Deutschland) überführt. Die Oozyten wurden jeweils mit $100 \mu 11 \mathrm{mM} \mathrm{NaOH}$ lysiert, um die aufgenommene Radioaktivität freizusetzen. Nach kompletter Lysis der Oozyten auf einem Schüttler wurde der Ansatz mit $100 \mu 11 \mathrm{mM}$ $\mathrm{HCl}$ neutralisiert und jeweils 2,5 ml Szintillationslösung (Packard Goldstandard, Packard, Dreieich, Deutschland) (Lumasafe, Lumac LSC, Groningen, Niederlande) hinzugegeben und gut vermischt. Die aufgenommene Radioaktivität wurde mit einem Flüssigkeits-SzintillationsZähler (Liquid Scintillation Analyzer Tri Carb 2100 TR, Packhard, Dreieich, Deutschland) gemessen. Es wurden immer, wenn nicht anders vermerkt, drei voneinander unabhängige Experimente mit Oozyten verschiedener Krallenfrösche durchgeführt.

\subsection{Expression des pOAT1 in Zelllinien}

\subsubsection{Kultivierung der ok-Zellen}

Bei den hier verwendeten ok-Zellen (ATCC No. CRL-1840) handelt es sich um eine Zelllinie aus Opossum-Nieren (Didelphys virginiana) mit epithelartigem Wachstum. Die Kultivierung 
der ok-Zellen erfolgte in einem Gemisch aus 50 \% DMEM-Medium und 50 \% Ham's F12Medium, versetzt mit $100 \mathrm{U} / \mathrm{ml}$ Penicillin und $100 \mu \mathrm{g} / \mathrm{ml}$ Streptomycin bei $37^{\circ} \mathrm{C}$ und einem $\mathrm{CO}_{2}$-Gehalt von $5 \%$. Als Kulturgefäße dienten Petrischalen $(100 \mathrm{~mm})$, in denen $10 \mathrm{ml} \mathrm{Kul-}$ turvolumen eingesetzt wurden. Die als Monolayer wachsenden Zellen erreichten nach 5-6 Tagen eine $90 \%$ ige Konfluenz und wurden subkultiviert oder für die Transfektion (siehe Abschnitt 2.10.6) vorbereitet.

\subsubsection{Kultivierung der CHO-Zellen}

Die CHO-K1-Zelllinie (ATCC No. CCL-61) ist ein prolinabhängiger Subklon der permanenten Ovarialzelllinie vom chinesischen Hamster. Dabei handelt es sich um polymorphepithelartige Zellen mit fibroblastenartiger Form und geringgradiger Synzytienbildung.

Die Kultivierung der Zellen erfolgte in DMEM-Medium unter Zugabe von FKS (10\% [v/v]), Prolin $(150 \mu \mathrm{g} / \mathrm{ml})$ und Gentamycin $(50 \mu \mathrm{g} / \mathrm{ml})$. Die Zellen wurden bei $37^{\circ} \mathrm{C}$, einer Luftfeuchtigkeit von $90 \%$ und einem $\mathrm{CO}_{2}$ Anteil der Luft von $5 \%$ auf Petrischalen in $10 \mathrm{ml} \mathrm{Kul-}$ turvolumen inkubiert, bis sie eine 90 \%ige Konfluenz erreichten. Anschließend wurden die Zellen subkultiviert oder für die Transfektion vorbereitet.

\subsubsection{Bestimmung der Zellzahl}

Die Zellzahl wurde mithilfe einer Neubauer-Zählkammer bestimmt. Hierzu wurde ein angefeuchtetes Deckgläschen mit leichtem Druck auf der Zählkammer fixiert und die zu bestimmende Zellsuspension in einer Verdünnung von 1:10 oder 1:100 in die Kammer pipettiert. Unter dem Lichtmikroskop wurden vier Großquadrate ausgezählt und deren Mittelwert gebildet. Die Zellzahl pro ml berechnete sich dann nach folgender Formel:

Mittelwert x Verdünnungsfaktor x $10^{4}=$ Zellzahl $/ \mathrm{ml}$.

\subsubsection{Aussaat und Ernte der Zellen}

Bei beiden Zelllinien erfolgte alle drei Tage ein Mediumswechsel. Dazu wurde der Überstand mithilfe einer Pasteurpipette abgesaugt und anschließend durch frisches, vorgewärmtes $\left(37^{\circ} \mathrm{C}\right)$ Medium ersetzt. Zur Transfektion und zum Passagieren der Zellen wurden diese nach Erreichen von 90 \%iger Konfluenz durch Trypsinierung geerntet. Dazu wurden zunächst alle benötigten Lösungen auf $37^{\circ} \mathrm{C}$ erwärmt und die Zellen nach Absaugung des Überstandes mit 


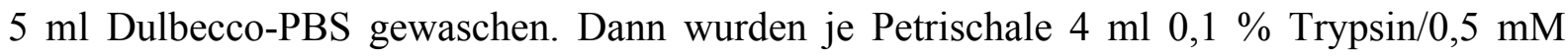
EDTA zugegeben und die Zellen für 2-3 min bei RT inkubiert.

Durch Zugabe von $4 \mathrm{ml}$ Kulturmedium wurde das Trypsin inaktiviert und die abgelöste Zellsuspension in ein Zentrifugenröhrchen überführt. Nach Zentrifugation bei RT mit $150 \mathrm{~g}$ für 5 min wurden das Zellpellet in frischem Kulturmedium resuspendiert und die Zellen je nach weiterer Verwendung und Zelllinie in einer Verdünnung von 1:6 bis 1:20 ausgesät.

\subsubsection{Einfrieren und Auftauen der Zellen}

Zur längeren Lagerung der Zellen wurden diese in flüssigem Stickstoff aufbewahrt. Dazu wurde, wie unter Abschnitt 2.10.4 beschrieben, die Zellen geerntet und das Zellpellet in $4 \mathrm{ml}$ Einfriermedium (Kulturmedium mit 10\% [v/v] DMSO) resuspendiert. Die Zellsuspension (ca. $2 \times 10^{6}$ Zellen/ml) wurde in $1 \mathrm{ml}$-Fraktionen in Kryoröhrchen überführt und langsam herunter gekühlt. Dazu wurden die Röhrchen zunächst für $30 \mathrm{~min}$ in Eiswasser gestellt, anschließend bei $-80{ }^{\circ} \mathrm{C}$ über Nacht eingefroren, um diese schließlich im flüssigen Stickstoff bei $-196{ }^{\circ} \mathrm{C}$ zu lagern.

Zum Auftauen der Zellen wurden die Kryoröhrchen dem flüssigen Stickstoff entnommen und möglichst schnell in ein Wasserbad mit $37^{\circ} \mathrm{C}$ gestellt. Die aufgetauten Zellen wurden in $10 \mathrm{ml}$ frischem Kulturmedium in einer Petrischale $(60 \mathrm{~mm})$ ausgesät und für 4-6 Std. im Brutschrank inkubiert. Anschließend wurden das Medium und nicht angewachsene Zellen abgesaugt und $5 \mathrm{ml}$ frisches Medium hinzugegeben. Bei einer Konfluenz der Zellen von 80-90 \% wurden die Zellen auf 100-mm-Petrischalen umgesetzt.

\subsubsection{Transfektion des pOAT1 in Zelllinien}

Sämtliche Transfektionen dieser Arbeit wurden mit „Lipofectamine“ (Invitrogen, Karlsruhe, Deutschland) durchgeführt. Nach der Ernte und der Auszählung der Zellen wurden diese mit Kulturmedium auf eine Konzentration von 4 x $10^{5}$ Zellen pro ml eingestellt. Die Transfektion sowie die folgenden Transportversuche wurden auf 24-Well-Platten durchgeführt. Dazu wurden zunächst pro Well 0,5 ml Zellsuspension ausgesät und die Zellen bis zum Erreichen einer 90 \%igen Konfluenz über Nacht inkubiert.

Zur eigentlichen Transfektion wurden pro Well $1 \mu \mathrm{g}$ der zu transfizierenden DNA in Form von Plasmiden in $50 \mu 1$ Antibiotika- und FKS-freiem Kulturmedium aufgenommen. Weiter- 
hin wurden pro Well $2 \mu 1$ Lipofectamine mit $50 \mu$ Antibiotika- und FKS-freiem Kulturmedium gemischt und beide Ansätze getrennt für 5 min bei RT inkubiert. Nach dieser Zeit wurden die beiden Ansätze, DNA und Lipofectamine, miteinander vermischt und, um die Bildung von DNA-Lipofectamine-Komplexen zu erlauben, für weitere 20 min bei RT inkubiert.

Unterdessen wurde das Medium der Zellkulturen durch Antibiotika- und FKS-freies Kulturmedium (0,5 ml pro Well) ersetzt. Nach der Inkubationszeit wurden pro Well $100 \mu 1$ des DNA-Lipofectamine-Komplexes zu den Zellen hinzupipettiert und der Ansatz für 4-6 Std. im Brutschrank gelagert. Schließlich wurde das Kulturmedium erneut abgesaugt und durch Medium mit FKS und Antibiotikum (1 ml pro Well) ersetzt. Die Zellen wurden eine weitere Nacht kultiviert und am nächsten Tag für Transportversuche eingesetzt.

\subsection{7 pOAT1-vermittelte Aufnahme von organischen Anionen in Zelllinien}

Die Transportuntersuchungen mithilfe transfizierter Zellkulturen wurden in 24-Well-Platten, in denen auch die Transfektion selbst stattfand, durchgeführt. Pro Versuchsbedingung wurden 3 Well eingesetzt und jeder Versuch mindestens dreimal mit voneinander unabhängigen Transfektionen wiederholt.

Alle Versuche wurden mit einer Standardinkubationszeit von 2 min, wenn nicht anders angegeben, bei RT durchgeführt. Als Transportmedium diente Ringer-Lösung, der je nach Versuchsaufbau verschiedene Substrate für den OAT1 beigesetzt wurden. Für cis-Inhibitionsversuche wurden Stammlösungen jedes potenziellen Inhibitors mit RingerLösung angesetzt. Die Endkonzentration der Inhibitoren in den Transportversuchen wurde dann auf $1 \mathrm{mM}$ eingestellt.

\subsubsection{1 pOAT1-vermittelte PAH-Aufnahme in ok- und CHO-Zellen}

Als eine der Transportsubstanzen für den pOAT1, dessen Aufnahme gemessen wurde, diente radioaktiv markiertes $\mathrm{PAH}$, das dem Transportmedium in einer Endkonzentration von $1 \mu \mathrm{M}$ beigegeben wurde. Im Falle der Km-Wert-Bestimmung wurden das $\left[{ }^{3} \mathrm{H}\right] \mathrm{PAH}(1 \mu \mathrm{M})$ mit unmarkiertem PAH in entsprechenden Konzentrationen zugesetzt und die Messdaten entsprechend umgerechnet.

Vor dem eigentlichen Transport wurde das Kulturmedium abgesaugt und die Zellen dreimal mit Ringer-Lösung (RT) gewaschen. Anschließend wurden je Well $200 \mu 1$ der zu testenden 
Transportlösung auf die Zellen pipettiert und die 24-Well-Platten auf einen Schüttler inkubiert. Durch dreimaliges Waschen der Zellen mit eiskalter Ringer-Lösung wurde der Transport gestoppt und extrazellulär anhaftende Radioaktivität entfernt. Die Zellen wurden durch Zugabe von $500 \mu \mathrm{l} 1 \mathrm{M} \mathrm{NaOH}$ pro Well lysiert und der Ansatz anschließend mit $500 \mu 11 \mathrm{M}$ $\mathrm{HCl}$ neutralisiert. Nach guter Durchmischung der Suspension wurden $900 \mu 1$ mit 2,5 ml Szintillationsflüssigkeit vermischt und die aufgenommene Radioaktivität quantitativ bestimmt; die restlichen $100 \mu \mathrm{l}$ wurden zur Bestimmung der Proteinkonzentration (siehe Abschnitt 2.8.2) verwendet.

\subsubsection{2 pOAT1-vermittelte Fluorescein-Aufnahme in ok- und CHO-Zellen}

Das Vorgehen bei den Transportversuchen in ok- und CHO-Zellen wurde analog zu den Versuchen mit PAH durchgeführt. Im Unterschied zu den oben beschriebenen Versuchen diente Fluorescein als Anion und damit als Substrat für den OAT1.

Für die Transportversuche wurde Fluorescein in einer Endkonzentration von $1 \mu \mathrm{M}$ eingesetzt. Je Well wurden $500 \mu 1$ der zu testenden Transportlösung auf die Zellen pipettiert und diese unter Lichtabschluss inkubiert. Zum Stoppen des Transports wurden die Zellen dreimal mit eiskalter Ringer-Lösung gewaschen und anschließend mit $400 \mu 11 \mathrm{M} \mathrm{NaOH}$ lysiert. Die 400 $\mu 1$ Suspension wurden gut durchmischt und $40 \mu \mathrm{l}$ der Proteinbestimmung zugeführt. Die restlichen $360 \mu 1$ mussten mit Ringer-Lösung auf $1000 \mu$ l ergänzt werden, um ein entsprechendes Volumen zu erreichen, das die Bestimmung der Fluorescenzeinheiten mithilfe eines Spektralfluorimeters (F2000, Hitachi, Tokyo, Japan) bei einer Exzitations-/ Emissionswellenlänge von 492/512 nm erlaubte. 


\section{Ergebnisse}

\subsection{Extraktion und Aufreinigung von mRNA}

Zur Erstellung der ok-cDNA-Bibliothek wurde zunächst aus ok-Zellen die Gesamt-RNA extrahiert (siehe Abschnitt 2.2). Aus ca. 4,3 x $10^{7}$ Zellen konnten 538,3 $\mu$ g Gesamt-RNA gewonnen werden. Des Weiteren wurden aus der Gesamt-RNA mithilfe der Oligo(dT)Chromatographie insgesamt 16,2 $\mu \mathrm{g}$ mRNA isoliert (siehe Abschnitt 2.3). Hiervon wurden nach Präzipitation letztlich 7,17 $\mu \mathrm{g}$ für die Synthese des ersten cDNA-Strangs der Bibliothek eingesetzt.

Analog hierzu konnten zum Aufbau der p-cDNA-Bibliothek aus 8 g Schweinenierenkortex $1989 \mu \mathrm{g}$ Gesamt-RNA gewonnen werden. Hieraus ließen sich 24,8 $\mu \mathrm{g}$ mRNA isolieren von der 7,5 $\mu \mathrm{g}$ eingesetzt wurden, um die p-cDNA zu synthetisieren.

\subsection{Erstellung der ok-Zelle- und Schweineniere-cDNA-Bank}

\subsubsection{Quantifizierung der cDNA}

Nach der Synthese der cDNA wurde diese nach der Länge der Fragmente fraktioniert und gelelektrophoretisch aufgetrennt (siehe Abschnitt 2.4.2.7). Insgesamt wurden 17 Fraktionen gesammelt und getrennt auf ein Agarosegel aufgetragen. Die Abbildung 3.1 A zeigt ein Agarosegel mit Teilen der fraktionierten cDNA aus ok-Zellen. In den Spuren 3, 4 und 5 sind Banden in erwarteter Größe des Klons von $1 \mathrm{~kb}$ bis $4 \mathrm{~kb}$ zu erkennen. In den Spuren 6 und den darauffolgenden sind Banden kleinerer Fragmente zu sehen. Diese waren im Hinblick auf die zu erwartende Größe der gesuchten Transportproteine zu klein, weshalb die entsprechenden Fraktionen keinen Eingang in die cDNA-Bibliothek fanden und verworfen wurden. Es erfolgte die Vereinigung der Fraktionen 3, 4, 5 und sicherheitshalber auch der Fraktion 2, um keinen Verlust an wichtiger cDNA zu erleiden. Die Konzentration der gepoolten cDNA bestimmten wir näherungsweise durch Vergleich mit einer DNA-Konzentrationsreihe eines Heringsperma-Standards (siehe Abbildung 3.1 B). Daraus ergab sich eine Konzentration der okcDNA von ca. $1000 \mathrm{ng} / \mu \mathrm{l}$. 

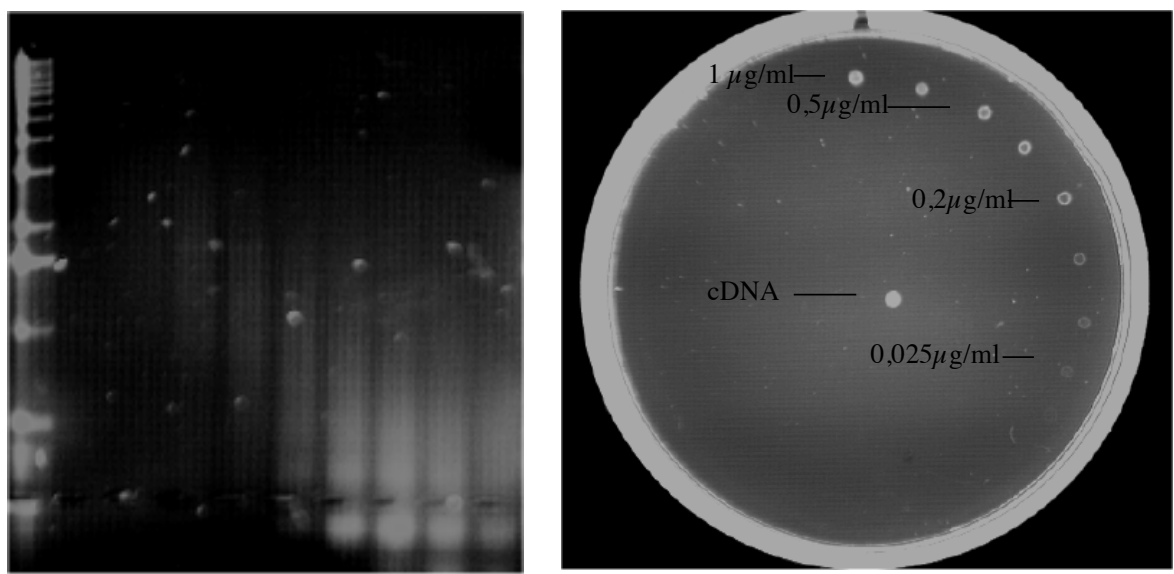

(A) $\quad \begin{array}{lllllllllll}1 & 2 & 3 & 4 & 5 & 6 & 7 & 8 & 9 & \text { (B) }\end{array}$

Abbildung 3.1: Gelelktrophorese der fraktionierten cDNA und vergleichende Konzentrationsbestimmung.

(A) Agarosegel der Fraktionen 1-9 im Vergleich mit einem 1 kb-Standard aufgetragen.

(B) Vergleichende Konzentrationsbestimmung der cDNA. Zentral aufgetragen die vereinigte cDNA; im oberen Quadranten die Konzentrationreihe eines Heringsperma-Standards.

Analog zur ok-cDNA wurde mit der cDNA aus Schweinenierengewebe verfahren. Von den insgesamt 12 gesammelten Fraktionen wurden die Fraktionen 3, 4 und 5 gepoolt und anschließend deren Konzentration bestimmt. Anschließend ergab sich für die p-cDNA eine Konzentration von ca. 400ng/ $\mu 1$. Für den anschließenden Einbau der ok- bzw. der p-cDNA in den Lambda-Phagen-ZAP-Express-Vektor (siehe Abschnitt 2.4.3) wurden jeweils 200 ng cDNA eingesetzt.

\subsubsection{Titration der Primärbibliotheken}

Nach der Integration der cDNA in ZAP-Express-Vektoren wurden diese durch Verpacken mit einem Hüllprotein (siehe Abschnitt 2.3.4) zu infektiösen Lambdaphagen vervollständigt. Damit war die Erstellung der Primärbibliotheken abgeschlossen. Die Phagen sind in der Lage, sich in bestimmten E.coli-Bakterien (XL1-Blue MRF') zu vermehren, wobei die Wirtszellen jeweils von genau einem Phagen infiziert werden. Dabei kommt es zur Amplifikation der eingebauten cDNA. Ausplattiert auf Agar sind die vermehrten Phagen eines Klons nach entsprechender Inkubationszeit makroskopisch als Plaques zu sehen und stellen das Amplifikat dieses Klons dar.

Die Amplifikation der Primärbibliotheken wurde durchgeführt, um die Anzahl der einzelnen Klone aus den Primärbanken zu erhöhen und genug Ausgangsmaterial für weitere Versuche zu gewinnen (siehe Abschnitt 2.4.5). Zur Optimierung der Amplifikation müssen die Phagen und die Wirtszellen nach Herstellerangaben in einem bestimmten Verhältnis zueinander vor- 
liegen, sodass zunächst die Konzentration der Primärbanken bestimmt werden musste. Nach Ausplattierung der Primärbibliotheken in unterschiedlichen Verdünnungen und anschließender Auszählung der Plaques ergab sich eine Konzentration der Primärbibliotheken von 4,57 x $10^{5} \mathrm{pfu} / \mu \mathrm{l}$ für die ok-cDNA-Bank und eine Konzentration von 1,3 x $10^{6} \mathrm{pfu} / \mu 1$ für die p-cDNA-Bank.

\subsection{Klonierung der organischen Anionen-Transporter}

Die OAT wurden nach dem Prinzip der Homologieklonierung aus den entsprechenden cDNABibliotheken isoliert (Abschnitt 2.5). Dazu wurden E.coli-Bakterien (XL1-Blue MRF') mit der $\lambda$ ZAP-cDNA-Phagen-Bank infiziert und auf Agar ausplattiert.

Ein Abklatsch der Phagenplaques auf Nitrozellulosefilter von den Agarplatten ermöglichte das Screening nach dem OAT1 mithilfe der Hybridisierung mit einer spezifischen DNASonde. Als Sonde diente ein 970 bp langes Fragment, das mithilfe von PCR aus dem rbOAT1 generiert wurde. Die entsprechenden Phagen konnten dann auf der Agarplatte aufgesucht, isoliert und über weitere Screening-Runden vermehrt werden.

\subsubsection{Klonierung des okOAT1}

Beim Screening der ok-cDNA-Bank mit der rbOAT1-Sonde konnten nach 3 ScreeningRunden insgesamt 20 Klone isoliert und amplifiziert werden. Nach Excision der integrierten cDNA aus dem Lambda-Phagen-Genom in Form des pBK-CMV-Phagamid mithilfe der Helferphagen fand die Sequenzierung der Plasmide statt. Ein Abgleich der Sequenzdaten erfolgte online (http://www.ncbi.nlm.nih.gov/BLAST/) mit der GenBank-Datenbank (http://www.ncbi.nlm.nih.gov/Genbank/index.htm) und zeigte signifikante Sequenzhomologien mit den OAT anderer Spezies: Mensch (hOAT1-1) 88 \% (Reid et al. 1998), Kanninchen $86 \%$ (Bahn et al. 2002), Ratte 82 \% (Sweet et al. 1997; Sekine et al. 1997), Maus $88 \%$ (Lopez-Nieto et al. 1997). Der Vergleich der Verwandtschaftsgrade erfolgte mithilfe des Programms „CustalW2“ des European Bioinformatics Institue (http://www.ebi.ac.uk/Tools/msa/clustalw/). Ein Vergleich einiger OAT1-Sequenzen und deren Verwandtschaftsgrade (Pylogenetic Tree) der verschiedenen Spezies sind in den Abbildungen 3.5 und 3.6 dargestellt. 
Die DNA-Sequenz des isolierten Klons wurde in der EMBL-Datenbank als okOAT1 unter der Accession Nr. AJ308236 registriert. Bei dem Klon handelt es sich um ein 1680 bp langes DNA-Fragment, das im Vergleich mit den OAT1 anderer Spezies im 5'Bereich eine Deletion aufweist. Diese Deletion zeigte sich bei allen positiven Klonen. Auch ein erneutes Screening der ok-cDNA-Bank, bei dem explizit darauf geachtet wurde, dass nur Klone sequenziert wurden, die unabhängig voneinander die einzelnen Runden durchlaufen hatten, erbrachte erneut den 1680 bp langen, unvollständigen okOAT1 mit der 5'Deletion.

\subsubsection{Vervollständigungsversuche des okOAT1}

Da sich aus der ok-cDNA-Bank kein vollständiger Klon isolieren ließ, wurde zunächst versucht, den okOAT1 mithilfe der PCR im Ausgangsmaterial nachzuweisen. Dazu wurden anhand der vorliegenden Teilsequenz spezifische Primer (okOAT1-267F22, okOAT1-1448R22) generiert. Als Matrize dienten Reste der cDNA, die zum Aufbau der Bank eingesetzt wurden, neu synthetisierte cDNA aus ok-Zellen und Phagensuspension aus der cDNA-Bank. Als Positivkontrolle wurden okOAT1-Plasmide mitgeführt. Es wurde das Standard-PCR-Protokoll verwendet (siehe Abschnitt 2.8.4). Abbildung 3.2 zeigt, dass es abgesehen von der Positivkontrolle nicht möglich war, ein spezifisches Amplifikat nachzuweisen. Auch eine Wiederholung unter Erhöhung des eingesetzten Templates zeigte keinen Erfolg.

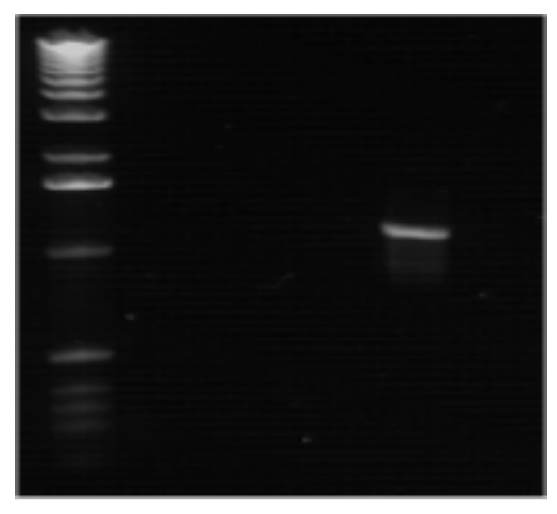

$\begin{array}{lllll}1 \mathrm{~kb} \mathrm{St} & 1 & 2 & 3 & 4\end{array}$

Abbildung 3.2: Gelelektrophorese der PCR-Produkte. Die aus ok-Zellen synthetisierte cDNA diente als Matrize für die PCR mit spezifischen Primern (okOAT1-267F22, okOAT1-1448R22). Spur 1 cDNA-Reste der Bank; Spur 2 neue cDNA; Spur 3 Phagensuspension; Spur 4 Positivkontrolle mit okOAT1-Plasmiden als Matrize.

Die Wiederholung der Standard-PCR mit dem Primerpaar rbOAT1-101F22 und rbOAT11117R24 und möglichen Kombinationen mit den spezifischen Primern (okOAT1-267F22, okOAT1-1448R22) führte ebenfalls zu keinem Amplifikat außer bei der Positivkontrolle. Der Versuch der Amplifikation von neu synthetisierter cRNA als Template mit den spezifischen Primern (okOAT1-267F22, okOAT1-1448R22) blieb ebenfalls erfolglos. 
Es wurden Primer entworfen, die auf konservierten Regionen der 5'UTR des hOAT1 und des mOAT1 basieren (hgOAT1 5UTR-2393F22, hgOAT1 5UTR-2438F22), um das fehlende Stück des 5'Ende des Klons zu generieren. Weiterhin wurden spezifische Reverse-Primer basierend auf der bekannten okOAT1 Sequenz generiert (okOAT1-447R22, okOAT1624R21). Rechnerisch ergab sich für die Primer eine Tm von ca. $59^{\circ} \mathrm{C}$. Die 4 Primer wurden in allen möglichen Kombinationen mit isolierter Gesamt-DNA aus ok-Zellen getestet, ohne dass ein Produkt mithilfe von Standard-PCR oder Touch-Down-PCR (Ta 61 bis $55^{\circ} \mathrm{C}$, siehe Abschnitt 2.8.4.1) amplifiziert werden konnte.

Ein weiterer Versuch zur Optimierung der PCR wurde durch die konstante Variation der annealing-Temperatur (Ta) pro Ansatz durchgeführt. Dazu wurde mithilfe eines GradientenThermocyclers (RoboCycler Gradient 96, Stratagene, La Jolla, CA, USA) die annealingTemperatur von 63 bis $52{ }^{\circ} \mathrm{C}$ in $1{ }^{\circ} \mathrm{C}$-Intervallen pro Ansatz reduziert. Außerdem wurde die annealing-Zeit zur Standard-PCR von $45 \mathrm{sec}$ auf $60 \mathrm{sec}$ erhöht. Lediglich für das Primerpaar hgOAT1 5UTR-2393F22, okOAT1-447R22 zeigte sich ein Amplifikat bei einer Ta von $55^{\circ} \mathrm{C}, 54{ }^{\circ} \mathrm{C} 53{ }^{\circ} \mathrm{C}$ und $52^{\circ} \mathrm{C}$, wobei die Bande bei $53{ }^{\circ} \mathrm{C}$ am stärksten zu erkennen war (siehe Abbildung 3.3).

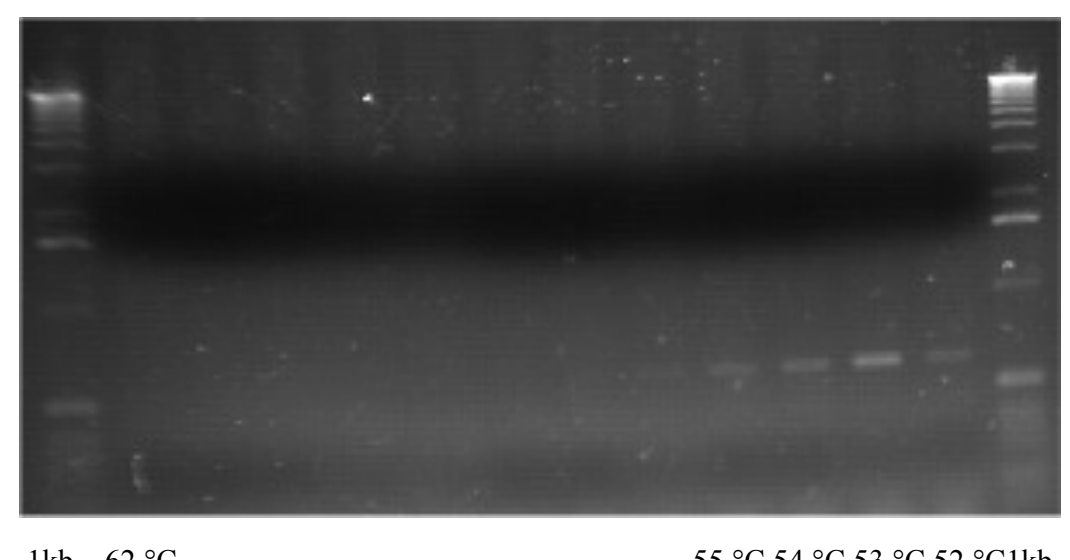

Abbildung 3.3: Optimierung der Anlagerungstemperatur der PCR. Dargestellt ist die gelelektrophoretische Auftrennung von PCR-Produkten aus ok-Zellen, Gesamt-DNA und dem Primerpaar hgOAT1 5UTR-2393F22, okOAT1-447R22. Die einzelnen Spuren entsprechen den unterschiedlichen annealing-Temperaturen von 63 bis $52{ }^{\circ} \mathrm{C}$ der Gradienten-PCR. Zum Vergleich $1 \mathrm{~kb}$ Standard.

Von den positiven PCR-Produkten wurde ein präparatives Gel angefertigt. Die Produkte wurden ausgeschnitten und extrahiert. Anschließend folgten die Sequenzierung der Produkte sowie der Sequenzvergleich mit bekannten OAT1 aus der GenBank (http://www.ncbi.nlm.nih.gov/Genbank/index.htm). Es fand sich jedoch keine Übereinstimmung zum OAT1 und somit handelte es sich bei den Amplifikaten weiterhin nicht um das gesuchte 5'Fragment des okOAT1. Da es bis zu diesem Zeitpunkt noch nicht gelungen war, 
den okOAT1 im Ausgangsmaterial nachzuweisen, sollte durch Zusätze im Kulturmedium die mRNA-Expression in den ok-Zellen gesteigert werden.

Dies geschah zum einen durch Substratinduktion mit PAH, zum anderen durch Stimulation der Adenylatcylase mithilfe von Dexamethason (Bahn et al. 2003) und Forskolin (Asif et al. 2006). Je $100 \mathrm{~mm}$ Kulturplatte wurden entweder PAH (1 mM Endkonzentration), Forskolin (20 mM Endkonzentration) oder Dexamethason (1 mM Endkonzentration) dem Kulturmedium beigegeben und die Zellen bis zur 90-\%-Konfluenz kultiviert. Eine Kulturplatte ohne Zusätze zum Kulturmedium diente als Kontrolle. Nach Isolierung der Gesamt-RNA und Umschreibung in cDNA erfolgte die erneute Touch-Down-PCR mit einer Variation der annealing-Temperatur von 55 bis $52{ }^{\circ} \mathrm{C}$. Hierzu wurden die spezifischen Primer okOAT1-267F22 und okOAT1-1448R22 benutzt.

Abbildung 3.4 zeigt ein Agarosegel mit den Amplifikaten aus den stimulierten Zellkulturen. In allen Spuren ist ein Produkt in der erwarteten Länge von ca. 1,2 kb zu sehen. Daraus ließ sich folgern, dass in der neu synthetisierten cDNA der okOAT1 vorlag und dieser für weitere Versuche geeignet war.

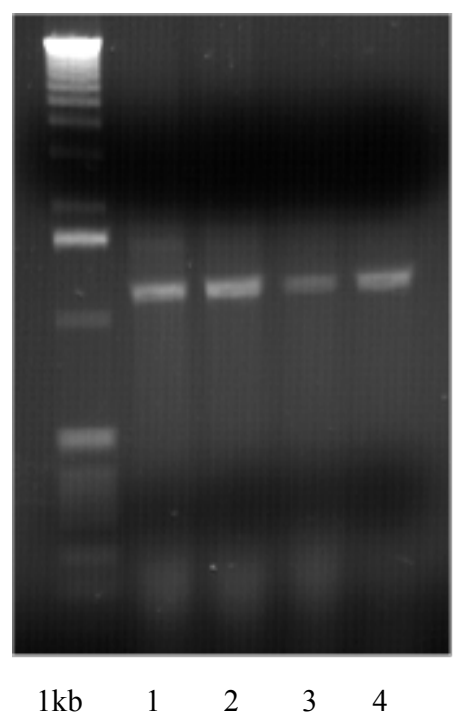

Abbildung 3.4: Nachweis des pOAT1 aus Forskolin-, Dexamethason- und PAH-stimmulierten ok-Zellen. Die cDNA aus stimulierten ok-Zellen wurde zusammen mit dem Primerpaar okOAT1-267F22; okOAT1-1448R22 für die PCR eingesetzt. Dargestellt ist die gelelektrophoretische Auftrennung der PCR-Produkte. 1 mit Forskolin; 2 mit Dexamethason; 3 mit PAH; 4 ohne Zusätze, zum Vergleich ein 1 kb Standard.

Die somit positiv auf OAT1 getestete cDNA diente dann erneut als Ausgangsmaterial für eine Standard- und Touch-Down-PCR mit den 5'UTR-Primern und den spezifischen Reverse Primern, wie oben beschrieben. Trotz mehrerer PCR-Ansätze konnte wiederum kein Produkt nachgewiesen werden. Ein weiterer Versuch zur Vervollständigung des Klons wurde mit dem 5'RACE (siehe Abschnitt 2.8.4.3) unternommen. Dies geschah unter Verwendung der cDNA 
aus den stimulierten Zellkulturen. Trotz mehrfacher Versuchsansätze gelang es nicht, das fehlende Produkt nachzuweisen und somit auch nicht, das fehlende 5'Fragment des okOAT1 zu generieren. Letztlich konnte der partiell vorliegende okOAT1 Klon nicht vervollständigt werden.

\subsubsection{Klonierung des pOAT1 und pOAT1A}

Beim Screening der p-cDNA-Bank gelang es, zwei verschiedene Klone des OAT1 zu isolieren, die als pOAT1 (Accession-Nr. AJ308234) und pOAT1A (Accession-Nr. AJ308235) bezeichnet und in der EMBL-Datenbank gespeichert wurden.

Beim pOAT1 handelt es sich um einen 2126 bp langen Klon, während der pOAT1A nur 1895bp umfasst. Dabei kommt es nicht zur Verschiebung des Leserahmens. Die beiden Klone sind als Splice-Variante anzusehen. Der pOAT1 kodiert ein 547 Aminosäuren umfassendes Protein. Das Protein des pOAT1A ist nur 533 Aminosäuren lang und zeigt im Vergleich zum pOAT1 eine Deletion von 42 bp bzw. 14 Aminosäuren im Bereich der vierten Transmembrandomäne.

Ähnlich wie der okOAT1 besitzt auch der pOAT1 eine hohe Homologie zu den Klonen der bekannten Spezies: Mensch (89\%) (Reid et al. 1998), Kanninchen (87 \%) (Bahn et al. 2002), Ratte (83 \%) (Sweet et al. 1997; Sekine et al. 1997) und Maus (81 \%) (Lopez-Nieto et al. 1997). Die Homologie zu dem von uns klonierten, unvollständigen okOAT1 liegt bei $99 \%$.

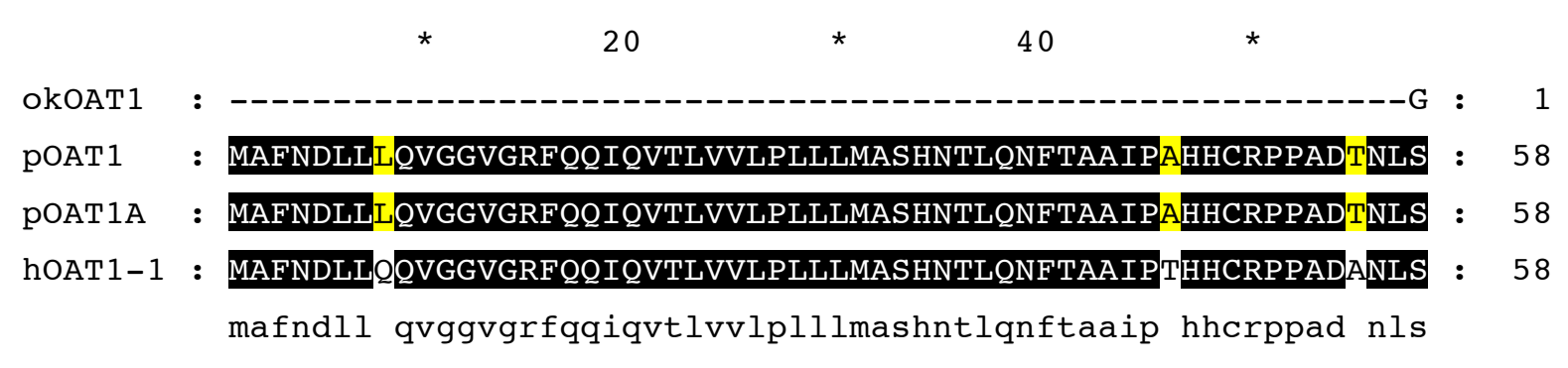

$60 \quad$ * 80 * 100 *

\footnotetext{
OKOAT1 : RDTELEAWLPRDGQGRPASCLRFTSPQRGPPFPNGTGTNGTGTTEPCTNGWIYDPGTF : 59

POAT1 : RDTELEAWLPRDGQGRPASCLRFTSPQRGPPFPNGTGTNGTGTTEPCTNGWIYDPGTF : 116

POAT1A : RDTELEAWLPRDGQGRPASCLRFTSPQRGPPFPNGTGTNGTGTTEPCTNGWIYDPGTF : 116

hOAT1-1 : KNGGLEVWLPRDRQGQPESCLRFTSPQWGLPFLNGTEANGTGATEPCTDGWIYDNSTF : 116 rdteLEaWLPRDgQGrPaSCLRFTSPQrGPPFPNGTgtNGTGtTEPCTnGWIYDpgTF
} 
$120 \quad$ * 140 * 160 *

OKOAT1 : PSTIVTEWDLVCSRRALRQLAQSLYMVGVLLGAMIFGYLADRLGRRKVLILNYLQTAV : 117

POAT1 : PSTIVTEWDLVCSRRALRQLAQSLYMVGVLLGAMIFGYLANRLGRRKVLILNYLQTAV : 174

POAT1A : PSTIVTEWDLVCSRRALRQLAQSLYMVGVLLGAMIFGYLADRLGRRKVLILNYLQTAV : 174

hOAT1-1 : PSTIVTEWDLVCSHRALRQLAQSLYMVGVLLGAMVFGYLADRLGRRKVLILNYLQTAV : 174

PSTIVTEWDLVCSTRALRQLAQSLYMVGVLLGAMIFGYLAdRLGRRKVLILNYLQTAV

$180 \quad * \quad 200 \quad * \quad 220$

OkOAT1 : SGTCAAFAPNFPVYCAFRLLSGMSLAGISLSCMTLNVEWMPIHTRACVGTLIGYVYSL : 175

POAT1 : SGTCAAFAPNFPVYCAFRLLSGMSLAGISLSCMTLNVEWMPIHTRACVGTLIGYVYSL : 232

pOAT1A : SGTCAAFAPNFPVYCAFRLLS-----------DVEWMPIHTRACVGTLIGYVYSL : 218

hOAT1-1 : SGTCAAFAPNFPIYCAFRLLSGMALAGISLNCMTLNVEWMPIHTRACVGTLIGYVYSL : 232

SGTCAAFAPNFPVYCAFRLLSgm lagisl cmtlnVEWMPIHTRACVGTLIGYVYSL

$240 \quad * \quad 260 \quad$ * $\quad 280$ *

OKOAT1 : GQFLLAGVAYAVPRWRHLQMLVSVPFFAFFIYSWFFIESARWYSSSGRLDLTLKALQR : 233

POAT1 : GQFLLAGVAYAVPRWRHLQMLVSVPFFAFFIYSWFFIESARWYSSSGRLDLTLKALQR : 290

POAT1A : GQFLLAGVAYAVPRWRHLQMLVSVPFFAFFIYSWFFIESARWYSSSGRLDLTLKALQR : 276

hOAT1-1 : GQFLLAGVAYAVPHWRHLQLLVSAPFFAFFIYSWFFIESARWHSSSGRLDLTLRALQR : 290

GQFLLAGVAYAVPrWRHLQmLVSVPFFAFF IYSWFF IESARWYSSSGRLDLTLkALQR

300

320

340

okOAT1 : VAWINGKREEGASLSMEVLRASLNKELTMDKGQASAMELLRCPVLRRLFLCLSLLWFA : 291

POAT 1 : VAWINGKREEGASLSMEVLRASLNKELTMDKGQASAMELLRCPVLRRLFLCLSLLWXA : 348

pOAT1A : VAWINGKREEGASLSMEVLRASLNKELTMDKGQASAMELLRCPVLRRLFLCLSLLWFA : 334

hOAT1-1 : VARINGKREEGAKLSMEVLRASLQKELTMGKGQASAMELLRCPTLRHLFLCLSMLWFA : 348

VAWINGKREEGASLSMEVLRASLnKELTMdKGQASAMELLRCPVLRILFLCLSILWfA

* $360 \quad$ * $380 \quad 380 \quad * \quad 400$

OkOAT1 : TSFAYYGLVMDLQGFGVSIYLIQVIFGAVDLPAKLVGFLVINTMGRRPAQMASLLLAG : 349

POAT1 : TSFAYYGLVMDLQGFGVSIYLIQVIFGAVDLPAKLVGFLVINTMGRRPAQMASLLLAG : 406

POAT1A : TSFAYYGLVMDLQGFGVSIYLIQVIFGAVDLPAKLVGFLVINTMGRRPAQMASLLVAG : 392

hOAT1-1 : TSFAYYGLVMDLQGFGVSIYLIQVIFGAVDLPAKLVGFLVINSLGRRPAQMAALLLAG : 406

TSFAYYGLVMDLQGFGVSIYLIQVIFGAVDLPAKLVGFLVINtmGRRPAQMASLLIAG

* $420 \quad$ * $440 \quad 4 \quad 460$

OKOAT1 : ICILINGVVPQDQSVVRTALAVLGKGCLAASFNCIFLYTGELYPTMIRQTGLGMGSTL : 407

POAT1 : ICILINGVVPQDQSIVRTALAVLGKGCLAASFNCIFLYTGELYPTMIRQTGLGMGSTL : 464

POAT1A : ICILINGVVPQDQSVVRTALVVVGKGCLAASFNCIFLYTGELYPTMIRQTGLGMGSTL : 450

hOAT1-1 : ICILLNGVIPQDQSIVRTSLAVLGKGCLAASFNCIFLYTGELYPTMIRQTGMGMGSTM : 464

ICILINGVVPQDQS VRTALAVIGKGCLAASFNCIFLYTGELYPTMIRQTGIGMGSTI 


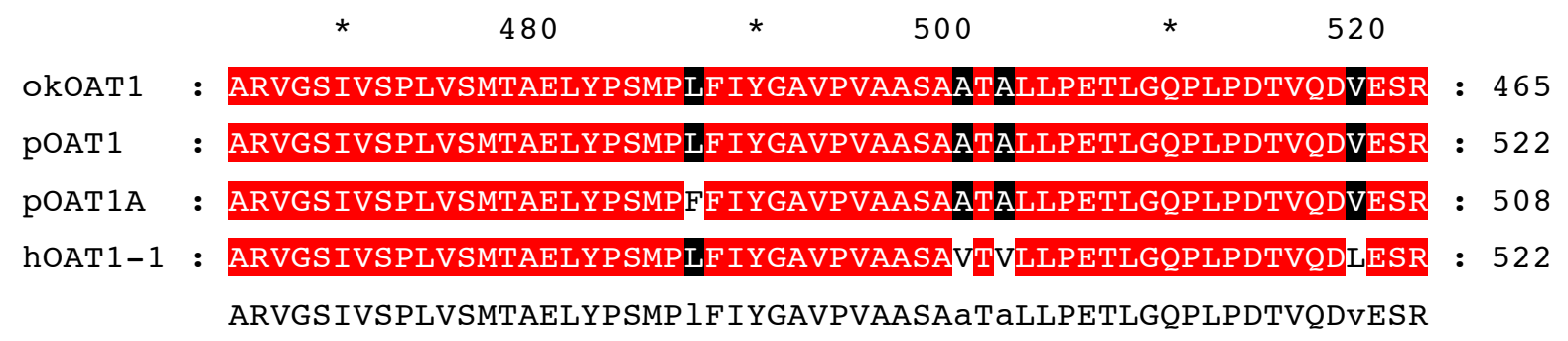

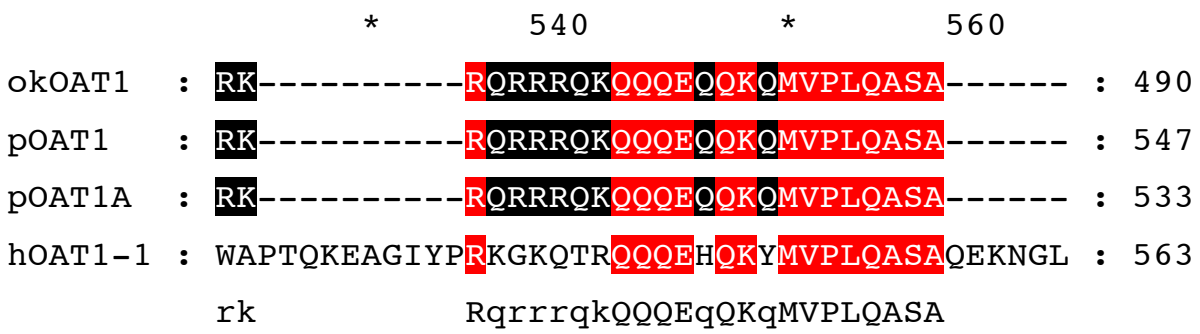

Abbildung 3.5: Alignment der neu klonierten OAT1 und des humanen OAT1-1 (hOAT1-1) (Reid et al. 1998). Rot markierte Aminosäuren sind über alle Klone identisch und somit konservierte Regionen. Schwarz markierte Aminosäuren sind über drei Klone identisch. Gelb markierte Aminosäuren sind noch über zwei Klone identisch. Durchgeführt mit http://www.ncbi.nlm.nih.gov/BLAST/.

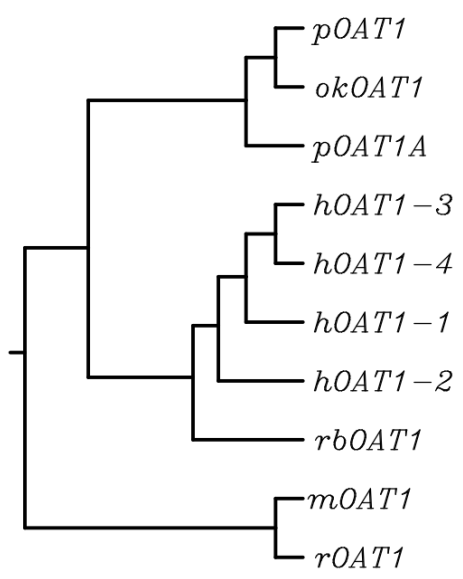

Abbildung 3.6: Phylogenetic Tree. Darstellung der Verwandschaftsgrade der bekannten OAT1. Durchgeführt mit „ClustalW“, (http://www.ebi.ac.uk/Tools/msa/clustalw2/). Die Länge der Arme ist relativ zum Verwandtschaftsgrad.

\subsection{Funktionelle Charakterisierung des okOAT1, pOAT1 und pOAT1A}

\subsubsection{Expression der OAT1 in Xenopus laevis-Oozyten}

Die neu klonierten pOAT1 und pOAT1A sowie auch der unvollständige okOAT1 sollten auf ihre Funktion als Transportprotein getestet werden. Als etabliertes Transfektions- und Transportsystem diente die heterologe Expression der OAT in Xenopus laevis-Oozyten. Es erfolgte die Injektion von zuvor synthetisierter cRNA der entsprechenden Klone in Oozyten (siehe 
Abschnitt 2.9). 2 Tage nach der Injektion wurden die Oozyten für 30 min in $10 \mu \mathrm{M}$ radioaktiv markiertem PAH $\left(\left[{ }^{3} \mathrm{H}\right] \mathrm{PAH}\right)$ enthaltende ORI-Lösung inkubiert und anschließend die $\left[{ }^{3} \mathrm{H}\right] \mathrm{PAH}-\mathrm{Aufnahme}$ gemessen. Als Kontrollgruppe dienten mit Wasser injizierte Oozyten.

In drei voneinander unabhängigen Versuchsreihen war keine signifikante $\left[{ }^{3} \mathrm{H}\right] \mathrm{PAH}$ Aufnahme durch die mit dem pOAT1A oder okOAT1 injizierten Oozyten gegenüber den Kontrolloozyten nachzuweisen. In der vorliegenden Form sind die beiden Transporter nicht funktionstüchtig, weshalb keine weitere funktionelle Charakterisierung mit den beiden Klonen stattfand.

Hingegen fand sich bei den pOAT1-injizierten Oozyten gegenüber der Kontrolle eine im Mittelwert 11,6-fach erhöhte Aufnahme von $\left[{ }^{3} \mathrm{H}\right] \mathrm{PAH}$ (Kontrolle $100 \pm 8,6 \%$ versus $1163,7 \pm 165,3 \%)$. In einem darauffolgenden Versuch konnte die komplette Hemmbarkeit $\operatorname{der}\left[{ }^{3} \mathrm{H}\right] \mathrm{PAH}-A u f n a h m e$ durch $1 \mathrm{mM}$ Probenecid und 0,5 mM Glutarat gezeigt werden (Kontrolle $100 \pm 8,6 \%$ versus Probenecid 99,3 $\pm 12,4 \%$, Glutarat 97,0 $\pm 22 \%$ ) (siehe Abbildung 3.7).

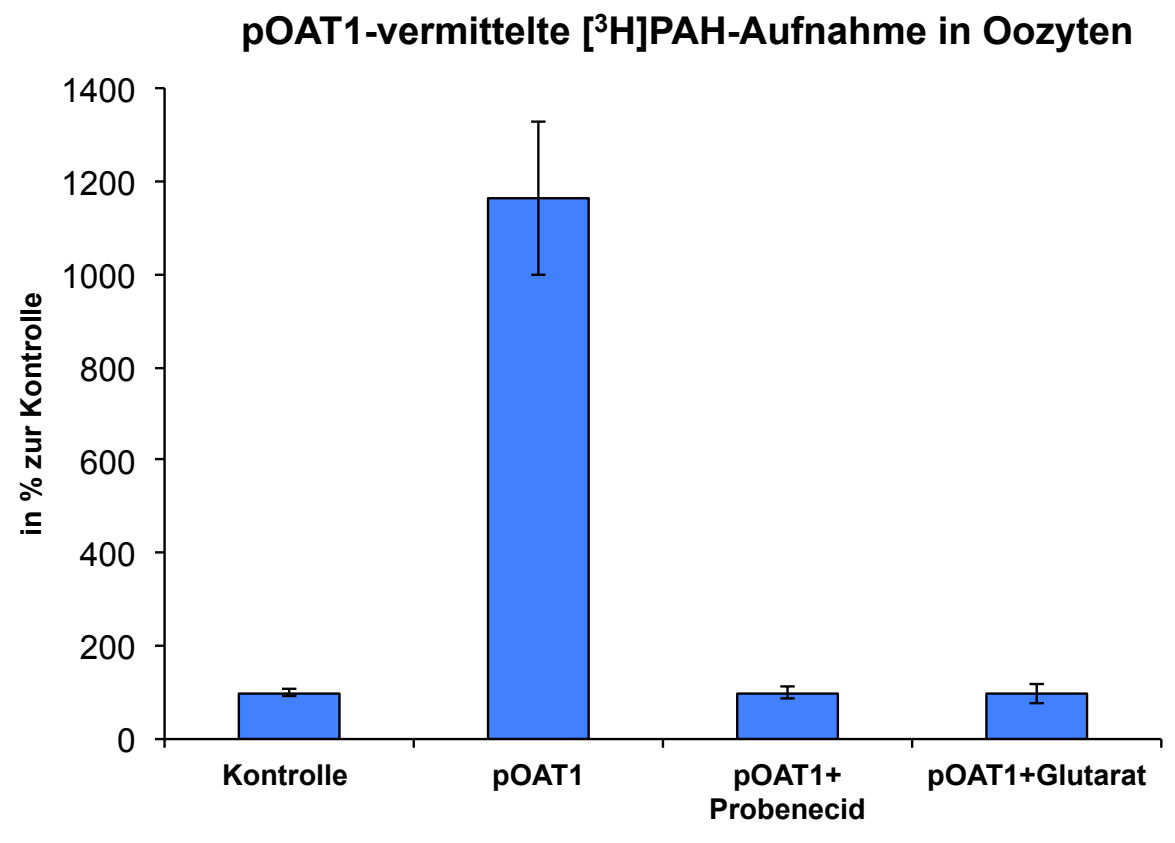

Abbildung 3.7: pOAT1-vermittelte $\left[{ }^{3} \mathrm{H}\right] \mathrm{PAH}-A u f n a h m e$ in Oozyten und dessen Hemmung durch Probenecid und Glutarat. Oozyten wurden für 30 min mit $\left.1 \mu \mathrm{M} \mathrm{[}{ }^{3} \mathrm{H}\right] \mathrm{PAH}$ in ORI inkubiert. Zusätzlich wurde durch Zugabe von $1 \mathrm{mM}$ Probenecid und 0,5 mM Glutarat die Hemmung untersucht. Als Kontrolle dienten nicht transfizierte Oozyten. Dargestellt sind die Mittelwerte \pm SEM aus 3 voneinander unabhängigen Versuchen mit je 7-10 Oozyten in Prozent zur Kontrolle (100\%). 


\subsubsection{Bestimmung des Km-Wertes für PAH in Oozyten}

Zur Bestimmung der Affinität des Transporters für PAH wurde die pOAT1-vermittelte Aufnahme von $\left[{ }^{3} \mathrm{H}\right] \mathrm{PAH}$ durch steigende Konzentrationen von unmarkierten PAH gehemmt. Der apparente Km-Wert wurde nach der modifizierten Michaelis-Menten-Gleichung (Malo und Berteloot 1991) mit SigmaPlot 2001 (SPSS Science, Chicago, IL, USA) errechnet und betrug 3,75 $\pm 1,6 \mu \mathrm{M}$ (siehe Abbildung 3.8).

\section{pOAT1-vermittelte [ $\left.{ }^{3} \mathrm{H}\right] \mathrm{PAH}-A u f n a h m e$ in Oozyten}

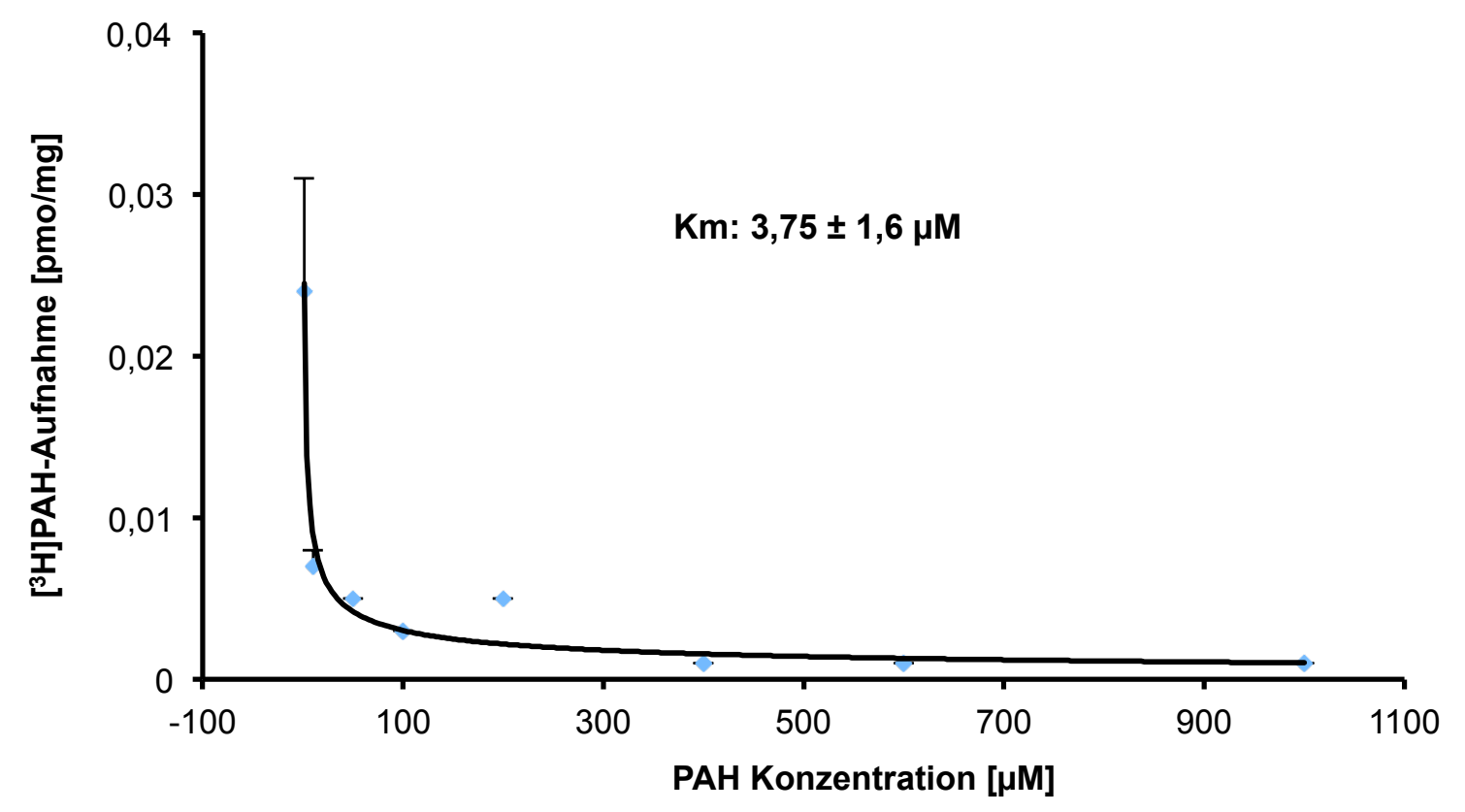

Abbildung 3.8: pOAT1-vermittelte ${ }^{3}$ H]PAH-Aufnahme in Oozyten und Hemmung durch unmarkiertes PAH. Die Oozyten wurden für 30 min mit $1 \mu \mathrm{M}\left[{ }^{3} \mathrm{H}\right] \mathrm{PAH}$ enthaltender ORI-Lösung inkubiert. Zusätzlich erfolgte die Zugabe von unmarkiertem PAH in steigender Konzentration. Dargestellt sind die Mittelwerte \pm SEM aus 3 voneinander unabhängigen Versuchen mit je 7-10 Oozyten in pmol pro mg Protein. Der apparente Km-Wert wurde nach der modifizierten MichaelisMenten-Gleichung mit SigmaPlot 2001 berechnet.

\subsubsection{Testung verschiedener Expressionssysteme und Substrate für den pOAT1}

Vor der eigentlichen Grundcharaktersierung des pOAT1 in ok-Zellen sollte dieses Expressionssystem zunächst mit anderen Zellkulturen verglichen werden, um die Effektivität zu überprüfen. Als Vergleich wurde mit den CHO-Zellen eine ebenfalls einschichtig epithelial wachsende Zelllinie ausgewählt. Außerdem wurde als alternatives Substrat zu $\left[{ }^{3} \mathrm{H}\right] \mathrm{PAH}$ Fluorescein getestet.

In Abbildung 3.9 ist die $\left[{ }^{3} \mathrm{H}\right] \mathrm{PAH}-A$ ufnahme $(1 \mu \mathrm{M})$ durch pOAT1-transfizierte ok- und CHO-Zellen sowie deren Hemmung durch unmarkiertes PAH (1 mM) in Prozent zu nicht transfizierten Zellen dargestellt. In den transfizierten ok-Zellen lag die Aufnahme im Mittel- 
wert um den Faktor 16,1 höher als in den Kontrollzellen (Kontrolle $100 \pm 6,2 \%$ versus $1609,8 \pm 266,9 \%)$.

Bei sonst äquivalenten Bedingungen wurde in den transfizierten CHO-Zellen lediglich eine

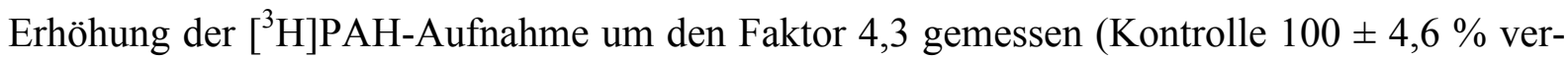
sus 431,4 $\pm 50,8 \%$ ). In beiden Zelllinien führte die Zugabe von unmarkierten PAH (1 mM) zur Transportlösung zu einer ungefähren Halbierung der $\left[{ }^{3} \mathrm{H}\right] \mathrm{PAH}-A u f n a h m e$ gegenüber der ungehemmten Aufnahme (ok-Zellen 1609,8 \pm 266,9 \% versus 858,6 $\pm 133,9 \%$; CHO-Zellen $431,4 \pm 50,8 \%$ versus $273,9 \pm 24 \%$ ).

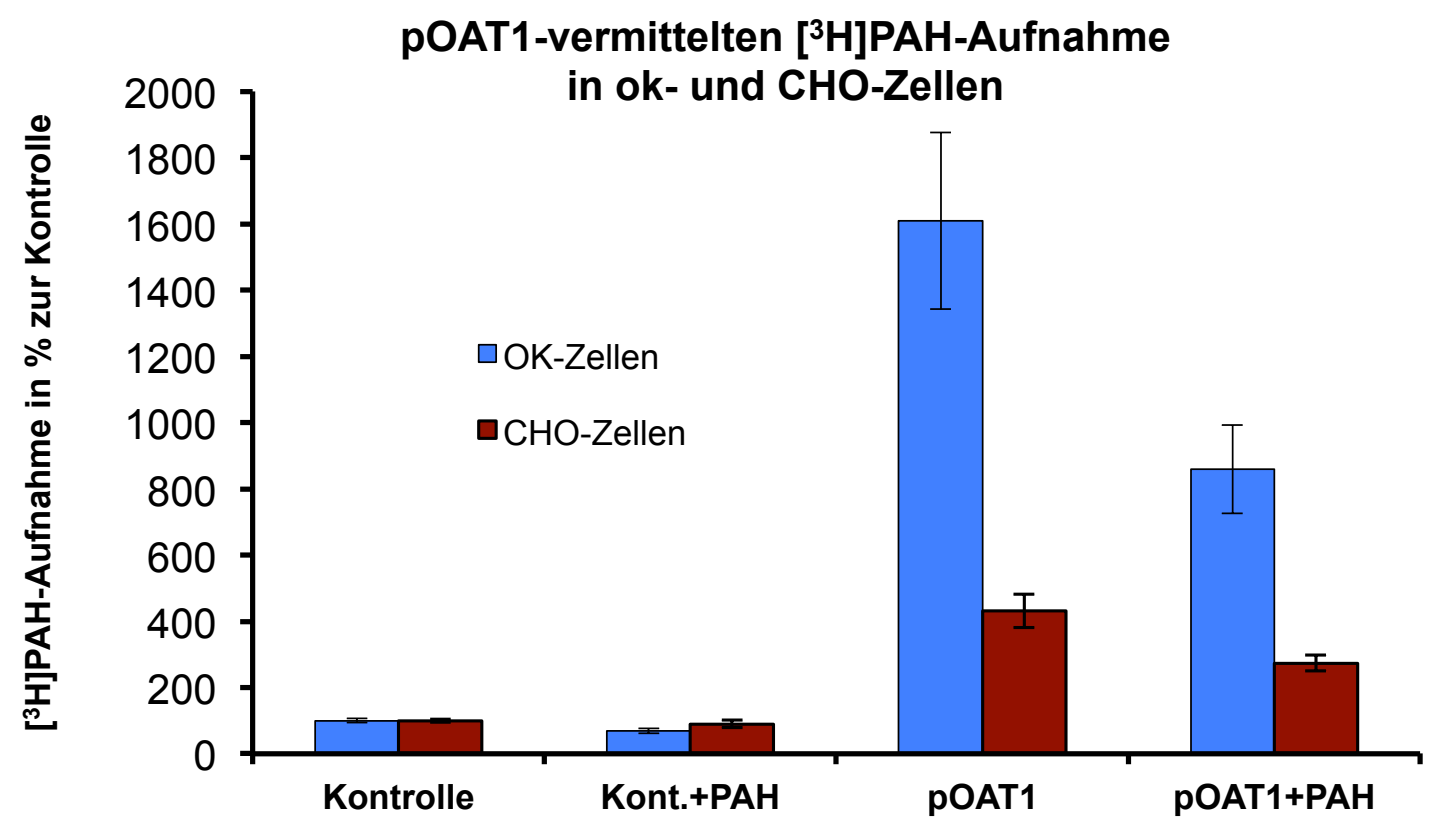

Abbildung 3.9: Vergleich der pOAT1-vermittelten [ $\left.{ }^{3} \mathrm{H}\right] \mathrm{PAH}-A$ ufnahme in ok- und CHO-Zellen. In 24-Well-Platten kultivierte ok- und CHO-Zellen wurden für 15 min mit $1 \mu \mathrm{M}\left[{ }^{3} \mathrm{H}\right] \mathrm{PAH}$ enthaltender Ringer-Lösung inkubiert. Zusätzlich wurde durch Zugabe von $1 \mathrm{mM}$ unmarkierten PAH die Hemmung der Aufnahme untersucht. Als Kontrolle dienten untransfizierte Zellen. Dargestellt sind die Mittelwerten \pm SEM aus drei voneinander unabhängigen Versuchen mit 3 Wells pro Bedingung in Prozent zur Kontrolle (100\%).

Aus Abbildung 3.10 ist entsprechend zu Abbildung 3.9 die Aufnahme von Fluorescein durch pOAT1-transfizierte ok- und CHO-Zellen zu entnehmen. Dazu wurden die Zellen für 15 min bei RT in Ringer-Lösung, die Fluorescein in einer Konzentration von $1 \mu \mathrm{M}$ enthielt, inkubiert. Nach dreimaligem Waschen mit Ringer-Lösung und Lyse der Zellen wurde die aufgenommene Fluorescein-Menge im Spektralfluorimeter bei einer Exzitations-/Emissionswellenlänge von 492/512 nm gemessen (siehe Abschnitt 2.10.7.2). 


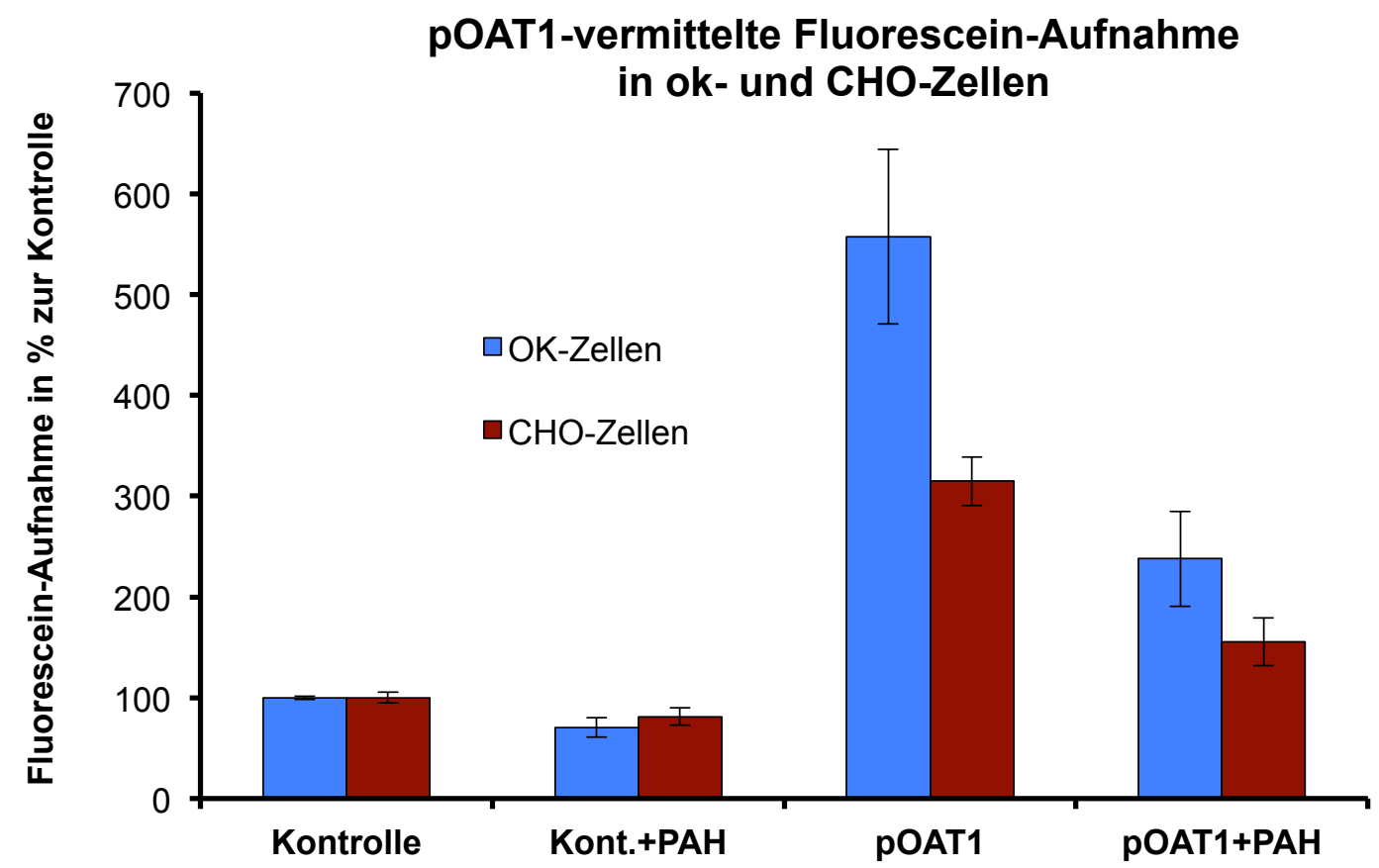

Abbildung 3.10: pOAT1-vermittelte Fluorescein-Aufnahme in ok- und CHO-Zellen. In 24-Well-Platten kultivierte okund CHO-Zellen wurden für 15 min mit $1 \mu \mathrm{M}$ Fluorescein enthaltende Ringer-Lösung inkubiert. Zusätzlich wurde durch Zugabe von $1 \mathrm{mM}$ unmarkiertem PAH die Hemmung der Aufnahme untersucht. Als Kontrolle dienten untransfizierte Zellen. Dargestellt sind die Mittelwerte \pm SEM aus drei voneinander unabhängigen Versuchen mit 3 Wells pro Bedingung in Prozent zur Kontrolle (100\%).

Ähnlich der $\left[{ }^{3} \mathrm{H}\right] \mathrm{PAH}-$ Aufnahme zeigte sich auch bei der Fluorescein-Aufnahme durch transfizierte ok-Zellen ein signifikant höherer Uptake als durch transfizierte CHO-Zellen. Die transfizierten ok-Zellen zeigten im Vergleich zu nicht transfizierten Kontrollzellen einen um den Faktor 5,6 höheren Fluorescein-Transport (Kontrolle $100 \pm$ 1,6 \% versus 557,6 \pm 86,7 \%). Die pOAT1-expremierenden CHO-Zellen hingegen zeigten lediglich eine 3,1-fach höhere Fluorescein-Aufnahme gegenüber den Kontrollzellen (Kontrolle $100 \pm 5,3 \%$ versus $314,9 \pm 24,2 \%)$.

Die Zugabe von unmarkierten PAH (1 mM) zur Transportlösung führte sowohl in den okZellen als auch in den CHO-Zellen zu einer ungefähren Halbierung der FluoresceinAufnahme (ok-Zellen 557,6 \pm 86,7 \% versus 237,8 \pm 47,4\%; CHO-Zellen $(314,9 \pm 24,2 \%$ versus $155,7 \pm 23,8 \%)$.

Zusammenfassend zeigte sich für die beiden getesteten Substrate sowohl prozentual als auch absolut (nicht dargestellt) eine deutlich höhere pOAT1-vermittelte Substrataufnahme in transfizierten ok-Zellen gegenüber transfizierten CHO-Zellen. Im Vergleich der beiden Substrate wurde für $\left[{ }^{3} \mathrm{H}\right] \mathrm{PAH}$ gegenüber Fluorescein die höhere Substrataufnahme gemessen, sodass für die folgende Charakterisierung des pOAT1 als Expressionssystem die ok-Zellen und als Substrat $\left[{ }^{3} \mathrm{H}\right] \mathrm{PAH}$ dienten. 


\subsubsection{Radioaktive Transportversuche mit pOAT1-transfizierten ok-Zellen}

In den folgenden Versuchen sollten die grundlegenden Merkmale des pOAT1 bestimmt werden, um sie mit Daten aus früheren Vesikelstudien und Daten isolierter OAT1 anderer Spezies zu vergleichen. Im Gegensatz zu diesen Studien wurde in dieser Arbeit erstmals der pOAT1 isoliert untersucht.

\subsubsection{Kinetik der PAH-Aufnahme in ok-Zellen}

Zunächst sollte der Km-Wert des pOAT1 für PAH bestimmt werden. Dafür wurde vorab die Zeitabhängigkeit der $\left[{ }^{3} \mathrm{H}\right] \mathrm{PAH}-A u f n a h m e$ ermittelt um eine zeitliche Optimierung der Versuchsbedingungen zu erreichen. Dazu wurden die Zellen 0,5 min, 1 min, 2 min, 5 min, 10 min und 15 min inkubiert und anschließend die PAH-Aufnahme gemessen. Abbildung 3.11 zeigt

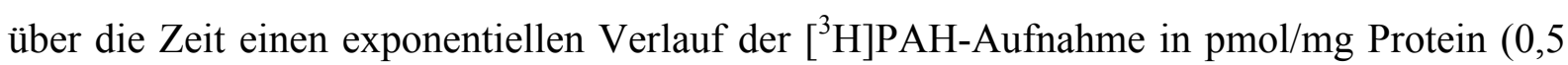
$\min 1,26 \pm 0,095 \mathrm{pmol} / \mathrm{mg} ; 1 \mathrm{~min} 1,88 \pm 0,096 \mathrm{pmol} / \mathrm{mg} ; 2 \mathrm{~min} 3,07 \pm 0,25 \mathrm{pmol} / \mathrm{mg} ; 5 \mathrm{~min}$ $5,15 \pm 0,33 \mathrm{pmol} / \mathrm{mg} ; 10 \min 8,09 \pm 0,67 ; 15 \mathrm{~min} 8,41 \pm 0,71 \mathrm{pmol} / \mathrm{mg})$.

\section{pOAT1- vermittelte $\left[{ }^{3} \mathrm{H}\right] \mathrm{PAH}-A u f n a h m e$ nach Zeit}

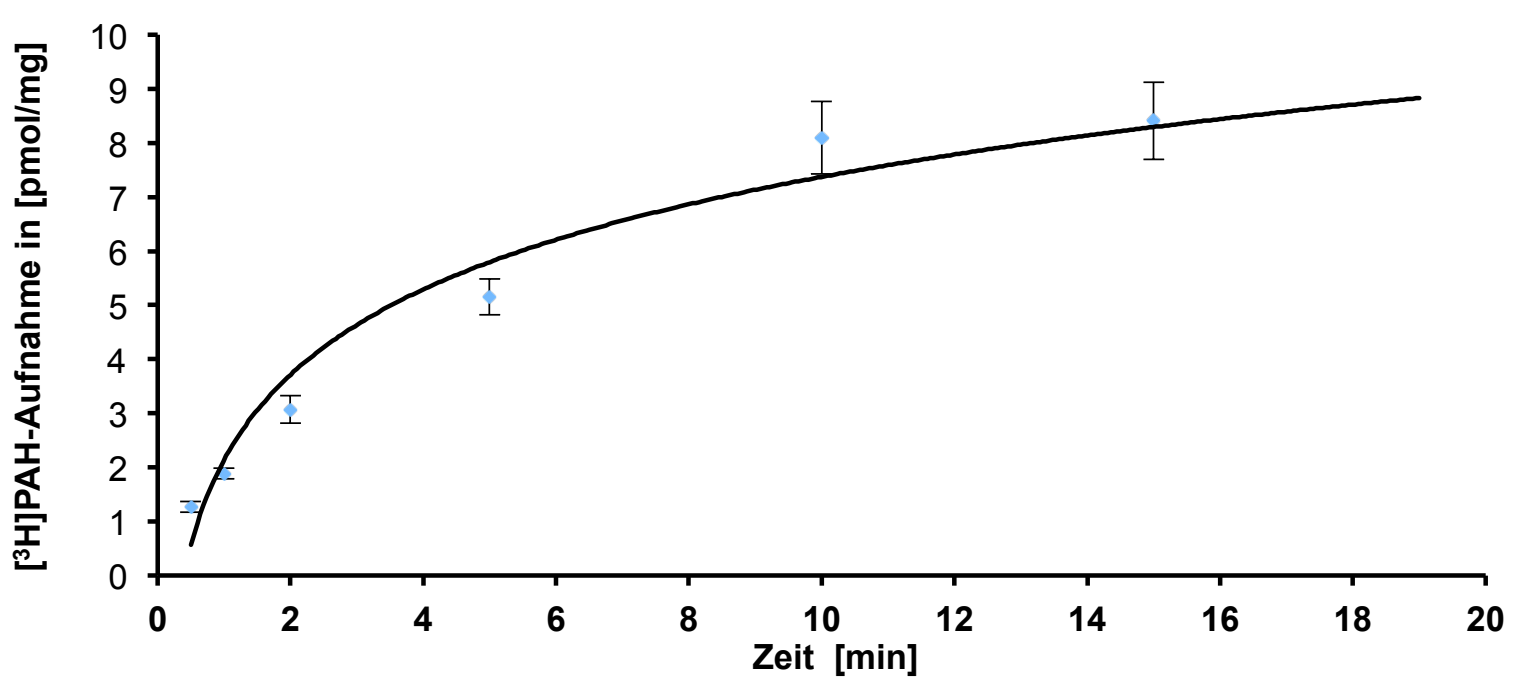

Abbildung 3.11: Zeitabhängigkeit der pOAT1-vermittelten $\left[^{3} \mathbf{H}\right]$ PAH-Aufnahme in ok-Zellen. Auf 24-Well-Platten kultivierte ok-Zellen wurden für 0,5 min, $1 \mathrm{~min}, 2 \mathrm{~min}, 5 \mathrm{~min}, 10 \mathrm{~min}$ und $15 \mathrm{~min}$ mit $\left.1 \mu \mathrm{M}{ }^{3} \mathrm{H}\right] \mathrm{PAH}$ enthaltender RingerLösung inkubiert. Dargestellt sind die Mittelwerte \pm SEM aus 4 voneinander unabhängigen Versuchen mit jeweils 3 Well pro Bedingung in $\mathrm{pmol} / \mathrm{mg}$ Protein.

\subsubsection{Bestimmung des Km-Wertes für PAH in ok-Zellen}

Für die pOAT1-vermittelte $\left[{ }^{3} \mathrm{H}\right] \mathrm{PAH}-A u f n a h m e$ in ok-Zellen wurde für die Zeit bis 2 Minuten ein nahezu linearer Transport ermittelt (siehe Abbildung 3.11). Idealerweise wäre also 
eine Messung nach im Bereich von 1 Minute aus kinetischen Gesichtspunkten am günstigsten. Aus Gründen des praktischen Vorgehens (Sicherheit und manuelle Handhabung aufeinander folgender Schritte mit radioaktiven Substanzen) und zur Vermeidung von systematischen Fehlern erfolgte die Bestimmung des Km-Wertes bei einer Inkubationszeit von 2 Minuten. Dazu wurde die $\left[{ }^{3} \mathrm{H}\right] \mathrm{PAH}-A u f n a h m e$ in pOAT1-transfizierten ok-Zellen in Anwesenheit von unmarkiertem PAH in unterschiedlichen Konzentrationen von 5, 10, 20 ,50 100, 200, 300,400 und $500 \mu \mathrm{M}$ bestimmt.

Die Ergebnisse sind in Abbildung 3.12 dargestellt und zeigen eine konzentrationsabhängige kompetitive cis-Inhibition der $\left[{ }^{3} \mathrm{H}\right] \mathrm{PAH}-\mathrm{Aufnahme}$ durch unmarkiertes PAH. Der aus diesem Experiment berechnete apparente $\mathrm{Km}$-Wert ist 8,54 $\pm 1,2 \mu \mathrm{M}$ (Berechnung nach der modifizierten Michaelis-Menten-Gleichung [Malo und Berteloot 1991] mit SigmaPlot 2001, SPSS Science, Chicago, IL, USA). Im Vergleich mit anderen Spezies liegt der apparente Km-Wert nahe an dem für den hOAT1 $(5-10 \mu \mathrm{M})$ (Bahn et al. 2000; Hosoyamada et al. 1999) und unter denen für die Ratte (14-70 $\mu \mathrm{M})$ (Sweet et al. 1997; Sekine et al. 1997), der Maus (37 $\mu \mathrm{M})$ (Lopez-Nieto 1997) und dem Kaninchen (18 $\mu \mathrm{M})$ (Bahn et al. 2002).

\section{pOAT1-vermittelte $\left[{ }^{3} \mathrm{H}\right] \mathrm{PAH}-A u f n a h m e$ in ok-Zellen}

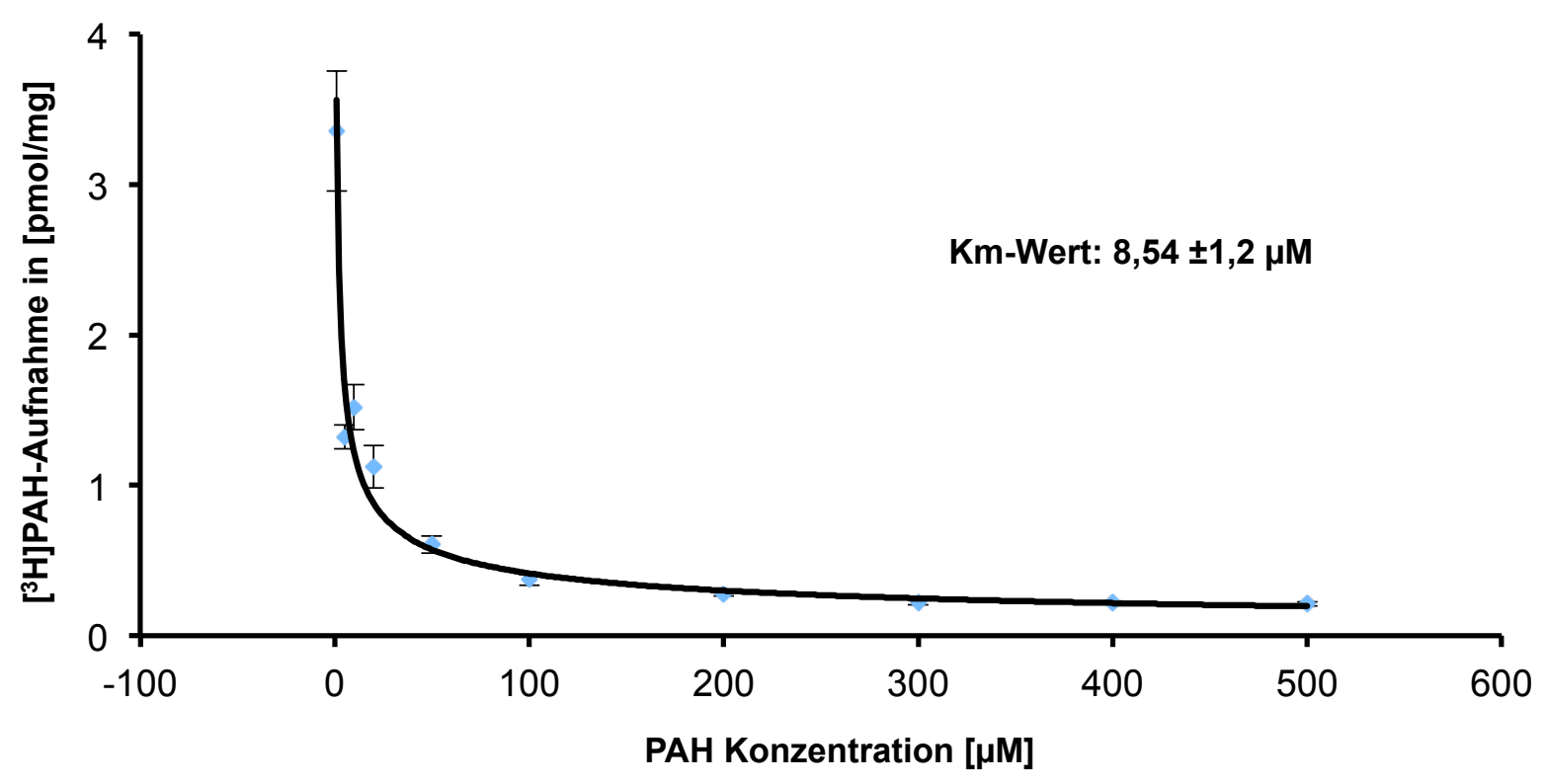

Abbildung 3.12: pOAT1-vermittelte $\left.{ }^{3} \mathrm{H}\right] \mathrm{PAH}-A u f n a h m e$ in ok-Zellen und Hemmung durch unmarkiertes PAH. Die ok-Zellen wurden für 2 min mit $1 \mu \mathrm{M}\left[{ }^{3} \mathrm{H}\right] \mathrm{PAH}$ enthaltender Ringer-Lösung inkubiert. Zusätzlich wurde unmarkiertes $\mathrm{PAH}$ in steigender Konzentration zugegeben. Dargestellt sind die Mittelwerte \pm SEM aus 5 voneinander unabhängigen Versuchen mit jeweils $3 \mathrm{Well}$ pro Bedingung in pmol/mg Protein. Der apparente Km-Wert wurde nach der modifizierten Michaelis-Menten-Gleichung mit SigmaPlot 2001 berechnet. 


\subsubsection{3 cis-Inhibition der pOAT1-vermittelten PAH-Aufnahme durch organische Anio- nen}

Zur genaueren Charakterisierung des pOAT1 wurde die Inhibition der $\left[{ }^{3} \mathrm{H}\right] \mathrm{PAH}-\mathrm{Aufnahme}$ durch eine Reihe von organischen Anionen getestet. In Anlehnung an Vesikelstudien von Werner und Roch-Ramel (1991) wurde Probenecid, ein klassischer Inhibitor der OAT, Glutarat, Pyrazinoat (PZA) und Urat untersucht. Zusätzlich wurde als Kontrolle Tetraethylammonium (TEA), ein organisches Kation und klassisches Substrat des organischen KationenTransport-Systems, getestet. Alle Substanzen wurden in einer Konzentration von $1 \mathrm{mM}$ eingesetzt.

\section{cis-Inhibition der pOAT1-vermittelten [ $\left.{ }^{3} \mathrm{H}\right] \mathrm{PAH}-A u f n a h m e$ in ok-Zellen}

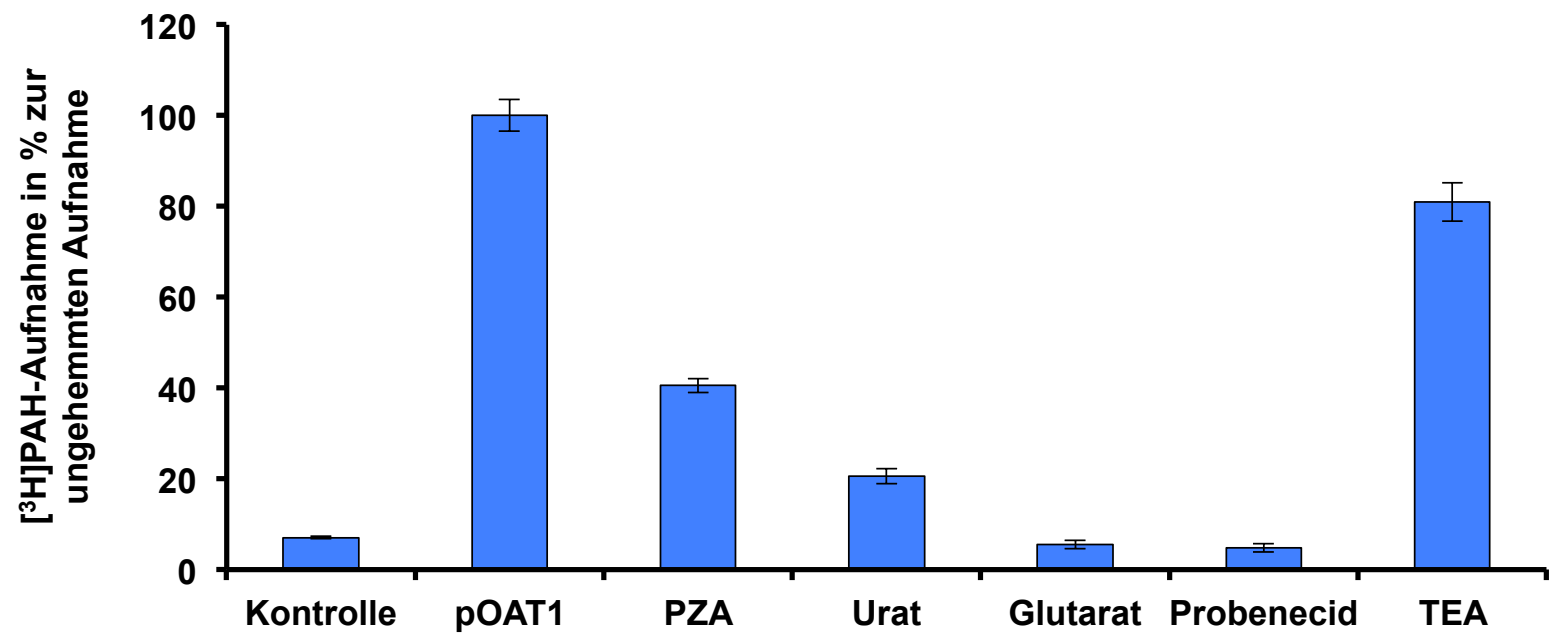

Abbildung 3.13: cis-Inhibition der pOAT1-vermittelten $\left[{ }^{3} \mathrm{H}\right] \mathrm{PAH}-A u f n a h m e$ in ok-Zellen. Unter Zugabe von Probenecid, Pyrazionat (PZA), Glutarat, Urat bzw. Tetraethylammonium (TEA) (je $1 \mathrm{mM}$ ) wurde nach 15 min Inkubationszeit die $\left[{ }^{3} \mathrm{H}\right] \mathrm{PAH}-$ Aufnahme $(1 \mu \mathrm{M})$ in ok-Zellen bestimmt. Als Kontrolle dienten nicht transfizierte ok-Zellen. Dargestellt sind die Mittelwerte \pm SEM von 3 unabhängigen Versuchen mit jeweils 3 Well pro Bedingung in Prozent zur ungehemmten PAHAufnahme (100\%).

Alle organischen Anionen führten zu einer signifikanten Hemmung der $\left[{ }^{3} \mathrm{H}\right] \mathrm{PAH}-\mathrm{Aufnahme}$ (ungehemmte Kontrolle $100 \pm 3,5 \%$ ) (siehe Abbildung 3.13). Probenecid und Glutarat $(4,8 \pm 0,9 \%$ und $5,5 \pm 0,9 \%$ versus Kontrolle 7,1 $\pm 0,3 \%)$ führten in der eingesetzten Kon-

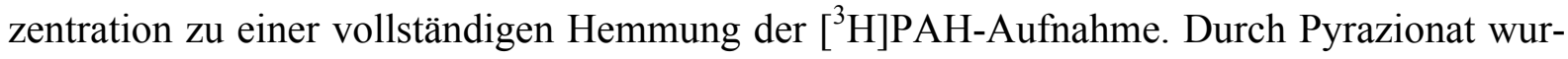
de die $\left[{ }^{3} \mathrm{H}\right] \mathrm{PAH}-A u f n a h m e$ auf 40,5 $\pm 1,5 \%$ und durch Urat auf 20,6 $\pm 1,7 \%$ reduziert. Für die Stärke der Inhibition der einzelnen Substanzen ergab sich damit folgende Reihenfolge: Probenecid $>$ Glutarat $>$ Urat $>$ Pyrazinoat. Diese stimmt mit den Daten aus Vesikelstudien der Schweineniere von Werner und Roch-Ramel (1991) überein. Tetraethylammonium (TEA) als organisches Kation führte ebenfalls zu einer signifikanten Hemmung der $\left[{ }^{3} \mathrm{H}\right] \mathrm{PAH}-$ Aufnahme auf $81 \pm 4,3 \%(\mathrm{p}<0,0034)$. 


\subsubsection{4 trans-Stimulation der pOAT1-vermittelten PAH-Aufnahme durch Glutarat}

Der Mechanismus des OAT1 wurde als tertiär aktiver Antiporter beschrieben (Shimada et al. 1987; Burckhardt und Burckhardt 2003), der organische Anionen im Austausch mit Dicarboxylaten wie z. B. $\alpha$-Ketoglutarat über die basale Zellmembran in die Zelle aufnimmt. Eine Vorbeladung der ok-Zellen müsste mit Glutarat zu einer erhöhten $\left[{ }^{3} \mathrm{H}\right] \mathrm{PAH}-A u f n a h m e$ führen, um die Funktionsweise des neu klonierten pOAT1 als Antiporter zu belegen,. Dazu wurde dem Kulturmedium der ok-Zellen 2 Stunden vor dem Transportversuch Glutarat in einer Endkonzentration von $0,1 \mathrm{mM}$ bzw. $1 \mathrm{mM}$ beigegeben, das sich intrazellulär anreichert und den Austausch mit PAH antreibt. Nach dreimaligem Waschen der Zellen mit Ringer-Lösung wurden die Zellen anschließend für 15 min mit $\left[{ }^{3} \mathrm{H}\right] \mathrm{PAH}(1 \mu \mathrm{M})$ inkubiert. Die $\left[{ }^{3} \mathrm{H}\right] \mathrm{PAH}-$ Aufnahme in den mit Glutarat vorbeladenen ok-Zellen war signifikant höher als in den nicht vorbeladenen Zellen (siehe Abbildung 3.14).

Gegenüber den nicht vorbeladenen Zellen $(100 \pm 3,4 \%)$ zeigten die mit 0,1 mM Glutarat vorbeladenen Zellen eine $\left[{ }^{3} \mathrm{H}\right] \mathrm{PAH}-A u f n a h m e$ von $142,1 \pm 4,4 \%$. Nach Vorbeladung der Zellen mit $1 \mathrm{mM}$ Glutarat wurde eine mehr als doppelt so hohe Aufnahme gemessen: $211,4 \pm 4,8 \%$.

\section{trans-Stimulation der pOAT1-vermittelten [ $\left.{ }^{3} \mathrm{H}\right] \mathrm{PAH}-A u f n a h m e$ in ok-Zellen}

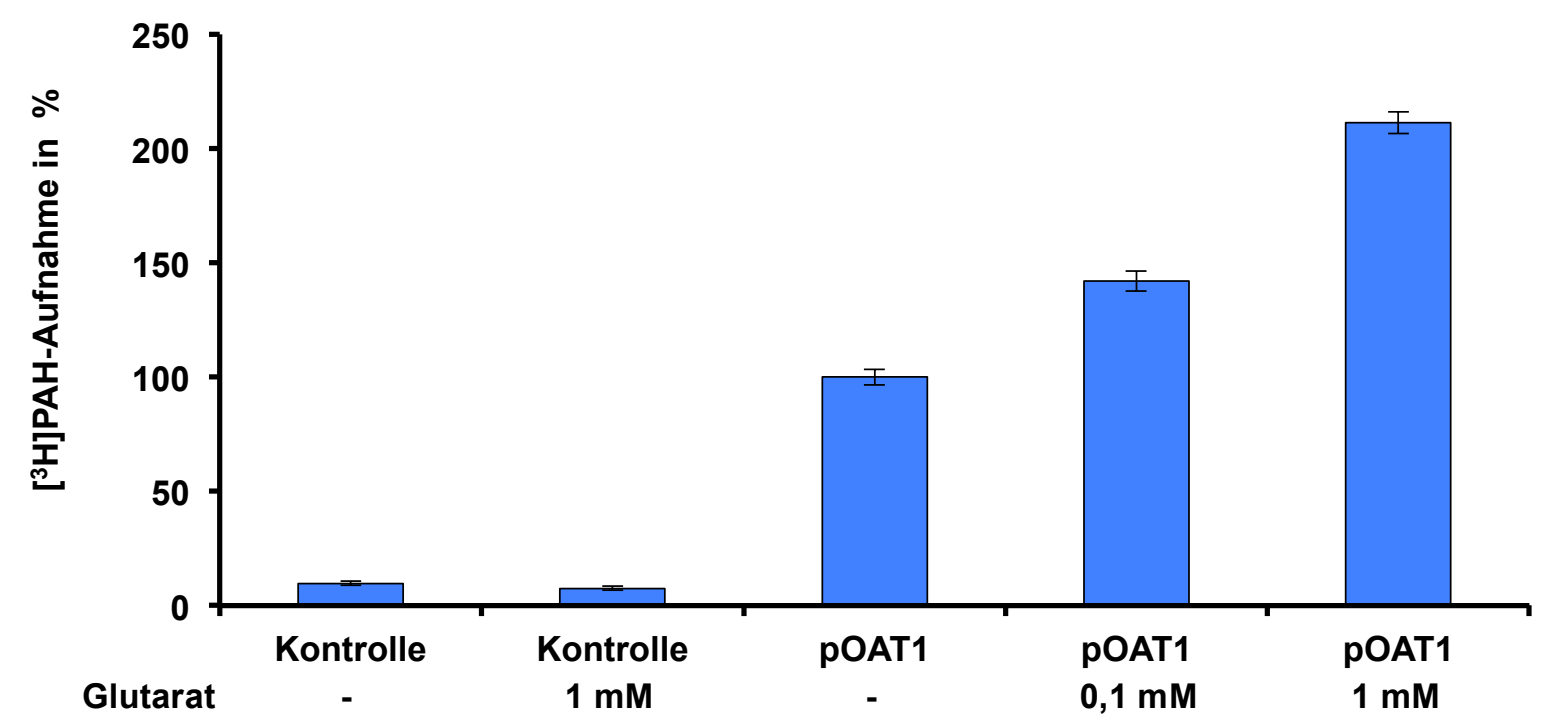

Abbildung 3.14: trans-Stimulation der pOAT1-vermittelten $\left[{ }^{3} \mathrm{H}\right] \mathrm{PAH}-A u f n a h m e$ in ok-Zellen. ok-Zellen wurden für 2 Stunden in 0,1 mM oder $1 \mathrm{mM}$ Glutarat enthaltender Ringer-Lösung vorinkubiert. Nach dem Waschen der Zellen mit glutaratfreier Ringer-Lösung wurden diese für 15 min mit $\left[{ }^{3} \mathrm{H}\right]-\mathrm{PAH}(1 \mu \mathrm{M})$ inkubiert und die PAH-Aufnahme gemessen. Dargestellt sind die Mittelwerte \pm SEM aus 3 unabhängigen Versuchen in Bezug auf die $\left[{ }^{3} \mathrm{H}\right]-\mathrm{PAH}-\mathrm{Aufnahme}$ von nicht vorbeladenen Zellen $(100 \pm 3,4 \%)$. Als Kontrolle dienten nicht transfizierte ok-Zellen mit und ohne Glutaratvorbeladung. 


\subsubsection{Chloridabhängigkeit der pOAT1-vermittelten PAH-Aufnahme}

Werner und Roch-Ramel (1991) konnten an Membranvesikeln aus dem proximalen Tubulus der Schweineniere eine direkte Chloridabhängigkeit der PAH-Aufnahme belegen. In Anlehnung daran wurde die Chloridabbhängigkeit des pOAT1 untersucht, indem eine chloridfreie Ringer-Lösung als Transportmedium genutzt wurde. Dazu wurde sämtliches Chlorid durch Glukonat ersetzt. Während die transfizierten Zellen in Anwesenheit von Chlorid eine 30-fach höhere [ $\left.{ }^{3} \mathrm{H}\right] \mathrm{PAH}-A u f n a h m e$ im Vergleich zur Kontrolle zeigten $(100 \pm 4,1 \%$ versus $3,3 \pm 0,2 \%)$, fand unter chloridfreien Bedingungen kein $\left[{ }^{3} \mathrm{H}\right] \mathrm{PAH}-$ Transport statt $(5,9 \pm$ 0,6 \% versus Kontrolle 5,3 $\pm 0,4 \%$ ) (siehe Abbildung 3.15).

\section{Chloridabhängigkeit der pOAT1 vermittelten $\left[{ }^{3} \mathrm{H}\right] \mathrm{PAH}$ Aufnahme in ok-Zellen}

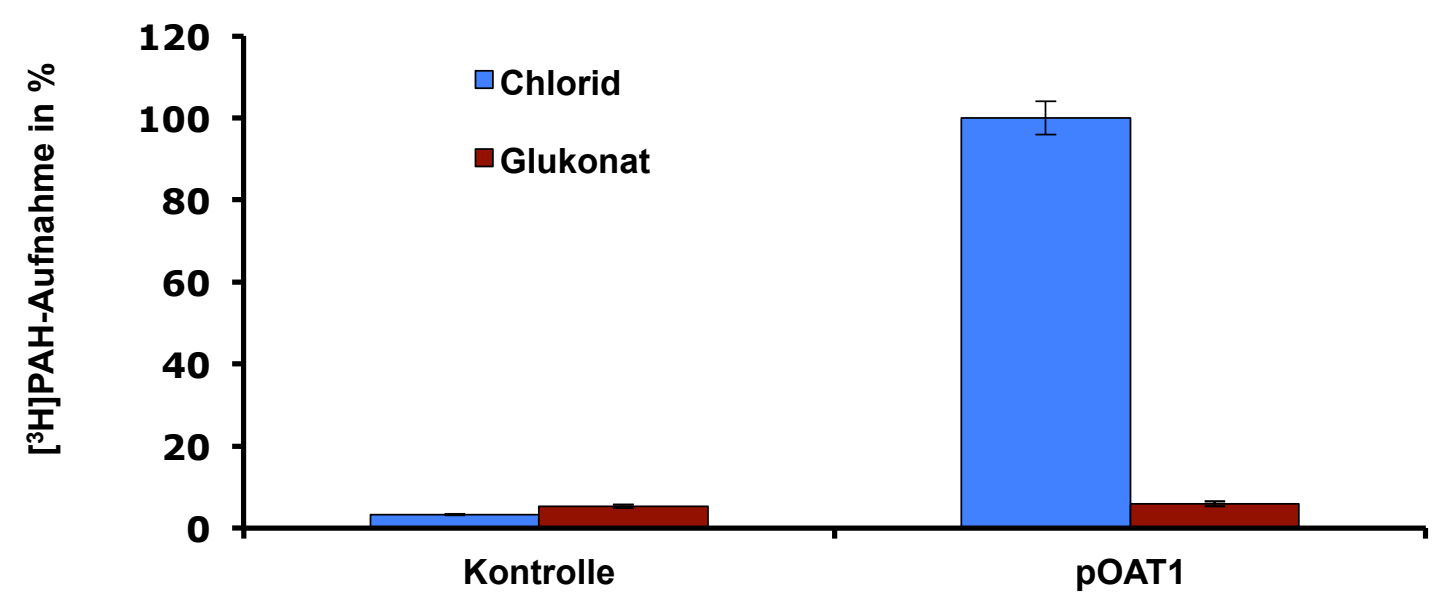

Abbildung 3.15: Chloridabhängigkeit der pOAT1-vermittelten [ $\left.{ }^{3} \mathbf{H}\right]$ PAH-Aufnahme in ok-Zellen. In 24-Well-Platten kultivierte ok-Zellen wurden für 15 min mit $1 \mu \mathrm{M}\left[{ }^{3} \mathrm{H}\right]-\mathrm{PAH}$ enthaltender Ringer-Lösung in An- und Abwesenheit von Chlorid bzw. Glukonat inkubiert. Als Kontrolle dienten nicht transfizierte ok-Zellen. Dargestellt sind die Mittelwerte \pm SEM aus 3 voneinander unabhängigen Versuchen mit 3 Well pro Bedingung in Prozent zur Aufnahme in chloridhaltiger Ringer-Lösung $(100 \%)$ in Bezug auf die PAH-Aufnahme mit Chlorid (100 \pm 4,1\%). Als Kontrolle dienten nicht transfizierte ok-Zellen.

\subsubsection{6 pOAT1-vermittelte Urat-Aufnahme}

Es konnte nachgewiesen werden, dass Urat zur Hemmug der PAH-Aufnahme in mit pOAT1transfizierten ok-Zellen führte (siehe Abbildung 3.13). Zur Differenzierung zwischen einer Inhibition oder einem konkurrierendem aktiven Transport wurde die pOAT1-vermittelte Aufnahme von radioaktiv markierten Urat $\left(\left[{ }^{14} \mathrm{C}\right]\right.$ Urat $)$ in ok-Zellen untersucht. $\left[{ }^{14} \mathrm{C}\right]$ Urat wurde in einer Endkonzentration von $50 \mu \mathrm{M}$ bei ansonsten gleichen Versuchsbedingungen eingesetzt. Es konnte keine vermehrte $\left[{ }^{14} \mathrm{C}\right]$ Urat-Aufnahme in transfizierten ok-Zellen $(104,9 \pm 1,7 \%)$ gegenüber der Kontrolle $(100 \pm 4,45 \%)$ nachgewiesen werden. Damit transportierte der pOAT1 aktiv kein Urat. 


\subsubsection{7 cis-Inhibition der pOAT1-vermittelten PAH-Aufnahme durch Steroide}

Als endogene Substrate des Körpers sollten eine Reihe von Steroiden auf ihre Affinität zum pOAT1 untersucht werden. Dazu wurde die cis-Hemmung der $\left[{ }^{3} \mathrm{H}\right] \mathrm{PAH}-\mathrm{Aufnahme}$ Dehydroxyepiandrosterone (DHEA) und dessen sulfatierte Form Dehydroxyepiandrosteronesulfat $\left(\mathrm{DHEA}-\mathrm{SO}_{4}\right)$ und Estronsulfat (Estron- $\left.\mathrm{SO}_{4}\right)$ untersucht. Alle Steroide wurden in einer Konzentration von $1 \mathrm{mM}$ eingesetzt und führten zu einer deutlichen Inhibition der [ $\left.{ }^{3} \mathrm{H}\right] \mathrm{PAH}-$ Aufnahme (siehe Abbildung 3.16).

Dabei kam es durch Zugabe von DHEA zu einer ungefähren Halbierung der [ $\left.{ }^{3} \mathrm{H}\right] \mathrm{PAH}-$ Aufnahme $(50,7 \pm 2,7 \%)$, während die sulfatierte Form $\left(\right.$ DHEA-SO $\left.{ }_{4}\right)$ die PAH-Aufnahme sogar auf 14,3 $\pm 1,1 \%$ gegenüber der ungehemmten Aufnahme $(100 \pm 2,2 \%)$ reduzierte. Durch Estron- $\mathrm{SO}_{4}$ wurde die $\left[{ }^{3} \mathrm{H}\right] \mathrm{PAH}-A$ ufnahme auf $16,0 \pm 1,1 \%$ gesenkt.

Der $\left[{ }^{3} \mathrm{H}\right] \mathrm{PAH}-\mathrm{Transport}$ in den durch DHEA-SO $\mathrm{S}_{4}$ gehemmtem pOAT1 lag damit nur um das 3,7-Fache über dem der untransfizierten Kontrolle und bei der Inhibition durch Estron-SO $\mathrm{SO}_{4}$ nur um das 3,3-Fache über der Kontrolle. Der ungehemmte Transport gegenüber der Kontrolle war um das 10,6-Fache höher. DHEA-SO $\mathrm{S}_{4}$ und Estron- $\mathrm{SO}_{4}$ führten auch in den untransfizierten Zellen zu einer signifikant $(p<0,00002)$ niedrigeren $\left[{ }^{3} \mathrm{H}\right] \mathrm{PAH}-\mathrm{Aufnahme.} \mathrm{Bei} \mathrm{der}$ Inhibition durch DHEA war der Transport nicht signifikant $(p=0,194)$ niedriger.

\section{cis-Inhibition der pOAT1-vermittelten $\left[{ }^{3} \mathrm{H}\right] \mathrm{PAH}-A u f n a h m e$ in ok-Zellen}

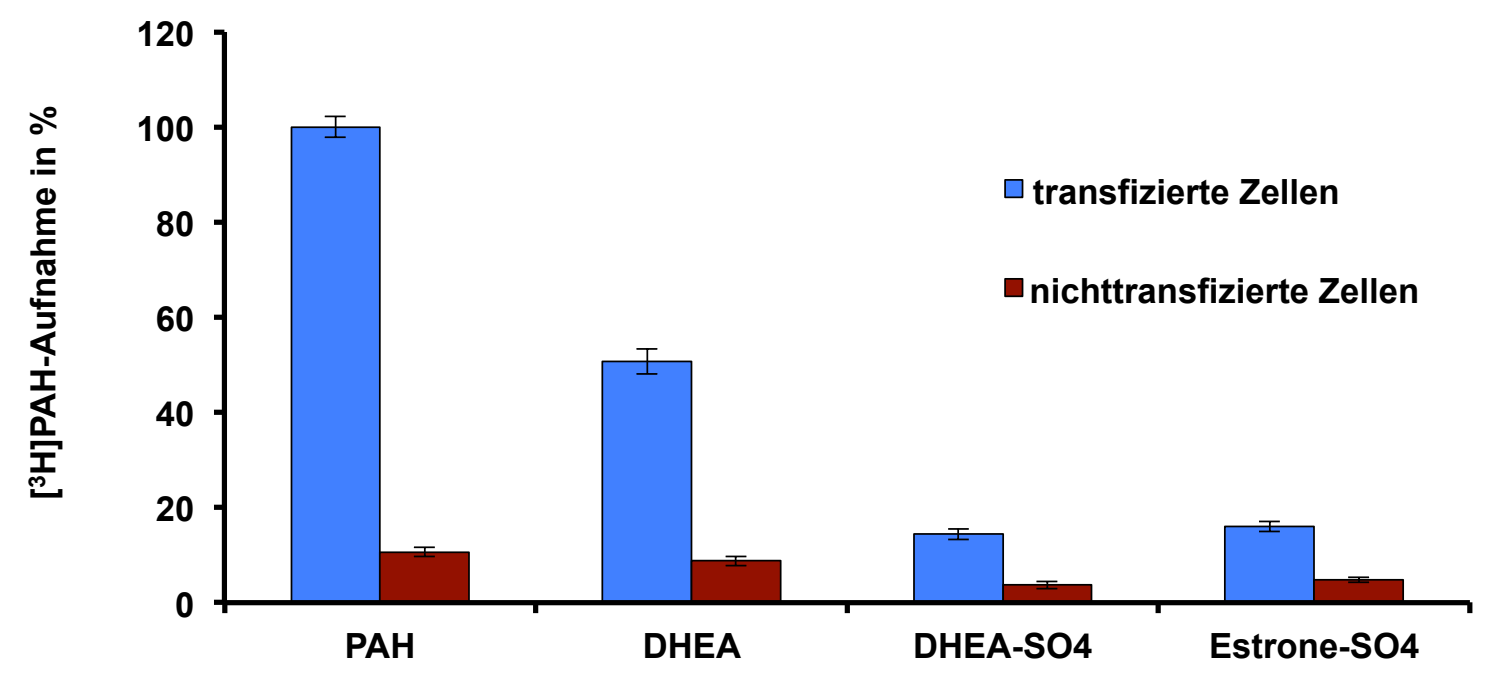

Abbildung 3.16: cis-Inhibition der pOAT1-vermittelten [ $\left.{ }^{3} \mathrm{H}\right] \mathrm{PAH}-A u f n a h m e$ in ok-Zellen durch Steroidhormone. okZellen wurden für 15 min mit $1 \mu \mathrm{M}\left[{ }^{3} \mathrm{H}\right] \mathrm{PAH}$ enthaltender Ringer-Lösung inkubiert. Zusätzlich erfolgte die Zugabe von $1 \mathrm{mM}$ Dehydroxyepiandrosteron (DHEA), Dehydroyepiandrosteronsulfat $\left(\right.$ DHEA-SO 4 ) oder Estronsulfat (Estron-SO $\left.\mathrm{S}_{4}\right)$. Als Kontrolle dienten nicht transfizierte ok-Zellen. Dargstellt sind die Mittelwerte \pm SEM aus 5 voneineander unabhängigen Versuchen mit je 3 Well pro Bedingung in Prozent zur ungehemmten Aufnahme (100\%). 


\subsubsection{Konzentrationabhängige cis-Inhibition der PAH-Aufnahme durch DHEA-SO$_{4}$ und Estron-SO 4}

Nachdem gezeigt werden konnte, dass die $\left[{ }^{3} \mathrm{H}\right] \mathrm{PAH}-\mathrm{Aufnahme}$ des pOAT1 durch die sulfatierte Steroidhormone nahezu komplett gehemmt wurde, sollte dieser Einfluss genauer charakterisiert und die Konzentrationsabhängigkeit dieses Effekts bestimmt werden.

Die Ergebnisse wurden mit Sigmaplot 2001 (SPSS Science, Chicago, IL, USA) ausgewertet und berechnet und sind in Abbildung 3.17 und 3.18 dargestellt. In den pOAT1-transfizierten ok-Zellen wurden die $\mathrm{IC}_{50}$-Werte für DHEA-SO $\mathrm{S}_{4}$ mit 116,5 $\pm 3,5 \mu \mathrm{M}$ und für Estron- $\mathrm{SO}_{4}$ mit $113,2 \pm 4,9 \mu \mathrm{M}$ berechnet.

cis Inhibition der pOAT1 vermittelten [ $\left.{ }^{3} \mathrm{H}\right] \mathrm{PAH}-A$ ufnahme in ok-Zellen

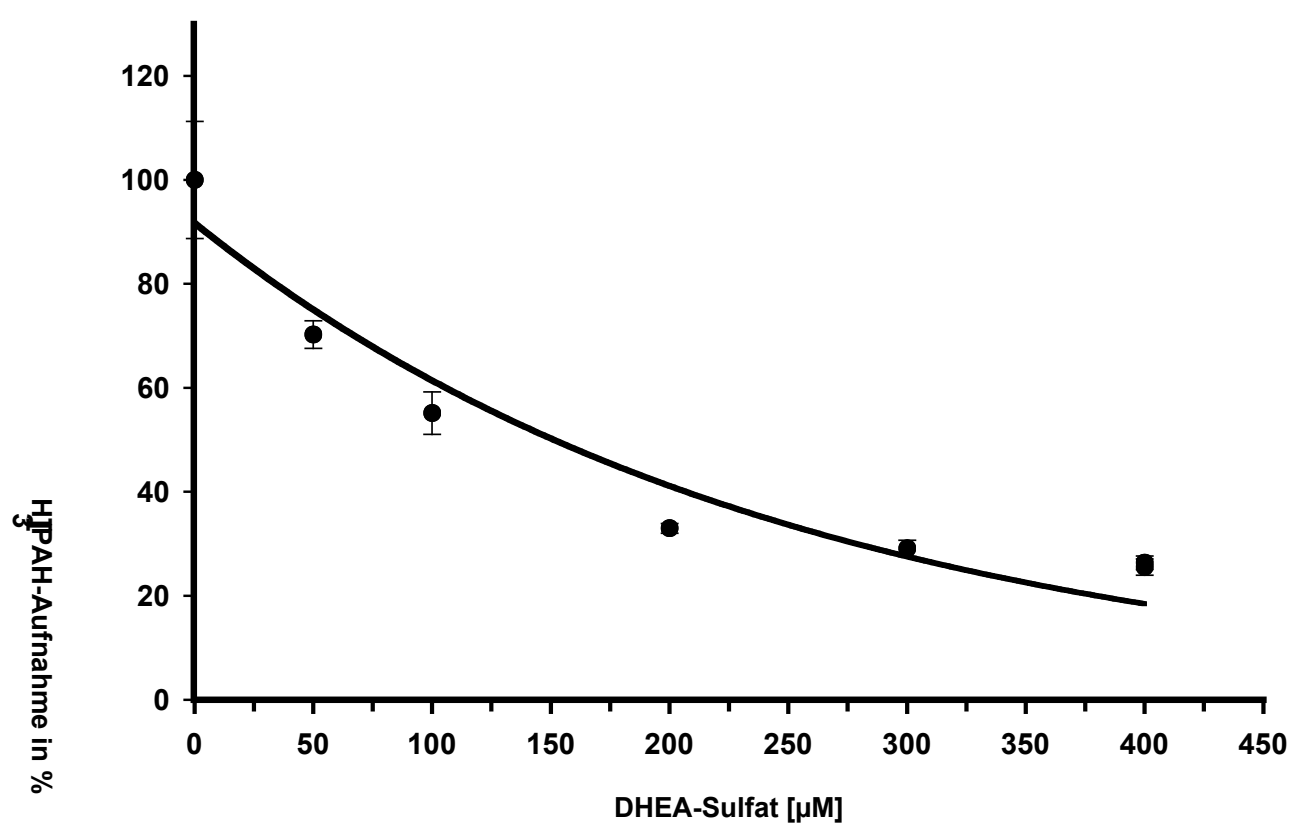

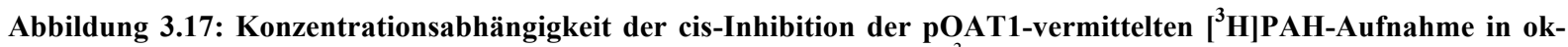

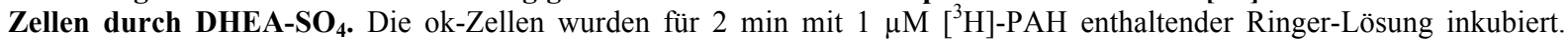
Zusätzlich wurden Dehydroyepiandrosteronsulfat $\left(\right.$ DHEA-SO ${ }_{4}$ ) oder Estronsulfat (Estron- $\left.\mathrm{SO}_{4}\right)$ in unterschiedlichen Konzentrationen beigegeben. Dargestellt sind die Mittelwerte \pm SEM aus 5 voneinander unabhängigen Versuchen mit je 3 Well pro Bedingung in Prozent zur ungehemmten PAH-Aufnahme (100\%). Der $\mathrm{IC}_{50}$-Wert wurde mit SigmaPlot 2001 (SPSS Science, Chicago, IL, USA) berechnet. 
cis Inhibition der pOAT1 vermittelten $\left[{ }^{3} \mathrm{H}\right] \mathrm{PAH}-A u f n a h m e$ in ok-Zellen

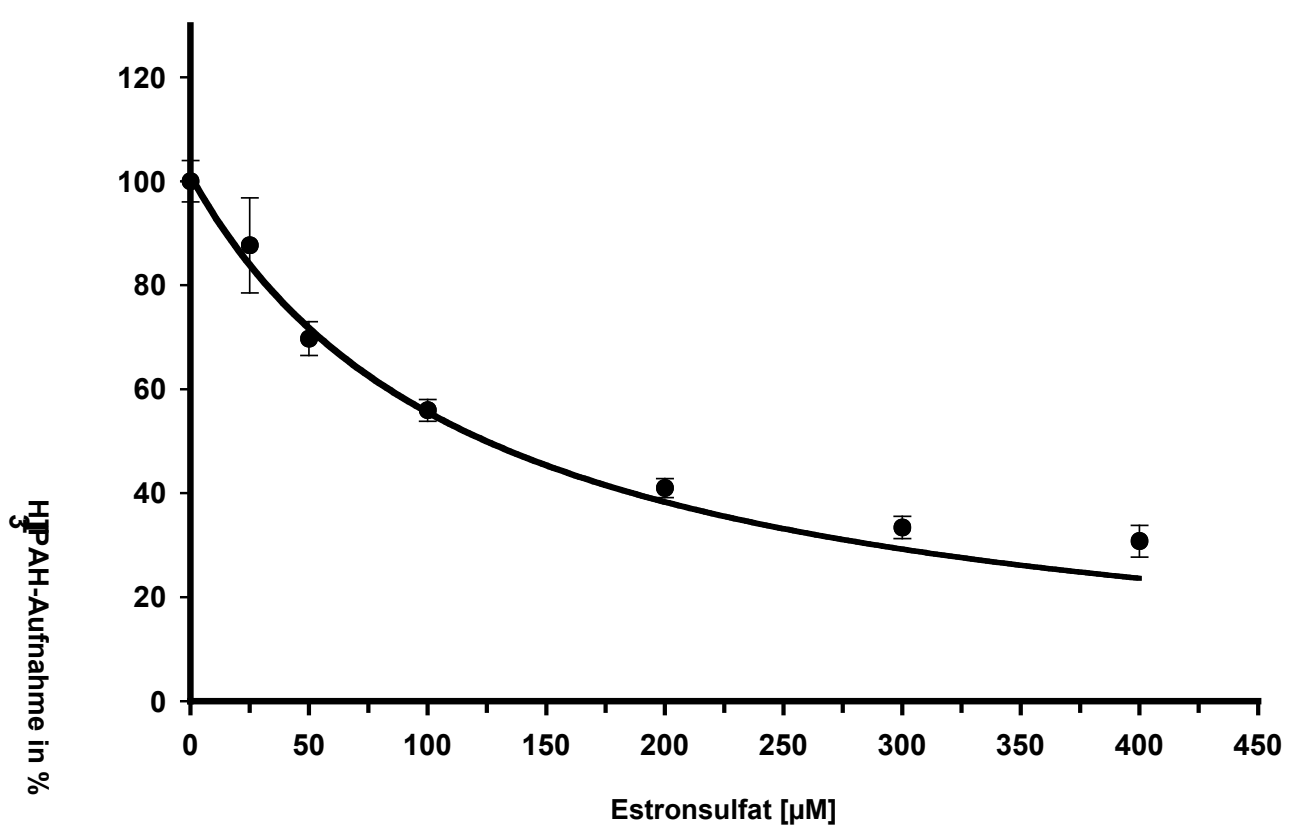

Abbildung 3.18: Konzentrationsabhängigkeit der cis-Inhibition der pOAT1-vermittelten $\left[{ }^{3} \mathrm{H}\right] \mathrm{PAH}-A$ ufnahme in ok-

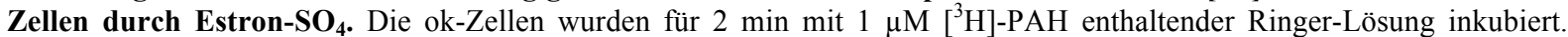
Zusätzlich wurden Dehydroyepiandrosteronsulfat $\left(\right.$ DHEA-SO ${ }_{4}$ ) oder Estronsulfat (Estron- $\left.\mathrm{SO}_{4}\right)$ in unterschiedlichen Konzentrationen beigegeben. Dargestellt sind die Mittelwerte \pm SEM aus 5 voneinander unabhängigen Versuchen mit je 3 Well pro Bedingung in Prozent zur ungehemmten PAH-Aufnahme (100\%). Der $\mathrm{IC}_{50}$-Wert wurde mit SigmaPlot 2001 (SPSS Science, Chicago, IL, USA) berechnet.

\subsubsection{9 pOAT1-vermittelte $\left[{ }^{3} \mathrm{H}\right]$ Estronsulfat-Aufnahme}

Wie zuvor beschrieben, konnte eine Interaktion zwischen dem pOAT1 und Steroidhormonen gezeigt werden. Zur Klärung der Frage, ob es sich um einen konkurrierenden Transport mit $\left[{ }^{3} \mathrm{H}\right] \mathrm{PAH}$ oder einer Hemmung des pOAT1 handelte, sollte die Fähigkeit des pOAT1 zum Transport von Estronsulfat untersucht werden. Weiterhin sollte die Hemmung dieses vermeintlichen Transports durch unmarkiertes PAH $(1 \mathrm{mM})$ und Glutarat $(1 \mathrm{mM})$ getestet werden. Beide Substanzen sind Inhibitoren des pOAT1, wie in den Abbildungen 3.8 und 3.13 gezeigt wird.

Analog $\mathrm{zu}$ den Versuchen mit $\left[{ }^{3} \mathrm{H}\right] \mathrm{PAH}$ wurde mit Tritium markiertes Estronsulfat ( $\left[{ }^{3} \mathrm{H}\right]$ Estronsulfat) in einer Endkonzentration von $0,5 \mu \mathrm{M}$ als Substrat für den pOAT1 eingesetzt. Alle anderen Versuchsbedingungen wurden nicht verändert. Die Ergebnisse sind in Abbildung 3.18 dargestellt. Verglichen mit untransfizierten ok-Zellen konnte für pOAT1transfizierte ok-Zellen kein $\left[{ }^{3} \mathrm{H}\right]$ Estronsulfat-Transport gemessen werden. Die Kontrollzellen 
zeigten im Gegenteil eine höhere $\left[{ }^{3} \mathrm{H}\right]$ Estronsulfat-Aufnahme gegenüber den transfizierten Zellen $(135,1 \pm 7,4$ versus $100 \pm 2,1 \%)$.

\section{pOAT1-vermittelte $\left[{ }^{3} \mathrm{H}\right]$ Estronsulfat-Aufnahme in ok-Zellen}

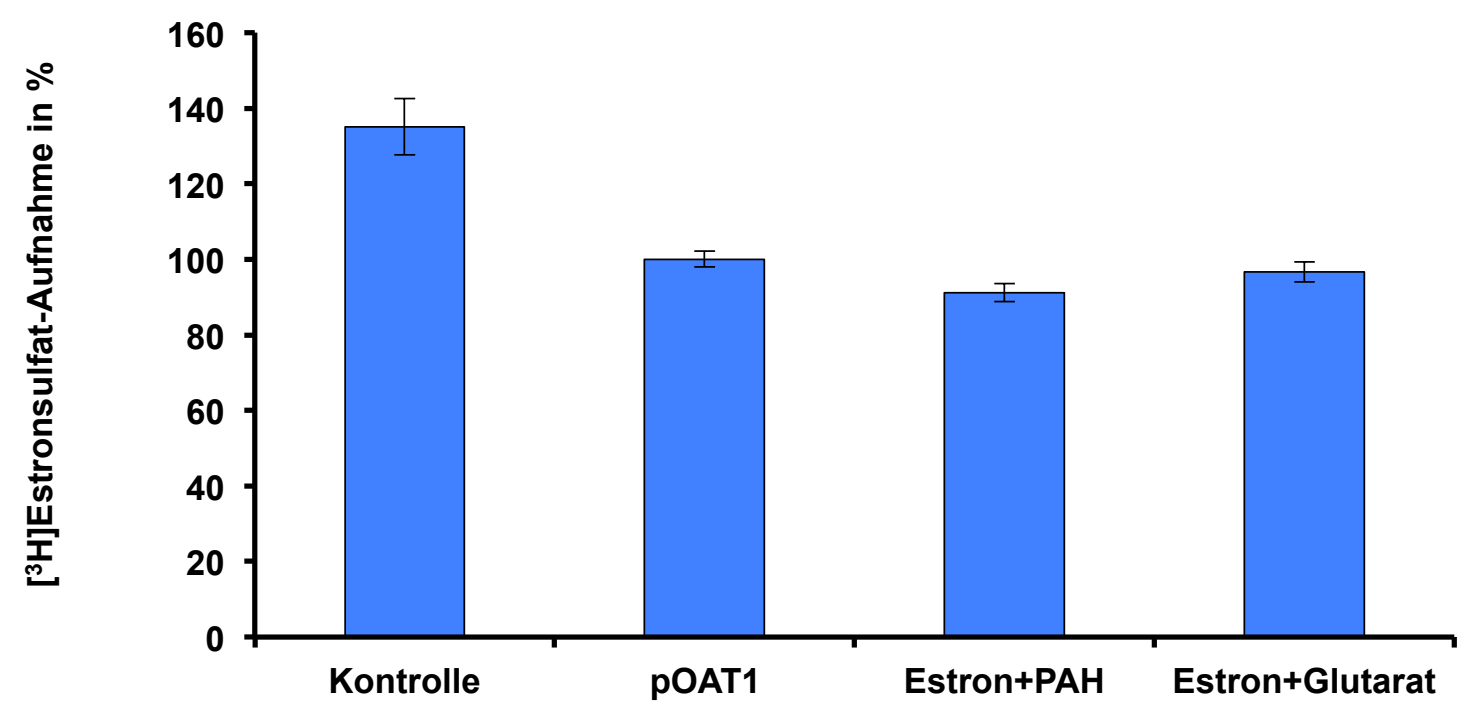

Abbildung 3.18: pOAT1-vermittelte $\left[{ }^{3} \mathrm{H}\right]$ Estronsulfat-Aufnahme in ok-Zellen und dessen Hemmung durch PAH und Glutarat. In 24-Well-Platten kultivierte ok-Zellen wurden für 15 min mit $0,5 \mu \mathrm{M}\left[{ }^{3} \mathrm{H}\right]$ Estronsulfat enthaltender RingerLösung inkubiert. Zusätzlich erfolgte die Zugabe von unmarkiertem PAH (1 mM) und Glutarat $(1 \mathrm{mM})$. Als Kontrolle dienten nicht transfizierte ok-Zellen. Dargestellt sind die Mittelwerte \pm SEM von 3 voneinander unabhängigen Versuchen mit je 3 Well pro Bedingung in Prozent zur ungehemmten Aufnahme (100\%). 


\section{Diskussion}

In dieser Arbeit sollte zunächst eine cDNA-Bank aus ok-Zellen erstellt werden, um im Weiteren einzelne OAT klonieren zu können. Die OAT sollten im Einzelnen funktionell charakterisiert werden, um sie mit Transportdaten aus nativen Nierenzellenmembranen vergleichen zu können. Es sollte zum einen geklärt werden, ob die OAT in der nativen Membran und exprimiert in Zellkulturen vergleichbare Transportcharakteristika besitzen. Zum anderen sollte auf diese weise aufgeschlüsselt werden, welchen Anteil die verschiedenen OAT(1-3) der basolateralen Membran an der Aufnahme von Anionen über die basolaterale Membran haben bzw. welche Substanzen von welchem OAT als Substrat verwendet werden.

Auf diese Weise sollte überprüft werden, ob sich ok-Zellen als Modell des proximalen Tubulus für Transportversuche im Hinblick auf die OAT eignen, um z. B. pharmakologische Untersuchungen durchzuführen.

Wie in Abschnitt 3.3 beschrieben und in Abschnitt 4.1 diskutiert, gelang es nicht, einen funktionsfähigen OAT1-Klon aus der ok-cDNA-Bank zu isolieren, sodass mit der gleichen Fragestellung parallel eine cDNA-Bank aus Gewebe von Schweinenierenrinden erstellt wurde. Das Schwein wurde ausgewählt, da es ein ebenfalls weit verbreitetes und gut verfügbares Modellsystem ist und dementsprechend viele funktionelle Studien an Membranvesikeln oder Tubuli durchgeführt wurden. Es stehen auch viele Daten für vergleichende Studien zur Verfügung.

\section{1 cDNA-Bank aus ok-Zellen und Schweinenierengewebe}

Zur Klonierung des OAT1 wurde eine cDNA-Bank in Form einer $\lambda Z A P-c D N A-P h a g e n-B a n k$ (Stratagene, La Jolla, CA, USA) aus ok-Zellen und Schweinenierenrindengewebe angelegt. Es wurde ein System aufgebaut, das bei Bedarf in weiteren Studien auch zur Klonierung anderer OAT-Subtypen verwendet werden kann. Die cDNA-Banken enthalten cDNAFragmente, die größer als $1 \mathrm{~kb}$ sind. Betrachtet man die Größe der bekannten OAT1, die alle eine Länge von ca. $2 \mathrm{~kb}$ besitzen, sollten die gesuchten Klone sicher enthalten sein (Sweet et al. 1997; mOAT1: 2161 bp, Lopez-Nieto et al. 1997).

Die Konzentration der Banken liegt für die ok-cDNA-Bank bei 4,57 x $10^{5} \mathrm{pfu} / \mu 1$ und für die pk-cDNA-Bank bei $1,3 \times 10^{6} \mathrm{pfu} / \mu 1$. Laut Hersteller der $\lambda$ ZAP-cDNA-Phagen-Bank ist eine Konzentration der Primärbank von $10^{6}$ bis $10^{8} \mathrm{pfu} / \mathrm{ml}$ zu erwarten. Die Konzentration der pk- 
cDNA-Bank liegt in dem vom Hersteller angegebenen Bereich, wohingegen die ok-cDNA die zu erwartende Konzentration unterschreitet.

Beide Banken wurden mit dem Prinzip der Homologieklonierung nach dem OAT1 durchsucht. Hierfür wurde ein ${ }^{32} \mathrm{P}$-markiertes und 970 bp langes DNA Fragment des Kaninchen OAT1 (rbOAT1) als Sonde verwendet (Bahn et al. 2002). Die Sequenz wurde anhand eines Sequenzaligments mit allen bekannten OAT1 ausgewählt und entspricht einer hochkonservierten Region, mit der die größtmögliche Wahrscheinlichkeit zu einer Homologie der gesuchten okOAT1 bzw. pOAT1 erreicht werden sollte. Kusukara et al. (1999) klonierten auf ähnliche Weise den rOAT3 aus einer Rattennieren-cDNA-Bank. Dies geschah mit einer Sonde, die aus konservierten Regionen des OAT1, OAT2 und OCT1 der Ratte generiert wurde.

\subsection{1 okOAT1}

Mithilfe der Homologieklonierung konnte aus der ok-cDNA ein 1680 bp langer Klon isoliert werden, der für 490 Aminosäuren codiert (Accession Nr. AJ308236). Der Sequenzvergleich mit OAT1 anderer Säugetierspezies zeigt eine sehr hohe Übereinstimmung (Mensch [hOAT11] $88 \%$ [Reid et al. 1998], Kaninchen $86 \%$ [Bahn et al. 2002], Ratte $82 \%$ [Sweet et al. 1997], Maus 88 \% [Lopez-Nieto et al. 1997]), sodass der isolierte Klon dem OAT1 aus okZellen entspricht.

Allerdings zeigt dieser Klon eine 5'Deletion, z. B. im Vergleich zum hOAT1-1 (2171 bp; 563AA; Reid et al. 1998), von einer Länge von 491 bp oder entsprechend 73 Aminosäuren. Diese Deletion ließ sich bei allen isolierten Klonen des ersten Screening-Durchgangs identifizieren. Auch ein erneutes Screening der cDNA-Bank erbrachte lediglich den unvollständigen Klon.

Es muss also davon ausgegangen werden, dass bereits bei der Konstruktion der cDNA-Bank im Ausgangsmaterial (mRNA) oder bei der Synthese der cDNA diese Deletion entstand und die gesamte ok-cDNA-Bank aus diesem Grund tatsächlich nur den unvollständigen Klon des OAT1 enthält. Deshalb wurde darauf verzichtet, die Bank ein drittes Mal zu screenen, um einen vollständigen Klon zu erhalten. Die Ursache für die Deletion bleibt letztlich unklar. Denkbar wäre eine Verkürzung der mRNA während der Erstellung der cDNA-Bank durch RNasen. 


\subsection{2 pOAT1 und pOAT1A}

Aus der cDNA-Bank des Schweins wurden zwei Klone isoliert, deren Nukleinsäuren eine Länge von 2126 bp bzw. 1895 bp besitzen. Diese Klone codieren für ein Protein mit 547 bzw. 533 Aminosäuren und wurden aufgrund der hohen Sequenzhomologie zu anderen OAT1 als pOAT1 und pOAT1A bezeichnet und unter den Accession-Nummern AJ308234 bzw. AJ30825 in der EMBL-Sequenz-Datenbank abgelegt. Die höchste Sequenzhomologie besteht dabei zum hOAT1 (563 AS) mit 89 \% (Reid et al. 1998), vernachlässigt man den unvollständigen okOAT1, dessen Homologie bei 99 \% liegt. Ebenfalls hohe Homologien bestehen zum OAT1 des Kaninchens (551 AS, 87 \%; Bahn et al. 2002), der Ratte (551 AS, 83 \%; Sweet et al. 1997; Sekine et al. 1997) und der Maus (545 AS, 81\%; Lopez-Nieto et al. 1997). Diese hohe Verwandtschaft des pOAT1 zum humanen OAT1 lässt das Schwein als geeignetes Modell für zukünftige Untersuchungen des OAT erscheinen.

Im Vergleich zu pOAT1 zeigt pOAT1A im 3. Exon eine Deletion von 42 Nukleotiden. Diese führt nicht zu einer Verschiebung des Leserahmens, aber zum Verlust von 14 Aminosäuren in der 4. Transmembrandomäne und bildet somit eine Splice-Variante.

Splice-Varianten des OAT1 sind auch vom hOAT1 bekannt, die als hOAT1-1 bis hOAT1-4 bezeichnet werden (Bahn et al. 2004). Diese haben jedoch eine Deletion in Exon 9 mit einer Länge von 39 bis 132 bp und sind strukturell nicht äquivalent zum pOAT1A. Auf die funktionellen Eigenschaften der verschiedenen Splice-Varianten wird in Abschnitt 4.2.1 eingegangen.

\subsection{Funktionelle Grundcharakterisierung der klonierten OAT1}

\subsubsection{Testung der Funktionalität in Xenopus laevis-Oozyten aller Klone}

Die Funktionalität der OAT wurde zunächst in Oozyten, einem gut etablierten Expressionssystem überprüft. Hierfür wurde cRNA aus den entsprechenden Plasmiden in Oozyten injiziert und mithilfe von radioaktiv markiertem PAH $\left(\left[{ }^{3} \mathrm{H}\right] \mathrm{PAH}\right)$ die Aufnahme dessen im Vergleich zu wasserinjizierten Oozyten als Kontrolle gemessen (siehe Abschnitt 2.9). Es zeigte sich, dass weder der okOAT1 noch der pOAT1A eine erhöhte Aufnahme von PAH gegenüber der Kontrolle aufwiesen und kein aktiver Transport in die Oozyten stattfand. Im Gegensatz dazu zeigte sich bei den mit dem pOAT1-injizierten Oozyten eine um den Faktor 11,6 erhöhte $\left[{ }^{3} \mathrm{H}\right] \mathrm{PAH}-A$ ufnahme gegenüber der Kontrolle. Des Weiteren konnte eine komplette Hemmung der Aufnahme durch Probenecid und Glutarat gemessen werden. Die gleichen Eigen- 
schaften wurden z. B. für den hOAT1 exprimiert in ok-Zellen von Motojima et al. (2002) beschrieben. Weitere typische Eigenschaften der OAT1, die sich auf den Mechanismus als Antiporter von organischen Anionen im Austausch gegen $\alpha$-Ketoglutarat begründen, sind die trans-Stimulation und cis-Inhibition der PAH-Aufnahme durch $\alpha$-Ketoglutarat, wie sie auch für den pOAT1 gezeigt werden konnte (siehe Abschnitte 3.4.3.3 und 3.4.3.4, Abschnitt 4.2.4). Eine Übersicht dieser Eckpunkte der OAT1 geben Burckhardt und Burckhardt (2003). Zusammenfassend zeigte unser pOAT1 neben den bereits oben beschriebenen strukturellen Ähnlichkeiten auch typische funktionelle Charaktereigenschaften im Vergleich zu den bekannten OAT1 der anderen Spezies.

Der Funktionsverlust beim okOAT1 lässt sich sicherlich durch den großen fehlenden 5'Bereich erklären, da hier kein vollständiges Protein exprimiert werden kann. Hingegen ist die Ursache beim pOAT1A unklar. Denkbar wäre der Verlust einer Substratbindungsstelle in der 4. TMD oder ein fehlender Einbau des Proteins in die Zellmembran. Um die zuletzt genannte Möglichkeit untersuchen zu können, wären z. B. Immunfluoreszenzuntersuchungen zur Lokalisation des Proteins innerhalb der Zelle notwendig.

Dieses wurde für die verschiedenen Splice-Varianten des hOAT1 durch Bahn et al. (2004) durchgeführt. Bahn et al. (2004) konnten nachweisen, dass alle Varianten zu einem Protein exprimiert wurden und diese auch alle, inklusive die funktionslosen Formen (hOAT1-3, hOAT1-4), in der Zellmembran lokalisiert waren. Es ist noch unklar, worin sich der Funktionsverlust dieser Splice-Varianten im Gegensatz zu den transportierenden hOAT1-1 und hOAT12 begründet.

Ebenfalls aus der SLC22-Familie sind beim hOAT2 zwei Splice-Varianten beschrieben worden, die sich lediglich um 2 Aminosäuren unterscheiden (Cropp et al. 2008). Ähnlich zum pOAT1 oder hOAT1 wird auch hier der komplette Funktionsverlust, in diesem Fall der Transport von cGMP, durch eine der Splice-Varianten gezeigt.

Die Funktion der nicht transportierenden Splice-Varianten ist nicht bekannt und eine Aufgabe weiterer Untersuchungen.

Für andere Transportproteine sind verschiedene Effekte als Folge des Splicens dokumentiert worden. Beim NBC1 besteht eine unterschiedliche Organverteilung (Niere, Pankreas und Herz) je nach Splice-Variante (Soleimani und Burnham 2001). Hingegen beschreiben Plata et al. (2001) eine Änderung der Substratspezifität für den $\mathrm{Na}^{+}-\mathrm{K}^{+}-\mathrm{Cl}^{-}-$Kotransporter. Des Weiteren wurden wie z. B. für den NaPi-2 der Ratte über gegenseitige regulatorische Effekte der Splice-Varianten berichtet (Tatsumi et al. 1998). 


\subsubsection{Funktionelle Grundcharakterisierung des pOAT1 in unterschiedlichen Expressi- onssystemen}

Der pOAT1 wurde zunächst in ok-Zellen und CHO-Zellen transfiziert und die PAHAufnahme untersucht, um die Expressionseffizienz unterschiedlich zur Verfügung stehender Zellkultursysteme zu untersuchen. Bei beiden Zellinien handelt es sich um einschichtig epithelial wachsende Zelllinien.

Wie in Abschnitt 3.4.2 dargestellt, konnte in beiden Zelllinien ein durch den pOAT1vermittelter Transport von $\left[{ }^{3} \mathrm{H}\right] \mathrm{PAH}$ in die Zelle nachgewiesen werden. Dieser war durch unmarkiertes PAH (1mM) ungefähr auf die Hälfte hemmbar, sodass gezeigt werden konnte, dass die Aufnahme von $\left[{ }^{3} \mathrm{H}\right] \mathrm{PAH}$ ein spezifischer und sättigbarer Prozess ist.

Unterschiede in den beiden Zelllinien bestanden in der Transportrate gegenüber der Kontrolle. Während sich in den ok-Zellen eine 16-fach höhere pOAT1-vermittelte PAH-Aufnahme zeigte, lag sie in CHO-Zellen nur bei einem Faktor von 4,3 unter ansonsten gleichen experimentellen Bedingungen wie Transportzeit und eingesetzter DNA-Menge zur Transfektion. Damit liegt die Transportrate der transfizierten ok-Zellen noch über der von Oozyten (11,6-fach) und erweist sich als effektives Expressionsystem für den pOAT1. Als Ursache lässt sich die endogene Ausstattung z. B. durch renal spezifische Transkriptionsfaktoren oder Regulatoren wie Kinasen der Nierenzelllinie vermuten, die auch unter physiologischen Bedingungen den endogenen OAT1 exprimiert. Es lässt sich durch den Vergleich mit den nicht transfizierten Kontrollzellen ausschließen, dass es sich bei dem gemessenen Uptake nicht nur um den Transport durch den endogenen okOAT handelt.

Zusätzlich wurde Fluorescein, ein Anion, das ebenfalls vom OAT1 transportiert wird (Cihlar et al. 2000) als alternatives Substrat $\mathrm{zu}\left[{ }^{3} \mathrm{H}\right] \mathrm{PAH}$ in beiden Zelllinien getestet, um gegebenenfalls auf die aufwendigen Versuche mit radioaktiv markierten Substraten verzichten zu können,. Die Aufnahme lag hier jedoch in ok-Zellen nur um den Faktor 5,6 bzw. in CHO-Zellen um den Faktor 3,1 über dem von nicht transfizierten Zellen. Aufgrund des geringeren overshoot und der besseren Vergleichbarkeit mit anderen Studien (z. B. Sweet et al. 1997, Hosoyamada et al. 1999, Chilar et al. 1999), in denen hauptsächlich $\left[{ }^{3} \mathrm{H}\right] \mathrm{PAH}$ als Testsubstrat verwendet wurde, führten wir die funktionelle Grundcharakterisierung des pOAT1 ebenfalls mit $\left[{ }^{3} \mathrm{H}\right] \mathrm{PAH}$ fort. 


\subsubsection{Konzentrationsabhängige pOAT1-vermittelte PAH-Aufnahme}

Ein Charaktaristikum von Transportvorgängen ist die Michaelis-Menten-Konstante (KmWert), die hauptsächlich in der Enzymkinetik eingesetzt wird. Die Konstante beschreibt die Substratkonzentration, bei der die halbmaximale Transportgeschwindigkeit des Transporters erreicht und als Maß für die Substrataffinität des Transportproteins benutzt wird. Je kleiner der Km-Wert ist, desto höher ist die Affinität zum Substrat.

Vor der eigentlichen Km-Wert-Bestimmung des pOAT1 wurde zunächst die optimale Transportzeit für transfizierte ok-Zellen untersucht. Die Messungen müssen zu einem Zeitpunkt stattfinden, zu dem sich ein näherungsweise linearer Anstieg der PAH-Aufnahme darstellt, um die Michaelis-Menten-Kinetik anwenden zu können (siehe Abschnitt 3.4.3.1). Zu diesem Zeitpunkt ist der theoretische Efflux zu vernachlässigen und der Km-Wert kann nach der modifizierten Michaelis-Menten-Gleichung bestimmt werden.

Für den pOAT1 stellt sich dieser Bereich näherungsweise bis zu einer Zeit von 2 Minuten dar. Anschließend ist eine Sättigung des Transporters erreicht. Aus diesem Grund wurde die Transportzeit für alle folgenden Versuche auf 2 Minuten festgelegt. Von kürzeren Versuchszeiten ist aus Gründen der Praktikabilität im C-Labor Abstand genommen worden.

Der Km-Wert des pOAT1 beträgt exprimiert in Oozyten 3,75 $\pm 1,6 \mu \mathrm{M}$ und exprimiert in okZellen $8,54 \pm 1,2 \mu \mathrm{M}$. Damit liegt der Km-Wert des pOAT1 nahe dem des hOAT1, der in Oozyten mit 9,3 $\pm 1,0 \mu \mathrm{M}$ (Hosoyamada et al. 1999), 3,9 $\pm 1,3 \mu \mathrm{M}$ (Ilsinger et al. 2001), 4,0 \pm 1,3 $\mu \mathrm{M}$ (Chilar et al. 1999) bzw. mit $22 \mu \mathrm{M}$ (Motojima et al. 2002) in ok-Zellen in der Literatur angegeben wird.

Die Affinität des OAT1 zu PAH der Ratte $(11-70 \mu \mathrm{M})$, Maus (37-162 $\mu \mathrm{M})$, Kaninchen $(18 \mu \mathrm{M})$ und Winterflunder $(21-58 \mu \mathrm{M})$ sind in einer Reihe von Studien kleiner als die von pOAT1 bzw. hOAT1. Eine Übersicht zu den bekannten und oben angegebenen Km-Werten ist in Burckhardt und Burckhardt (2003) aufgelistet. Ob sich die Affinitäten tatsächlich signifikant voneinander unterscheiden oder versuchsbedingt sind, lässt sich nur vermuten. Es gibt jedoch Hinweise, dass versuchsbedingt sind wenn man z. B. die Variabilität des Km-Wertes des rOAT1 betrachtet. Hier zeigt sich eine Abweichung der Km-Werte um den Faktor 7 trotz des gleichen Expressionssystems in vier Arbeitsgruppen (Pombrioet al. 2001; Sekine et al. 1997; Uwai et al. 2000; Sweet et al. 1997). Dementsprechend lässt sich auch zu den unterschiedlichen Km-Werten des pOAT1 in den beiden Expressionssystemen der Oozyten bzw. ok-Zellen keine eindeutige Aussage treffen, zumal die Km-Werte nahe beieinanderliegen. 
Vergleicht man die Km-Werte für PAH des pOAT1 in Oozyten und ok-Zellen mit dem KmWert gemessen in BLMV des Schweins, der von Braun (2006) mit $103 \pm 6 \mu \mathrm{M}$ angegeben wird, liegt dieser deutlich höher als für den isolierten pOAT1. Braun postuliert eine veränderte Regulation in den Vesikeln gegenüber den transfizierten Zellen bzw. sieht die PAHAufnahme in den BLMV als Summe mehrer Transporter an, von denen mindestens einer einen hohen Km-Wert haben müsse.

\subsection{4 trans-Stimulation der pOAT1-vermittelten PAH-Aufnahme}

Es handelt sich beim OAT1 (Shimada et al. 1987; Burckhardt und Burckhardt 2003) um einen tertiär aktiven Antiporter von Anionen im Austausch mit $\alpha$-Ketoglutarat bzw. Dicarboxylaten. Daher sollte eine Vorbeladung der transfizierten ok-Zellen mit Glutarat, einer nicht metabolisierten Vorstufe von $\alpha$-Ketoglutarat, zu einer gesteigerten Aufnahme von PAH führen (siehe Abschnitt 3.4.3.4). Wir fanden erwartungsgemäß eine Steigerung der PAH-Aufnahme in Abhängigkeit von der Konzentration des Glutarats auf $142 \%$ bei $0,1 \mathrm{mM}$ bzw. auf $211 \%$ bei 1 mM im Vorbeladungspuffer. Dieses Ergebnis weist darauf hin, dass auch der pOAT1 als Antiporter arbeitet. Im Vergleich mit den Daten aus BLMV des Schweins liegt diese Stimulierung näherungsweise in dem Bereich von Werner und Roch-Ramel (1991), die eine Steigerung auf $158 \%$ bei einer 2-Oxoglutaratvorbeladung mit $0,1 \mathrm{mM}$ beschrieben. Es scheint der OAT1 der Haupttransporter für die PAH-Aufnahme über die basolaterale Zellmembran in proximalen Tubuluszellen des Schweins zu sein.

Weitere mögliche Transporter der basolateralen PAH-Aufnahme wären der pOAT2 und pOAT3. Die genaue Funktion des OAT2 ist noch nicht geklärt und er konnte bislang auch nur beim Menschen in der basolateralen Membran nachgewiesen werden (Enomoto et al. 2002b), wohingegen er bei Ratten und Mäusen in der apikalen Membran lokalisiert wurde (Kojima et al. 2002).

In den Arbeiten von Hagos et al. (2005) und Braun (2006) konnte der pOAT3 kloniert werden. Es zeigte sich, dass der pOAT3 eine nur sehr geringe Affinität zu PAH besitzt und vor allem Steroidhormone und Urat transportiert (siehe Abschnitt 4.2.7). Der exakte Km-Wert für PAH beim pOAT3 ist bislang allerdings nicht bestimmt worden. Betrachtet man jedoch analog die Km-Werte des hOAT1 (3,9-9,3 $\mu$ M; Race et al. 1999, Islinger et al. 2001, Cihlar et al. 1999) und hOAT3 (87 $\mu \mathrm{M}$; Cha et al. 2001) für PAH in Oozyten, wobei der Km-Wert für den 
hOAT3 verhältnismäßig hoch ist, kann der pOAT1 tatsächlich als vornehmlicher Transporter für PAH in der basolateralen Membran des Schweins angesehen werden.

\subsubsection{Hemmstoffprofil der pOAT1-vermittelten PAH-Aufnahme}

Für die Chararkterisierung des pOAT1 in ok-Zellen wurde ein Hemmstoffprofil erstellt, um es mit Daten aus der BMVL des Schweins und OAT1 anderer Spezies vergleichen zu können. Ziel dieser Untersuchungen ist es, den kumulativen Uptake von Anionen durch mehrere in der basolateralen Membran lokalisierten Transportern aus Vesikeln den einzelnen klonierten OAT zuordnen zu können.

Allgemein gibt es drei Mechanismen, über die eine Substanz die Aufnahme von PAH hemmen kann. Entweder diese Substanz wird selbst transportiert und konkurriert mit PAH oder es kommt zu einer kompetitiven bzw. nicht kompetitiven Hemmung des Transportproteins. In den Untersuchungen zeigte sich eine deutliche Hemmung der PAH-Aufnahme durch alle getesteten Substanzen (siehe Abbildung 3.11). Probenecid, ein bekannter Inhibitor des OAT1, führte zu einem kompletten Transportverlust des pOAT1. Darüber hinaus lag die PAHAufnahme in den mit Probenecid gehemmten ok-Zellen niedriger als in den nicht transfizierten Kontrollzellen, was auf eine zusätzliche Hemmung des endogenen okOAT1 hinweist. für OAT1 anderer Spezies wie den rOAT1 (Sweet et al. 1997) oder hOAT1 (Hosoyamada et al. 1999) konnte auch gezeigt werden, dass Probenecid ein hochaffiner Inhibitor ist. Chilar und Ho 2000 geben die $\mathrm{IC}_{50}$ für Probenecid beim hOAT1 mit 6,2 $\mu \mathrm{M}$ an.

Ähnliches gilt für Glutarat, das in der Konzentration von $1 \mathrm{mM}$ und einer Uptakezeit von 2 min die PAH-Aufnahme komplett hemmt. Erklärt wird dies durch den Mechanismus, dass der pOAT1 als Antiporter eines organischen Anions gegen $\alpha$-Ketoglutarat fungiert, sodass hohe extrazelluläre Konzentrationen zu einer cis-Inhibition führen und im Gegensatz zur trans-Stimulation durch Glutarat stehen.

In ihrer Stärke als Inhibitoren folgen dann Urat und Pyrazionat (siehe Abbildung 3.13). Dieses Ergebnis deckt sich mit den Angaben von Werner und Roch-Ramel (1991) zum Hemmstoffprofil der PAH-Aufnahme in BLMV des Schweins und zu den Daten von Braun (2006). Zusammengefasst wird die PAH-Aufnahme in BLMV des Schweins und durch den isolierten pOAT1 in ok-Zellen durch die gleichen Substanzen und in ähnlicher Größenordnung gehemmt. Dieses Ergebnis bekräftigt die Aussage, dass die PAH-Aufnahme in der basolateralen Membran des proximalen Tubulus vor allem durch den OAT1 vermittelt wird. 
TEA wurde als ein typisches Kation der OCT auf die Substratspezifität des pOAT1 getestet, da bekannt ist, dass organische Anionentransporter auch mit Kationen interagieren (Sweet et al. 1997). Hierbei fand sich, dass TEA die PAH-Aufnahme signifikant hemmt, also mit dem pOAT1 in Wechselwirkung tritt. $\mathrm{Zu}$ einem ähnlichen Ergebnis gelangten auch Sweet et al. (1997) für den rOAT1, der durch hohe TEA-Konzentrationen diskret gehemmt wurde. Hingegen konnten Motojima et al. (2002) keinen Einfluss von TEA auf den hOAT1 in okZellen feststellen, ebenso wie Chilar et al. 1999 für den hOAT1 in Oozyten. Zusammenfassend scheint TEA kein hochaffines Substrat für die OAT1 zu sein.

Als weiteren Nachweis für eine Interaktion von Kationen mit dem OAT beschreiben Ahn et al. (2009) in diesem Fall u. a. die Reaktion des mOAT1, mOAT3 und mOAT6 mit Cimetidin. Cimetidin ist ein H2-Rezeptor-Antagonist und wird vor allem durch den OCT2 transportiert (Burckhardt BC et al. 2002). Bei allen drei Transportern konnte eine Hemmung der Fluorescein-Aufnahme durch Cimetidin in Oozyten festgestellt werden. Der mOAT3 transportierte im Gegensatz zum mOAT1 und mOAT6 das Kation Cimetidin sogar aktiv in transfizierte Oozyten. Hierfür lag der Km-Wert bei $105 \pm 28 \mu \mathrm{M}$.

Ein aktiver Transport mit höherer Affinität wurde auch für den hOAT3 (Km $57 \mu \mathrm{M}$, Cha et al. 2001) und rOAT3 (Km $40 \mu \mathrm{M}$, Kusuhara et al. 1999) beschrieben. Anders als bei der Maus transportieren der hOAT1 und fROAT1 das Cimetidin ebenfalls aktiv (Burckhardt et al. 2002).

\subsubsection{Chloridabhängigkeit der pOAT1-vermittelten PAH- und Urat-Aufnahme}

In der bereits zitierten Studie von Werner und Roch-Ramel (1991) mit BLMV vom Schwein wurden eine chloridabhängige PAH-Aufnahme und eine chloridunabhängige Urat-Aufnahme beschrieben.

In Versuchen mit chloridfreiem Transportmedium, in denen sämtliches Chlorid durch Glukonat ersetzt wurde, konnten wir zeigen, dass die PAH-Aufnahme durch den pOAT1 chloridabhänig ist. Der Austausch des Chlorids durch Glukonat führte zu einem kompletten Funktionsverlust des Transporters (siehe Abschnitt 3.4.3.5).

Um den von Werner und Roch-Ramel (1991) beschriebenen chloridunabhängigen UratTransport weiter zu untersuchen, sollte zunächst differenziert werden, ob die Hemmung der PAH-Aufnahme des pOAT1 durch Urat ein kompetitiver Vorgang ist oder ein aktiv konkurrierender Transport von Urat vorliegt. In Versuchen mit radioaktiv markiertem Urat 
$\left(\left[{ }^{14} \mathrm{C}\right]\right.$ Urat $)$ stellte sich heraus, dass der pOAT1, transfiziert in ok-Zellen, Urat nicht aktiv transportiert. Damit ist der pOAT1 nicht der von Werner und Roch-Ramel (1991) postulierte Urat-Transporter in BLMV.

Fasst man die Daten von Hagos et al. (2005) und Braun (2006) zusammen, die nachweisen konnten, dass der pOAT3 neben Steroidhormonen auch Urat chloridunabhängig aktiv transportiert, lassen sich die von Werner und Roch-Ramel (1991) beschriebenen Eigenschaften von BMLV des Schweins nun einzelnen Transportern zuordnen und decken sich mit unseren Ergebnissen. Die chloridabhängige PAH-Aufnahme ist pOAT1-vermittelt, während die chloridunabhängige Urat-Aufnahme dem pOAT3 zuzuordnen ist. Mit dieser Arbeit konnten erstmals die bereits in den 1990er Jahren postulierten Transporter zutreffend charakterisiert und zugeordnet werden.

Den Mechanismus der chloridabhängigen PAH-Aufnahme durch den OAT1 untersuchten Rizwan et al. (2007) in späteren Studien in Kombination mit Mutationsanalysen genauer. Die Abwesenheit von Chlorid im Transportmedium führte beim hOAT1 nicht zu einer Veränderung des $\mathrm{Km}-\mathrm{Werts}$ für $\mathrm{PAH}$, sondern verringerte die maximale Transportgeschwindigkeit $\left(\mathrm{V}_{\max }\right)$ und identifizierte die bei diesem Prozess beteiligten Aminosäuren. Mit Ergebnissen von Pritchard (1988), der berichtet, dass Chlorid nicht über die BMLV transportiert wird, kommt Rizwan zu dem Schluss, dass Chlorid am Protein bindet und für die Substrattranslokation eine Rolle spielt. Zur gleichen Aussage kommen Ueo et al. (2007), die ebenfalls die Chloridabhängigkeit des hOAT1 und zusätzlich des hOAT3 untersuchten. Hierbei fand sich im Gegensatz zur chloridunabhängigen Urat-Aufnahme des pOAT3 eine Chloridabhängigkeit der Estronsulfat-, PAH- und Cefotiam-Aufnahme durch den hOAT3. Eine Testung der UratAufnahme und deren Chloridabhängigkeit durch den hOAT3 sind nicht erfolgt. Die Diskrepanz zwischen pOAT3 und hOAT3 lässt sich aktuell nicht erklären. Die Frage bleibt offen, ob es sich um einen Speziesunterschied handelt oder ob die Substrate in unterschiedlicher Weise chloridabhängig sind. Es erscheint wahrscheinlicher, dass es ich um einen Speziesunterschied handelt, da Ueo et al. (2007) die Chloridabhängigkeit des hOAT3 in gleicher Weise für eine Reihe von Substraten belegen konnten. Diese These wäre in weiteren Studien zu untersuchen. 


\subsubsection{Steroidhormone}

Als eine Gruppe von endogenen Substraten wurden Steroidhormone und ihre Interaktionen mit dem pOAT1 untersucht. Wir konnten eine starke cis-Inhibition der PAH-Aufnahme durch den pOAT1 für alle drei getesteten Steroide (DHEA, DHEA-SO 4 und Estron-SO ${ }_{4}$ ) feststellen, wobei die sulfatierten Substrate eine stärkere Inhibition zeigten (siehe Abbildung 3.16). Die Hemmung der PAH-Aufnahme durch die sulfatierten Steroide zeigte sich sogar signifikant $(p<0,00002)$ in den nicht transfizierten Kontrollzellen, was auf eine Hemmung des endogenen okOAT1 in der Zelllinie schließen lässt. Die $\mathrm{IC}_{50}$ für $\mathrm{DHEA}-\mathrm{SO}_{4}$ lag bei 116,5 $\pm 3,5 \mu \mathrm{M}$ und für Estron- $\mathrm{SO}_{4}$ bei 113,2 \pm 4,9 $\mu \mathrm{M}$. Damit war jedoch wie beim Urat nicht bewiesen, dass es sich bei der Hemmung um einen aktiv konkurrierenden Transport zwischen PAH und Steroidhormon handelte, sodass wir dieses mit Tritium-markierte Estronsulfat ([ $\left.{ }^{3} \mathrm{H}\right]$ Estronsulfat) überprüften. Es konnte keine aktive pOAT1-vermittelte Estronsulfat-Aufnahme festgestellt werden (siehe Abbildung 3.18).

Im Gegensatz hierzu konnten Hagos et al. (2005) für den pOAT3 nachweisen, dass es sich um einen hochaffinen Transporter für Steroidhormone handelt. Für $\left[{ }^{3} \mathrm{H}\right]$ Estronsulfat wird ein KmWert von 7,8 $\pm 1,3 \mu \mathrm{M}$ in Oozyten angegeben. Analoge Ergebnisse liegen für den hOAT3 und hOAT1 vor. So konnten z. B. Cha et al. (2001) den hochaffinen $\left[{ }^{3} \mathrm{H}\right]$ EstronsulfatTransport für den hOAT3 mit einem Km-Wert von 3,1 $\mu \mathrm{M}$ zeigen, während der hOAT1 Estronsulfat ebenfalls nicht transportiert (Ueo et al. 2007). 


\subsection{8 Übersicht der pOAT1-Eigenschaften im Vergleich mit pOAT3 und BLMV}

In Tabelle 4.1 werden die Daten des pOAT1 zusammenfassend den Daten zum pOAT3 (Braun 2006) und BLMV des Schweins (Braun 2006, Werner und Roch-Ramel 1991) gegenübergestellt.

\begin{tabular}{|c|c|c|c|}
\hline Substrate & pOAT1 & pOAT3 & BLMV \\
\hline cis-Inhibition & $\begin{array}{c}\left.{ }^{3} \mathrm{H}\right] \text { PAH-Aufnahme } \\
\text { in } \%\end{array}$ & $\begin{array}{c}\left.{ }^{3} \mathrm{H}\right] \text { Estrone-SO } \\
\text { Aufnahme in } \%\end{array}$ & $\begin{array}{c}\left.{ }^{3} \mathrm{H}\right] \text { PAH-Aufnahme } \\
\text { in } \%\end{array}$ \\
\hline Kontrolle & 100,00 & 100,00 & 100,00 \\
\hline PAH & 15,12 & 45,4 & 17,5 \\
\hline Probenecid & 4,8 & 27,2 & 0,5 \\
\hline Pyrazinoat & 40,5 & $\mathrm{Nt}$ & $\mathrm{nt}$ \\
\hline Glutarat & 5,5 & $\mathrm{Nt}$ & $\mathrm{nt}$ \\
\hline TEA & 81,0 & $\mathrm{Nt}$ & $\mathrm{nt}$ \\
\hline Urat & 20,6 & 32,1 & 47,3 \\
\hline Estronsulfat & 16,0 & $\mathrm{Nt}$ & 0,5 \\
\hline DHEA & 50,7 & $\mathrm{Nt}$ & $\mathrm{Nt}$ \\
\hline DHEA- $\mathrm{SO}_{4}$ & 14,3 & $\mathrm{Nt}$ & $\mathrm{Nt}$ \\
\hline Chloridabhängigkeit & $\mathrm{Ja}$ & Nein & Substratabhängig \\
\hline$\left[{ }^{14} \mathrm{C}\right]$ Urat-Aufnahme in $\%$ & Nein & 154 & $\mathrm{Ja}\left(\mathrm{Cl}^{-}\right.$-unabhängig)* \\
\hline$\left[{ }^{3} \mathrm{H}\right] \mathrm{PAH}-\mathrm{Aufnahme}$ in $\%$ & 1609 & 53 & $\mathrm{Ja}\left(\mathrm{Cl}^{-}\right.$-abhängig)* \\
\hline$\left[{ }^{3} \mathrm{H}\right]$ Estrone- $\mathrm{SO}_{4}$-Aufnahme in $\%$ & Nein & 277 & $\mathrm{nt}$ \\
\hline
\end{tabular}

Tabelle 4.1: Vergleich des pOAT1, pOAT3 in ok-Zellen und BLMV des Schweins. Die cis-Inhibitionen wurden mit Konzentrationen von $1 \mathrm{mM}$ durchgeführt. Als Bezug dient die ungehemmte Kontrolle (100\%). Die Daten zum pOAT3 und BLMV sind aus Braun (2006) entnommen. (*) Daten zur Chloridabhängigkeit aus Werner und Roch-Ramel (1991). 


\section{Zusammenfassung}

Die Niere spielt neben anderen Organen eine wichtige Rolle in der Eliminierung von toxischen Substanzen aus dem Körper. Diese Substanzen liegen häufig in ionischer Form als Anionen oder Kationen vor. Neben der reinen Filtration im Glomerulus der Niere werden diese Ionen auch aktiv mithilfe von Transportproteinen sezerniert. Ein wichtiges System, mit dem sich diese Arbeit beschäftigt, ist das organische Anionen-Transportsystem (OAT) des proximalen Tubulus (Pritchard und Miller 1993; van Aubel et al. 2000). Erste Untersuchungen dieses Systems erfolgten mit isolierten Tubuli und später an Membranvesikeln aus Tubuluszellen. 1997 gelang es zwei Arbeitsgruppen unabhängig voneinander, einen organischen Anionen-Transporter mithilfe der Expressionklonierung aus Rattennieren zu isolieren und exprimiert in Oozyten zu charakterisieren (Sweet et al. 1997; Sekine et al. 1997). In den folgenden Jahren wurden weitere organische Anionen-Transporter (OAT1-OAT10) aus verschiedenen Spezies kloniert und charakterisiert. Zusammen mit anderen strukturverwandten Transportproteinen werden diese zur SLC22-Familie zusammengefasst (Koepsell und Endou 2004).

In dieser Arbeit wurden erstmals der OAT1 aus Schweinenieren und ok-Zellen kloniert und funktionell charakterisiert, um diese mit Daten aus Tubulus- und Membranvesikelstudien vergleichen zu können.

Aus Schweinenierengewebe wurden zwei Splice-Varianten mit einer Länge von 2126 bp bzw. 1895 bp kloniert, die als pOAT1 (Accession Nr. AJ308234) und pOAT1A (Accession Nr. AJ308235) bezeichnet und in der EMBL-Datenbank hinterlegt wurden. Des Weiteren wurde ein Klon mit einer Länge von 1680 bp aus ok-Zellen isoliert und unter der AccessionNummer AJ308236 als okOAT1 gespeichert. Der Sequenzvergleich zu OAT1 anderer Spezies konnte eine hohe Homologie zu den neuen Klonen nachweisen. Insbesondere im Vergleich zum hOAT1 (Reid et al. 1998) zeigt sich diese hohe Homologie, die zwischen okOAT1 und hOAT1 bei $88 \%$ liegt bzw. zwischen pOAT1 und hOAT1 sogar bei $89 \%$.

Die funktionelle Charakterisierung, d.h. die Testung der Transportereigenschaften hinsichtlich Kinetik und Substratspezifität der Klone erfolgte zum einen in Xenopus laevis-Oozyten, zum anderen - nach Austestung weiterer Expressionssysteme - schließlich in ok-Zellen. Es konnte gezeigt werden, dass lediglich der pOAT1 einem funktionellen Klon entsprach. Der pOAT1 weist allerdings eindeutige Transportcharakteristika der bekannten OAT1 anderer Spezies auf und transportiert deren Modellsubstrat PAH mit einem Km-Wert von 3,75 \pm 1,6 $\mu \mathrm{M}$ in Oozyten bzw. 8,54 $\pm 1,2 \mu \mathrm{M}$ in ok-Zellen. Dieser PAH-Transport ist komplett durch $1 \mathrm{mM}$ Pro- 
benecid oder $1 \mathrm{mM}$ Glutarat hemmbar. In Bezug auf die funktionelle Charakterisierung des pOAT1 ist hervorzuheben, dass die pOAT1-vermittelte PAH-Aufnahme durch die gleichen Substanzen (Pyrazionat, Urat, Glutarat, Probenecid) und in ähnlicher Größenordnung einer cis-Inhibition unterliegt wie die PAH-Aufnahme durch BLMV des Schweins (Werner und Roch-Ramel 1991). Somit konnten wir nachweisen, dass die PAH-Aufnahme in der basolateralen Membran des proximalen Tubulus des Schweins vor allem durch den pOAT1 vermittelt wird.

Außerdem konnte erstmals in dieser Arbeit die ebenfalls bereits 1991 von Werner und RochRamel beschriebene chloridabhängige $\mathrm{PAH}-$ Aufnahme und chloridunabhängige UratAufnahme in BLMV einzelnen Transportern zugeordnet werden. Die chloridabhängige PAHAufnahme wird durch den pOAT1 vermittelt, während die Urat-Aufnahme durch den pOAT3 erfolgt (Hagos et al. 2005).

Steroidhormone, eine weitere Substratgruppe, die hochaffin vom OAT3 (Hagos et al. 2005) transportiert werden, zeigten zwar eine starke Hemmung des pOAT1 in ok-Zellen (Ki-Werte: Estronsulfat 113,2 \pm 4,9 $\mu \mathrm{M}$; DHEA-Sulfat 116,5 \pm 3,5 $\mu \mathrm{M}$ ), ein aktiver Transport von Estronsulfat durch den pOAT1 konnte jedoch nicht gemessen werden. Mit der Klonierung und der funktionellen Charakterisierung insbesondere des pOAT1 gelang die weitere Aufschlüsselung des komplexen organischen Anionen-Systems und erstmals auch die Zuordnung einzelner Transportprozesse zu einzelnen Transportproteinen im Vergleich zu den Summationstransporten aus BLMV. Zukünftig müssten weitere OAT aus der cDNA-Bank isoliert und funktionell untersucht werden, um deren Zusammenspiel besser zu verstehen und geeignete in vitro-Modelle entwickeln zu können. 


\section{Anhang}

\subsection{Abkürzungen}

$(\mathrm{v} / \mathrm{v})$

$\left[{ }^{3} \mathrm{H}\right]-$

$\left[{ }^{3} \mathrm{H}\right] \mathrm{PAH}$

Abb.

AS

ATP

BBMV

BLMV

cAMP

cDNA

cGMP

CML

dATP

$\mathrm{dCTP}$

DEPC

dGTP

DHEA

DHEA-SO 4

DMEM

DNA

dNTP

dTTP

EDTA

G

$\mathrm{IC}_{50}$

$\mathrm{Kb}$

Ki-Wert

$\mathrm{Km}$

M
Volumen pro Volumen

Tritium-markiertes Substrat

Tritium-markiertes p-Aminohippurat

Abbildung

Aminosäure

Adenosintriphosphat

Bürstensaum Membranvesikel (brushborder membrane vesicle)

Basolaterale Menbranvesikel (basolateral membran vesicel)

Zyklisches Adenosinmonophosphat

komplementäre Desoxyribonukleinsäure (complementary DNA)

Zyklisches Guanosinmonophosphat

chronisch myeloische Leukämie

Desoxyadenosintriphosphat

Desoxycytidintriphosphat

Diethyldicarbonat

Desoxyguanosintriphosphat

Dehydroxyepiandrosteron

Dehydroxyepiandrosteronesulfat

Dulbecco's modified eagle medium

Desoxyribonukleinsäure

Desoxynukleosidtriphosphat

Desoxythymidintriphosphat

Ethylendiamintetraacetat

Erdbeschleunigung oder Gramm

Konzentration bei halbmaximaler Hemmung

Kilo-Basenpaare

Dissoziationskonstante

Michaelis-Menten-Konstante

Mol, Stoffmenge 


\begin{tabular}{|c|c|}
\hline $\mathrm{mM}$ & Millimol \\
\hline$\mu \mathrm{M}$ & Mikromol \\
\hline Min & Minuten \\
\hline $\mathrm{ml}$ & Milliliter \\
\hline$\mu 1$ & Mikroliter \\
\hline MPP & 1-Methyl-4-phenylpyridinium \\
\hline mRNA & Boten-Ribonukleinsäure (messenger RNA) \\
\hline MTX & Methotrexat \\
\hline OAT & organischer Anionen-Transporter/Transportsystem \\
\hline OCT & organischer Cationen-Transporter/Transportsystem \\
\hline OD & optische Dichte, Extinktion \\
\hline okOAT & opossum kidney OAT \\
\hline ORI & Oozyten-Ringer-Lösung \\
\hline PAH & p-Aminohippurat \\
\hline PBS & Phosphatgepufferte Salzlösung (phosphate buffered saline) \\
\hline PCR & Polymerase-Kettenreaktion (polymerase chain reaction) \\
\hline PFU & plaque forming unit \\
\hline $\mathrm{PGE}_{2}$ & Prostaglandin $\mathrm{E}_{2}$ \\
\hline pOAT & pig OAT \\
\hline rATP & Riboseadenosintriphosphat \\
\hline RNA & Ribonukleinsäure \\
\hline RT & Raumtemperatur \\
\hline SDS & Natriumdodecylsulfat (sodium dodecyl sulfate) \\
\hline Std. & Stunde \\
\hline $\mathrm{Ta}$ & Bindungstemperatur (annealing temperature) \\
\hline Tab. & Tabelle \\
\hline TBE & Tris-Borat-EDTA \\
\hline TEA & Tetraethylammoniumion \\
\hline $\mathrm{Tm}$ & Schmelztemperatur (melting temperature) \\
\hline TMD & Transmembrandomäne \\
\hline $\mathrm{U}$ & Einheiten (units) \\
\hline
\end{tabular}




\section{Literaturverzeichnis}

1. Ahn SY, Eraly SA, Tsigelny I, Nigam SK (2009): Interaction of organic cations with organic anion transporters. $\mathrm{J}$ Biol Chem $\underline{284}$ (45), 31422-30. doi: 10.1074/jbc.M109.024489. Epub 2009 Sep 8

2. Alebouyeh M, Takeda M, Onozato ML, Tojo A, Noshiro R, Hasannejad H, Inatomi J, Narikawa S, Huang XL, Khamdang S et al. (2003): Expression of human organic anion transporters in the choroid plexus and their interactions with neurotransmitter metabolites. J Pharmacol Sci 93 (4), 430-6

3. Anzai N, Jutabha P, Enomoto A, Yokoyama H, Nonoguchi H, Hirata T, Shiraya K, He $\mathrm{X}$, Cha SH, Takeda M et al. (2005): Functional characterization of rat organic anion transporter 5 (Slc22a19) at the apical membrane of renal proximal tubules. J Pharmacol Exp Ther 315 (2), 534-44. Epub 2005 Aug 3

4. Anzai N, Kanai Y, Endou H (2006): Organic anion transporter family: current knowledge. J Pharmacol Sci 100 (5), 411-26

5. Asif AR, Steffgen J, Metten M, Grunewald RW, Müller GA, Bahn A, Burckhardt G, Hagos Y (2005): Presence of organic anion transporters 3 (OAT3) and 4 (OAT4) in human adrenocortical cells. Pflugers Arch $\underline{450}$ (2), 88-95. Epub 2004 Dec 10

6. Asif AR, Ljubojevic M, Sabolic I, Shnitsar V, Metten M, Anzai N, Müller GA, Burckhardt G, Hagos Y (2006): Regulation of steroid hormone biosynthesis enzymes and organic anion transporters by forskolin and DHEA-S treatment in adrenocortical cells. Am J Physiol Endocrinol Metab 291 (6), E1351-9. Epub 2006 Jul 11

7. Babu E, Takeda M, Narikawa S, Kobayashi Y, Enomoto A, Tojo A, Cha SH, Sekine T, Sakthisekaran D, Endou H (2002): Role of human organic anion transporter 4 in the transport of ochratoxin A. Biochim Biophys Acta 1590 (1-3), 64-75

8. Bahn A, Prawitt D, Buttler D, Reid G, Enklaar T, Wolff NA, Ebbinghaus C, Hillemann A, Schulten HJ, Gunawan B et al. (2000): Genomic structure and in vivo expression of the human organic anion transporter 1 (hOAT1) gene. Biochem Biophys Res Commun $\underline{275}(2), 623-30$

9. Bahn A, Knabe M, Hagos Y, Rodiger M, Godehardt S, Graber-Neufeld DS, Evans KK, Burckhardt G, Wright SH (2002): Interaction of the metal chelator 2,3-dimercapto-1propanesulfonate with the rabbit multispecific organic anion transporter 1 (rbOAT1). Mol Pharmacol $\underline{62}$ (5), 1128-1136

10. Bahn A, Hauss A, Appenroth D, Ebbinghaus D, Hagos Y, Steinmetzer P, Burckhardt G, Fleck C (2003): RT-PCR-based evidence for the in vivo stimulation of renal tubular paminohippurate (PAH) transport by triiodothyronine (T3) or dexamethasone (DEXA) in kidney tissue of immature and adult rats. Exp Toxicol Pathol 54 (5-6), 367-73

11. Bahn A, Ebbinghaus C, Ebbinghaus D, Ponimaskin EG, Fuzesi L, Burckhardt G , Hagos (2004): Expression studies and functional characterization of renal human organic anion transporter 1 isoforms. Drug Metab Dispos 32 (4), 424-430 
12. Bahn A, Ljubojevic M, Lorenz H, Schultz C, Ghebremedhin E, Ugele B, Sabolic I, Burckhardt G and Hagos Y (2005): Murine renal organic anion transporters mOAT1 and mOAT3 facilitate the transport of neuroactive tryptophan metabolites. Am J Physiol Cell Physiol 289, C1075-84, Epub 2005 Jun 8

13. Bahn A, Hagos Y, Reuter S, Balen D, Brzica H, Krick W, Burckhardt BC, Sabolic I, Burckhardt G. (2008): Identification of a new urate and high affinity nicotinate transporter, hOAT10 (SLC22A13). J Biol Chem 283 (24), 16332-41. doi: 10.1074/jbc.M800737200. Epub 2008 Apr 14

14. Blomstedt JW, Aronson PS (1980): $\mathrm{pH}$ gradient-stimulated transport of urate and paminohippurate in dog renal microvillus membrane vesicles. J Clin Invest $\underline{65}$ (4), 931-4

15. Bradford MM (1976): A rapid and sensitive method for the quantitation of microgram quantities of protein utilizing the principle of protein-dye binding. Anal Biochem $\underline{72}$, $248-254$

16. Braun I (2006): Transport organischer Anionen über die basolaterale Membran proximaler Tubuli der Schweineniere. Med. Diss. Göttingen 2006

17. Burckhardt BC and Burckhardt G (2003): Transport of organic anions across the basolateral membrane of proximal tubule cells. Rev Physiol Biochem Pharmacol 146, 95-158. Epub 2003 Jan 30

18. Burckhardt BC, Brai S, Wallis S, Krick W, Wolff NA, Burckhardt G (2002): Transport of cimetidine by flounder and human renal organic anion transporter 1 . Am J Physiol Renal Physiol 284 (3), F503-9. Epub 2002 Nov 12

19. Burckhardt G (1984): Sodium-dependent dicarboxylate transport in rat renal basolateral membrane vesicles. Pflugers Arch 401 (3), 254-61

20. Burckhardt G (2012): Drug transport by Organic Anion Transporters (OATs). Pharmacol Ther 136 (1), 106-30. Epub 2012 Jul 25

21. Burckhardt G, Pritchard JB (2000): Organic anion and cation antiporters. In Seldin DW, Giebisch G: The kidney. Physiology and pathophysiology. 3 rd. edition; 193-222. Lippincott Williams and Wilkins, Philadelphia

22. Burckhardt G, Wolff NA (2000): Structure of renal organic anion and cation transporters. Am J Physiol Renal Physiol 278 (6), F853-F866

23. Burckhardt G, Bahn A, Wolff NA (2001): Molecular physiology of renal paminohippurate secretion. News Physiol Sci 16, 114-8.

24. Burckhardt G, Wolff NA, Bahn A (2002): Molecular characterization of the renal organic anion transporter 1. Cell Biochem.Biophys $\underline{36}$ (2-3), 169-174

25. Cha SH, Sekine T, Kusuhara H, Yu E, Kim JY, Kim DK, Sugiyama Y, Kanai Y, Endou $\mathrm{H}$ (2000): Molecular cloning and characterization of multispecific organic anion transporter 4 expressed in the placenta. J Biol Chem 275 (6), 4507-12 
26. Cha SH, Sekine T, Fukushima JI, Kanai Y, Kobayashi Y, Goya T, Endou H (2001): Identification and characterization of human organic anion transporter 3 expressing predominantly in the kidney. Mol Pharmacol 59 (5), 1277-86

27. Chasis H, Redish J, Goldring W, Ranges HA, Smith HW (1945): The use of sodium pAminohippurate for the functional evaluation of the human kidney J Clin Invest 24 (4), $583-588$

28. Cihlar T, Lin DC, Pritchard JB, Fuller MD, Mendel DB, Sweet DH (1999): The antiviral nucleotide analogs cidofovir and adefovir are novel substrates for human and rat renal organic anion transporter 1. Mol Pharmacol 56 (3), 570-80

29. Cihlar T, Ho ES (2000): Fluorescence-based assay for the interaction of small molecules with the human renal organic anion transporter 1. Anal Biochem 283 (1) 4955

30. Cropp CD, Komori T, Shima JE, Urban TJ, Yee SW, More SS, Giacomini KM. (2008): Organic anion transporter 2 (SLC22A7) is a facilitative transporter of cGMP. Mol Pharmacol 73 (4), 1151-8. Epub 2008 Jan 23

31. Dantzler WH (1989): Organic acid (or anion) and organic base (or cation) transport by renal tubulus of nonmammalian vertebrates. J. Exp Zool 249 (3): 247-257

32. Deguchi T, Kusuhara H, Takadate A, Endou H, Otagiri M, Sugiyama Y. (2004): Characterization of uremic toxin transport by organic anion transporters in the kidney. Kidney Int $\underline{65}(1), 162-74$

33. Don RH, Cox PT, Wainwright BJ, Baker K, Mattick JS (1991): 'Touchdown' PCR to circumvent spurious priming during gene amplification. Nucleic Acids Res 19 (14), 4008

34. Dumont JN (1972): Oogenesis in Xenopus laevis (Daudin). I. Stages of oocyte development in laboratory maintained animals. J Morphol $\underline{136}$ (2), 153-79

35. Ekaratanawong S, Anzai N, Jutabha P, Miyazaki H, Noshiro R, Takeda M, Kanai Y, Sophasan S, Endou H (2004): Human organic anion transporter 4 is a renal apical organic anion/dicarboxylate exchanger in the proximal tubules. J Pharmacol Sci 94 (3), 297304

36. Enomoto A, Kimura H, Chairoungdua A, Shigeta Y, Jutabha P, Cha SH, Hosoyamada M, Takeda M, Sekine T, Igarashi T et al. (2002a): Molecular identification of a renal urate anion exchanger that regulates blood urate levels. Nature 417 (6887), 447-52. Epub 2002 Apr 14

37. Enomoto A, Takeda M, Shimoda M, Narikawa S, Kobayashi Y, Kobayashi Y, Yamamoto T, Sekine T, Cha SH, Niwa T (2002b): Interaction of human organic anion transporters 2 and 4 with organic anion transport inhibitors. J Pharmacol Exp Ther 301 (3), 797-802

38. Foulkes EC, Miller BF (1959): Steps in p-aminohippurate from cell to lumen in kidney tubule. Am. J. Physiol. 196 (1), 83-85 
39. Frohman MA, Dush MK, Martin GR (1988): Rapid production of full-length cDNAs from rare transcripts. Amplification using a single gene-specific oligonucleotide primer. Proc Natl Acad Sci U S A $\underline{85}$ (23), 8998-9002

40. Gupta S, Burckhardt G, Hagos Y (2011): SLC22 transporter family proteins as targets for cytostatic uptake into tumor cells. Biol Chem 392 (1-2), 117-24. doi: 10.1515/BC.2011.014

41. Gurdon JB, Lane CD, Woodland HR, Marbaix G (1971): Use of frog eggs and oocytes for the study of messenger RNA and its translation in living cells. Nature 233 (5316), $177-82$

42. Hagos Y, Bahn, A, Asif, AR, Krick W, Sendler M, Burckhardt G (2002): Cloning of the pig renal organic anion transporter 1 (pOAT1). Biochimie $\underline{84}$ (12), 1221-1224

43. Hagos Y, Braun IM, Krick W, Burckhardt G, Bahn A (2005): Functional expression of pig renal organic anion transporter 3 (pOAT3). Biochimie $\underline{87}$ (5), 421-4

44. Hagos Y, Stein D, Ugele B, Burckhardt G and Bahn A. (2007): Human Renal Organic Anion Transporter 4 Operates as an Asymmetric Urate Transporter. J Am Soc Nephrol $\underline{18}$ (2), 430-9. Epub 2007 Jan 17

45. Hosoyamada M, Sekine T, Kanai Y and Endou H (1999): Molecular cloning and functional expression of a multispecific organic anion transporter from human kidney. Am $\mathrm{J}$ Physiol 276 (1 Pt 2), F122-F128

46. Islinger F, Gekle M and Wright SH (2001): Interaction of 2,3-dimercapto-1-propane sulfonate with the human organic anion transporter hOAT1. J Pharmacol Exp Ther 299 (2), 741-747

47. Kasher JS, Holohan PD, Ross CR (1983): Na+ gradient-dependent p-aminohippurate (PAH) transport in rat basolateral membrane vesicles. J Pharmacol Exp Ther 227 (1), $122-9$

48. Kekuda R, Wang H, Huang W, Pajor AM, Leibach FH, Devoe LD, Prasad PD, Ganapathy V (1999): Primary structure and functional characteristics of a mammalian sodium-coupled high affinity dicarboxylate transporter. J Biol Chem 274 (6), 3422-9

49. Kikuchi Y, Koga H, Yasutomo Y, Kawabata Y, Shimizu E, Naruse M, Kiyama S, Nonoguchi H, Tomita K, Sasatomi Y et al. (2000): Patients with renal hypouricemia with exercise-induced acute renal failure and chronic renal dysfunction. Clin Nephrol $\underline{53}(6), 467-72$

50. Kikuchi R, Kusuhara H, Sugiyama D, Sugiyama Y (2003): Contribution of organic anion transporter 3 (Slc22a8) to the elimination of p-aminohippuric acid and benzylpenicillin across the blood-brain barrier. J Pharmacol Exp Ther 306 (1), 51-8. Epub 2003 Apr 8.

51. Kippen I, Klinenberg JR (1978): Effects of renal fuels on uptake of PAH and uric acid by separated renal tubules of the rabbit. Am J Physiol 235 (2), F137-41 
52. Koepsell H, Endou H. (2004): The SLC22 drug transporter family. Pflugers Arch 447 (5), 666-676. Epub 2003 Jul 19

53. Koepsell H, Lips K, Volk C (2007): Polyspecific organic cation transporters: structure, function, physiological roles, and biopharmaceutical implications. Pharm Res 24 (7), 1227-51. Epub 2007 May 1

54. Kojima R, Sekine T, Kawachi M, Cha SH, Suzuki Y, Endou H (2002): Immunolocalization of multispecific organic anion transporters, OAT1, OAT2, and OAT3, in rat kidney. J Am Soc Nephrol 13 (4), 848-57

55. Koyama H, Goodpasture C, Miller MM, Teplitz RL, Riggs AD (1978): Establishment and characterization of a cell line from the American opossum (Didelphys virginiana). In Vitro 14 (3), 239-46

56. Kusuhara H, Sekine T, Utsunomiya-Tate N, Tsuda M, Kojima R, Cha SH, Sugiyama Y, Kanai Y, Endou H (1999): Molecular cloning and characterization of a new multispecific organic anion transporter from rat brain. J Biol Chem 274 (19), 13675-80

57. Lopez-Nieto CE, You G, Bush KT, Barros EJ, Beier DR, Nigam SK (1997): Molecular cloning and characterization of NKT, a gene product related to the organic cation transporter family that is almost exclusively expressed in the kidney. J Biol Chem 272 (10), 6471-8

58. Lotspeich WD (1958): Kidney, water and electrolyte metabolism. Annu Rev Physiol 20 339-76.

59. Malo C, Berteloot A (1991): Analysis of kinetic data in transport studies: new insights from kinetic studies of $\mathrm{Na}(+)$-D-glucose cotransport in human intestinal brush-border membrane vesicles using a fast sampling, rapid filtration apparatus. J Membr Biol 122 (2), 127-41

60. Marshall EK, Grafflin AL (1928): The structure and function of the kidney of Lophius piscatorius. Bull Johns Hopkins Hosp 43, 205-235

61. Martinez F, Manganel M, Montrose-Rafizadeh C, Werner D, Roch-Ramel F (1990): Transport of urate and p-aminohippurate in rabbit renal brush-border membranes. Am J Physiol 258 (5 Pt 2), F1145-53

62. Møller JV, Sheikh I (1983): Renal organic anion transport system: Pharmacological, physiological and biochemical aspects. Pharmacol Rev 34 (4), 315-358

63. Monte JC, Nagle MA, Eraly SA, Nigam SK (2004): Identification of a novel murine organic anion transporter family member, OAT6, expressed in olfactory mucosa. Biochem Biophys Res Commun $\underline{323}$ (2), 429-36

64. Motojima M, Hosokawa A, Yamato H, Muraki T, Yoshioka T (2002): Uraemic toxins induce proximal tubular injury via organic anion transporter 1-mediated uptake. Br J Pharmacol 135 (2), 555-63

65. Mullis KB and Faloona FA (1987): Specific synthesis of DNA in vitro via a polymerase-catalyzed chain reaction. Methods Enzymol 155, 335-50 
66. Plata C, Meade P, Hall A, Welch RC, Vázquez N, Hebert SC, Gamba G (2001): Alternatively spliced isoform of apical $\mathrm{Na}(+)-\mathrm{K}(+)-\mathrm{Cl}(-)$ cotransporter gene encodes a furosemide-sensitive $\mathrm{Na}(+)-\mathrm{Cl}(-)$ cotransporter. Am J Physiol Renal Physiol 280 (4), F57482

67. Pombrio JM, Giangreco A, Li L, Wempe MF, Anders MW, Sweet DH, Pritchard JB, Ballatori N (2001): Mercapturic acids (N-acetylcysteine S-conjugates) as endogenous substrates for the renal organic anion transporter-1. Mol Pharmacol 60 (5), 1091-9

68. Pritchard JB (1988): Coupled transport of p-aminohippurate by rat kidney basolateral membrane vesicles. Am J Physiol 255 (4 Pt 2), F597-604

69. Pritchard JB, Miller DS (1991): Comparitive insights into the mechanisms of renal organic anion and cation secretion. Am J Physiol 261 (6 Pt 2), R1329-40

70. Pritchard JB, Miller DS (1993): Mechanisms mediating renal secretion of organic anions and cations 2. Physiol Rev $\underline{73}$ (4), 765-96

71. Puck TT, Cieciura SJ, Robinson A (1958): Genetics of somatic mammalian cells. III. Long-term cultivation of euploid cells from human and animal subjects. J Exp Med 108 (6), 945-56

72. Reid G, Wolff NA, Dautzenberg FM and Burckhardt G (1998): Cloning of a human renal p-aminohppurate transporter, hROAT1. Kidney Blood Press Res 21 (2-4), 233-7

73. Rizwan AN, Burckhardt G (2007): Organic anion transporters of the SLC22 family: biopharmaceutical, physiological, and pathological roles. Pharm Res 24 (3), 450-70

74. Rizwan AN, Krick W, Burckhardt G (2007): The chloride dependence of the human organic anion transporter 1 (hOAT1) is blunted by mutation of a single amino acid. $\mathrm{J}$ Biol Chem 282 (18), 13402-9

75. Roch-Ramel F, Guisan B, Schild L (1996): Indirect coupling of urate and paminohippurate transport to sodium in human brush-border membrane vesicles. Am J Physiol 270 (1 Pt 2), F61-8

76. Roch-Ramel F, Guisan B, Diezi J (1997): Effects of uricosuric and antiuricosuric agents on urate transport in human brush-border membrane vesicles. J Pharmacol Exp Ther $\underline{280}(2), 839-45$

77. Saiki RK, Gelfand DH, Stoffel S, Scharf SJ, Higuchi R, Horn GT, Mullis KB, Erlich HA. (1988): Primer-directed enzymatic amplification of DNA with a thermostable DNA polymerase. Science 239 (4839), 487-91

78. Sambrook J, Frisch EF, Maniats T (1989): Molecular cloning, A Laboratory Manual. Second Edition, Cold Spring Harbor, New York: Cold Spring Harbor Laboratory Press

79. Sekine T, Watanabe N, Hosoyamada M, Kanai Y and Endou H (1997): Expression cloning and characterization of a novel multispecific organic anion transporter. J Biol Chem 272 (30), 18526-9 
80. Sekine T, Cha SH, Endou H (2000): The multispecific organic anion transporter (OAT) family. Pflugers Arch $\underline{440}$ (3), 337-50

81. Sheikh MI, Møller JV (1983): Nature of Na+-independent stimulation of renal transport of p-aminohippurate by exogenous metabolites. Biochem Pharmacol 32 (18), 2745-9

82. Shimada H, Moewes B, Burckhardt G (1987): Indirect coupling to Na+ of paminohippuric acid uptake into rat renal basolateral membrane vesicles. Am J Physiol 253 (5 Pt 2), F795-801

83. Shin HJ, Anzai N, Enomoto A, He X, Kim do K, Endou H, Kanai Y (2007): Novel liver-specific organic anion transporter OAT7 that operates the exchange of sulfate conjugates for short chain fatty acid butyrate. Hepatology $\underline{45}$ (4), 1046-55

84. Simonson GD, Vincent AC, Roberg KJ, Huang Y, Iwanij V. (1994): Molecular cloning and characterization of a novel liver-specific transport protein. J Cell Sci 107 (Pt 4), $1065-72$

85. Smeets PH, van Aubel RA, Wouterse AC, van den Heuvel JJ, Russel FG (2004): Contribution of multidrug resistance protein 2 (MRP2/ABCC2) to the renal excretion of $\mathrm{p}$ aminohippurate (PAH) and identification of MRP4 (ABCC4) as a novel PAH transporter. J Am Soc Nephrol 15 (11), 2828-35

86. Soleimani M, Burnham CE (2001): $\mathrm{Na}+\mathrm{HCO}(3-)$ cotransporters (NBC): cloning and characterization. J Membr Biol 183 (2), 71-84

87. Strauss WM (2001): Using DNA fragments as probes. Curr Protoc Mol Biol Chapter 6, Unit6.3. doi: 10.1002/0471142727.mb0603s 13

88. Sumikawa K, Houghton M, Emtage JS, Richards BM, Barnard EA (1981): Active multi-subunit ACh receptor assembled by translation of heterologous mRNA in Xenopus oocytes. Nature 292 (5826), 862-4

89. Sun W, Wu RR, van Poelje PD, Erion MD (2001): Isolation of a family of organic anion transporters from human liver and kidney. Biochem Biophys Res Commun 283 (2), 417-22

90. Sweet DH, Pritchard JB (1999): The molecular biology of renal organic anion and cation transporters. Cell Biochem Biophys $\underline{31}$ (1), 89-118

91. Sweet DH, Wolff NA, Pritchard JB (1997): Expression cloning and characterization of ROAT1, the basolateral organic anion transporter in rat kidney. J Biol Chem 272 (48), 30088-95

92. Tatsumi S, Miyamoto K, Kouda T, Motonaga K, Katai K, Ohkido I, Morita K, Segawa $\mathrm{H}$, Tani Y, Yamamoto $\mathrm{H}$ et al. (1998): Identification of three isoforms for the Na+dependent phosphate cotransporter (NaPi-2) in rat kidney. J Biol Chem 273 (44), 28568-75

93. Thomas J, Wang L, Clark RE, Pirmohamed M (2004): Active transport of imatinib into and out of cells: implications for drug resistance. Blood 104 (12), 3739-45. Epub 2004 Aug 17 
94. Tsuchida H, Anzai N, Shin HJ, Wempe MF, Jutabha P, Enomoto A, Cha SH, Satoh T, Ishida M, Sakurai H et al. (2010): Identification of a novel organic anion transporter mediating carnitine transport in mouse liver and kidney. Cell Physiol Biochem 25 (4-5), 511-22. doi: 10.1159/000303060. Epub 2010 Mar 23

95. Ueo H, Motohashi $\mathrm{H}$, Katsura T, Inui $\mathrm{K}$ (2007): $\mathrm{Cl}^{-}$-dependent upregulation of human organic anion transporters: different effects on transport kinetics between hOAT1 and hOAT3. Am J Physiol Renal Physiol 293 (1), F391-7. Epub 2007 Apr 11

96. Ullrich KJ (1997): Renal transporters for organic anions and organic cations. Strucural requirements for substrates. J Membr Biol 158 (2), 95-107

97. Uwai Y, Saito H, Hashimoto Y, Inui KI (2000): Interaction and transport of thiazide diuretics, loop diuretics, and acetazolamide via rat renal organic anion transporter rOAT1. J Pharmacol Exp Ther 295 (1), 261-5

98. Van Aubel RA, Masereeuw R, Russel FG (2000): Molecular pharmacology of renal organic anion transporters. Am J Physiol Renal Physiol 279 (2), F216-32

99. Van Wert AL, Gionfriddo MR, Sweet DH (2010): Organic anion transporters: discovery, pharmacology, regulation and roles in pathophysiology. Biopharm Drug Dispos 31 (1), 1-71. doi: 10.1002/bdd.693

100. Werner D, Roch-Ramel F (1991): Indirect Na+ dependency of urate and paminohippurate transport in pig basolateral membrane vesicles. Am J Physiol 261 (2 Pt 2), F265-72

101. Werner D, Martinez F, Roch-Ramel F (1990): Urate and p-aminohippurate transport in the brush border membrane of the pig kidney. J Pharmacol Exp Ther 252 (2), 792-9

102. White DL, Dang P, Engler J, Frede A, Zrim S, Osborn M, Saunders VA, Manley PW, Hughes TP (2010): Functional activity of the OCT-1 protein is predictive of long-term outcome in patients with chronic-phase chronic myeloid leukemia treated with imatinib. J Clin Oncol 28 (16), 2761-7. Epub 2010 Apr 26

103. Wolff NA, Werner A, Burkhardt S, Burckhardt G (1997): Expression cloning and characterization of a renal organic anion transporter from winter flounder. FEBS Lett $\underline{417}$ (3), 287-91

104. Wright SH, Dantzler WH (2004): Molecular and Cellular Physiology of Renal Organic Cation and Anion Transport. Physiol Rev $\underline{84}$ (3), 987-1049

105. Yokoyama H, Anzai N, Ljubojevic M, Ohtsu N, Sakata T, Miyazaki H, Nonoguchi H, Islam R, Onozato M, Tojo A et al. (2008): Functional and immunochemical characterization of a novel organic anion transporter Oat8 (Slc22a9) in rat renal collecting duct. Cell Physiol Biochem 21 (4), 269-78. doi: 10.1159/000129385. Epub 2008 Apr 23

106. Youngblood GL, Sweet DH (2004): Identification and functional assessment of the novel murine organic anion transporter Oat5 (Slc22a19) expressed in kidney. Am J Physiol Renal Physiol 287 (2), F236-44. Epub 2004 Apr 6 


\section{Danksagung}

Herrn Prof. Dr. med G. Burckhardt danke ich für die Vermittlung der Faszination der menschlichen Physiologie, die zur Vergabe des Themas führte. Außerdem danke ich für die wissenschaftliche Diskussionsbereitschaft und die Bereitstellung der Arbeitsmöglichkeiten.

Für die wertvolle und vor allem geduldige sowie ausdauernde Unterstützung möchte ich mich ganz besonders bei Prof. Dr. rer. nat. Y. Hagos bedanken, der mir über die Jahre stets für Rückfragen bereit stand und die Arbeit bis zum Schluss begleitet hat.

Zuletzt gilt mein Dank auch dem Institutsteam der Vegetativen Physiologie und Pathophysiologie, insbesondere S. Holpert und S. Petzke, die mich während meiner Laborzeit jederzeit fachlich und persönlich unterstützten. 
Lebenslauf von Mark Florian Sendler

Am 01.12.1976 wurde ich als Sohn von Helga Sendler, geb. Paul und Andreas Sendler in Osterode geboren.

Meine Schulausbildung begann ich 1983 in Oldenburg und schloss sie 1996 am Gymnasium Corvinianum in Northeim mit der allgemeinen Hochschulreife ab.

Nach dem Zivildienst in Kassel begann ich mein Studium der Humanmedizin zum Wintersemester 1997/98 an der Georg August Universität zu Göttingen. Nach der Ärztlichen Vorprüfung im September 1999, setzte ich mein Studium an der Medizinischen Universität zu Lübeck fort und absolvierte dort den ersten Abschnitt der Ärztlichen Prüfung im September 2000. Anschließend kehrte ich an die Georg August zu Göttingen zurück und legte im März 2003 den zweiten Teil der Ärztlichen Prüfung ab. Mein Praktisches Jahr absolvierte ich in der Chirurgie, Inneren Medizin und Hals-Nasen-Ohren Heilkunde in Hamburg, wo ich auch mein Studium am 08. Dezember 2004 an der Universität zu Hamburg beendete.

Mit der Approbation nahm ich im Juni 2005 meine ärztliche Tätigkeit als Assistenzarzt unter Prof. Dr. med. T. Lehnert in der Abteilung für Allgemeine, Viscerale und Onkologische Chirurgie in Bremen auf. Die weitere Ausbildung erfolgte dann vom April 2006 bis Dezember 2008 unter Prof. Dr. med. C. Zornig in der chirurgischen Abteilung des Israelitischen Krankenhauses in Hamburg. Nach einjährigem Austausch mit dem Berufsgenossenschaftlichen Unfallkrankenhaus Hamburg unter der Leitung von Prof. Dr. C. Jürgens, konnte ich die Ausbildung zum Facharzt für Allgemeinchirurgie im Januar 2011 bei Prof. Dr. C. Zornig abschließen. Seit August 2013 bin ich dort als Oberarzt der Abteilung für Chirurgie tätig und erlangte im September 2014 den Facharzt für Visceralchirurgie und spezielle Visceralchirurgie. 